Florida International University FIU Digital Commons

$10-18-2017$

\title{
Eliciting a Perpetrator Description Using the Cognitive Interview: Influences on Investigative Utility
}

Geri Satin

Florida International University, gsati001@fiu.edu

DOI: $10.25148 /$ etd.FIDC004009

Follow this and additional works at: https://digitalcommons.fiu.edu/etd

Part of the Cognition and Perception Commons, Cognitive Psychology Commons, and the Other Psychology Commons

\section{Recommended Citation}

Satin, Geri, "Eliciting a Perpetrator Description Using the Cognitive Interview: Influences on Investigative Utility" (2017). FIU

Electronic Theses and Dissertations. 3557.

https://digitalcommons.fiu.edu/etd/3557 


\title{
FLORIDA INTERNATIONAL UNIVERSITY \\ Miami, Florida
}

ELICITING A PERPETRATOR DESCRIPTION USING THE

COGNITIVE INTERVIEW: INFLUENCES ON INVESTIGATIVE UTILITY

\author{
A dissertation submitted in partial fulfillment of the \\ requirements for the degree of \\ DOCTOR OF PHILOSOPHY \\ in \\ PSYCHOLOGY
}

by

Geri E. Satin

2017 
To: Dean Michael R. Heithaus

College of Arts, Sciences and Education

This dissertation, written by Geri E. Satin, and entitled Eliciting a Perpetrator Description Using the Cognitive Interview: Influences on Investigative Utility, having been approved in respect to style and intellectual content, is referred to you for judgment.

We have read this dissertation and recommend that it be approved.

Steven Charman

Jacqueline Evans

Rob T. Guerette

Ronald P. Fisher, Major Professor

Date of Defense: October 18, 2017

The dissertation of Geri E. Satin is approved.

Dean Michael R. Heithaus College of Arts, Sciences and Education

Andrés G. Gil Vice President for Research and Economic Development and Dean of the University Graduate School

Florida International University, 2017 
(C) Copyright 2017 by Geri E. Satin

All rights reserved. 


\section{DEDICATION}

I dedicate this dissertation to my husband, Eric Satin, who logged many hours on daddy duty to allow me to go back to school and complete this work. Without his support and love, the last few years would not have been possible. 


\section{ACKNOWLEDGMENTS}

I wish to thank the members of my committee for their support, patience, critical feedback, and insight. I would also like to thank the primary research assistants on this project - Henya Mizrahi, Valentina Iturriaga, Carolina Gomez-Lostalo, Chris Thompson, Costanza Alessio, Nina Labadi, Sean Smith, and Samantha Choo - without whom this project would not have run like a well-oiled machine and, quite certainly, would not be complete. Finally, I would like to extend a special thank you to my major professor, Dr. Ronald P. Fisher. From the beginning of my time at FIU, Ron has been a mentor, teacher, advocate, and friend. Without Ron's unwavering and incomparable support, guidance, and confidence, I would not be where I am today - prideful of the past, gratified by the present, and excited for the future. 


\begin{abstract}
OF THE DISSERTATION
ELICITING A PERPETRATOR DESCRIPTION USING THE

COGNITIVE INTERVIEW: INFLUENCES ON INVESTIGATIVE UTILITY
\end{abstract}

\author{
by
}

Geri E. Satin

Florida International University, 2017

Miami, Florida

\title{
Professor Ronald P. Fisher, Major Professor
}

The Cognitive Interview (CI) has been shown in over one hundred studies to enhance eyewitness recall. However, no study has explored whether the CI improves police job performance. The current study was the first to test the practical value of the CI in a criminal investigation, testing participants' performance on key police tasks using either a perpetrator description elicited from a CI or from a standard police interview (SI).

In an earlier study, student witnesses were exposed to a simulated robbery and were then interviewed using either a CI or an SI to elicit a description of the robber (comprised of individual descriptors). In Experiment 1, a sample of student participants $(\mathrm{N}=320)$ completed two investigative tasks using the descriptors: (a) identifying the perpetrator from a group of ten potential suspect photographs; and (b) allocating hours among the top three potential suspects dictated by who should be the focus of the police's time (i.e., investigative resources). Participants also subjectively assessed each descriptor's value in terms of completing the tasks. Presentation methods to enhance the utility of the CI were also tested. Relative to the SI, the CI resulted in a near-30\% 
increase in accurately identifying the perpetrator. Also, significantly more hours were allocated toward investigating the perpetrator using the CI as compared with the SI. Participants did not, however, subjectively value CI descriptors more than SI descriptors; and, the CI's utility was not enhanced by the presentation methods tested.

Experiment 2 sought to reproduce and generalize the CI's effect on investigative utility by using police officers $(\mathrm{N}=71)$ and student participants $(\mathrm{N}=67)$. As in Experiment 1, the CI significantly improved investigative performance in accurately identifying the perpetrator, and in allocating resources toward investigating the perpetrator. Police and students did not significantly differ in their performance of investigative tasks or in their utility ratings of the CI descriptors.

The current study was the first to find that the CI can be properly used by police in a criminal investigation. Investigating the actual perpetrator as opposed to an innocent suspect is likely to have a domino effect on subsequent phases of an investigation. 


\section{TABLE OF CONTENTS}

CHAPTER

PAGE

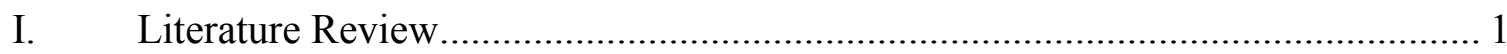

The Inadequacy of Eyewitness Descriptions of Perpetrators ................................... 1

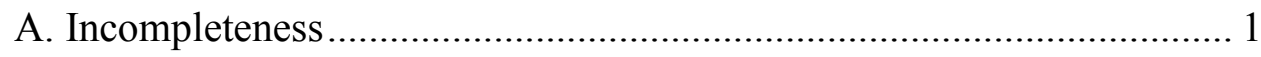

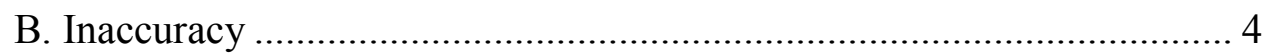

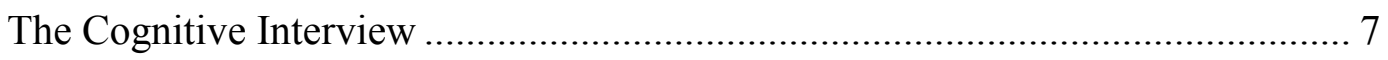

A. CI Theoretical Principles …………………………….................... 7

B. CI Empirical Testing and Real-World Application.............................. 14

Using the CI to Elicit Perpetrator Descriptions ................................................. 15

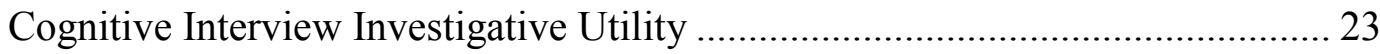

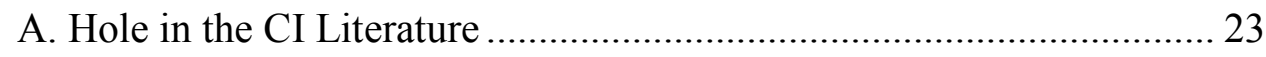

B. Empirical Basis for CI Utility …………………….............................. 24

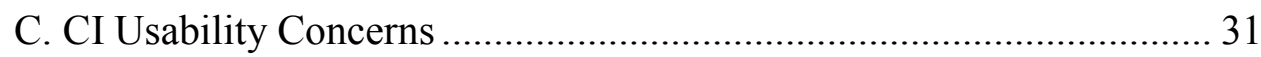

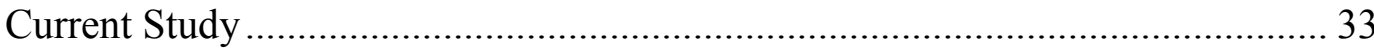

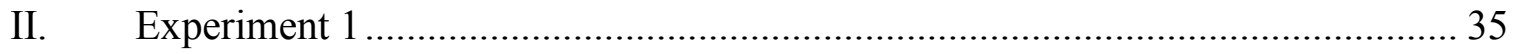

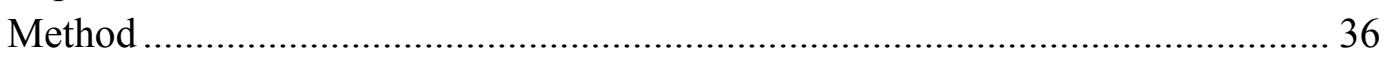

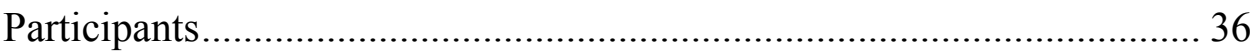

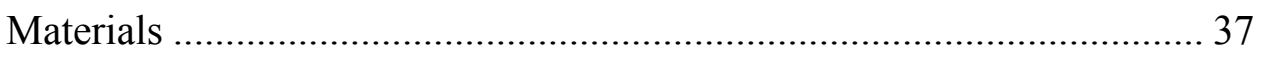

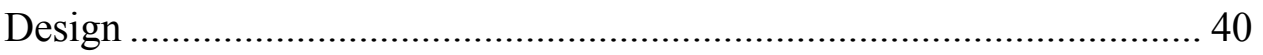

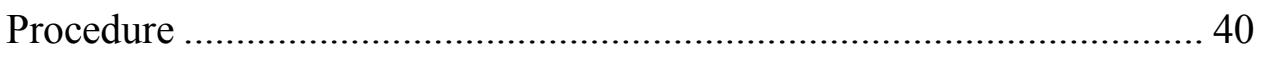

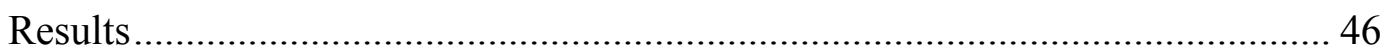

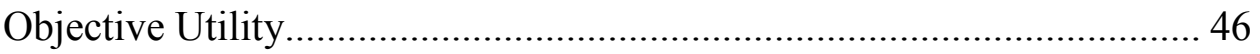

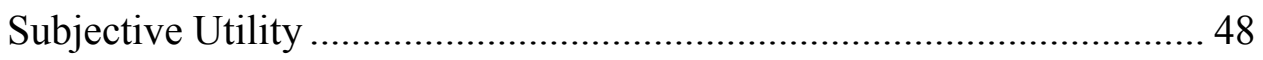

Enhancing Investigative Utility .......................................................... 54

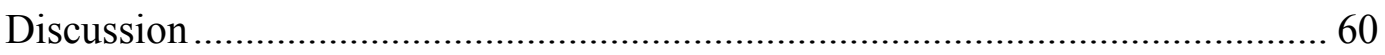

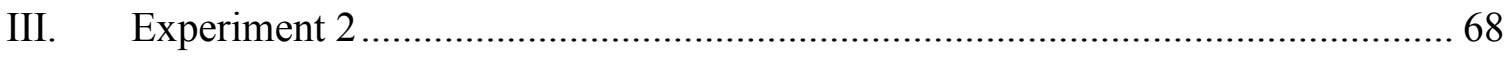

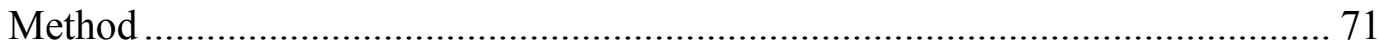

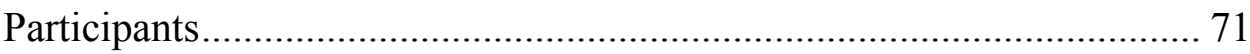

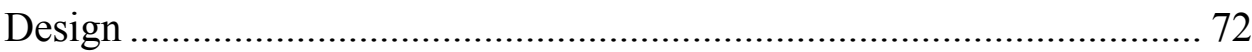

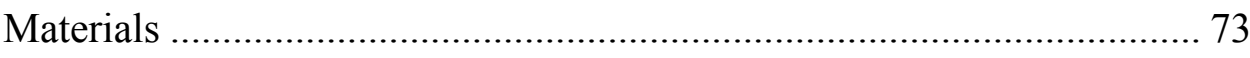

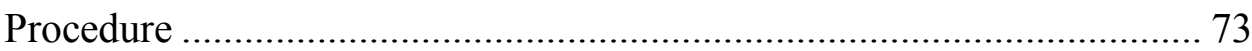

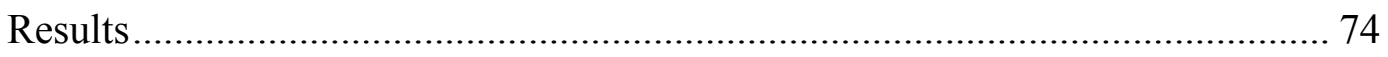

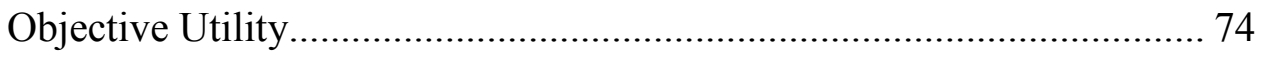

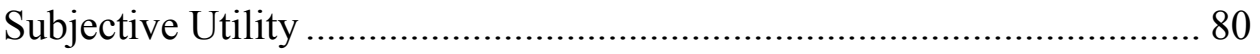

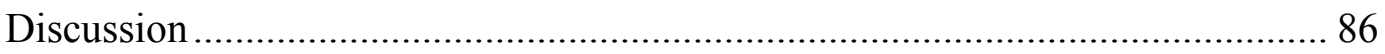




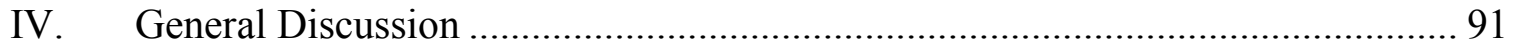

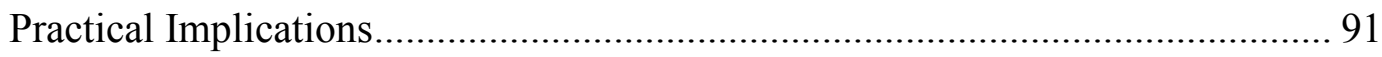

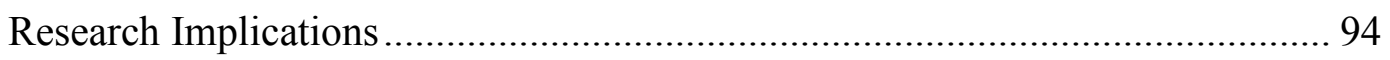

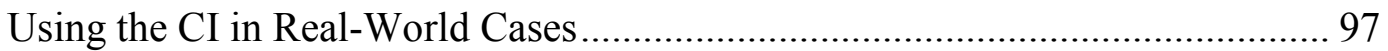

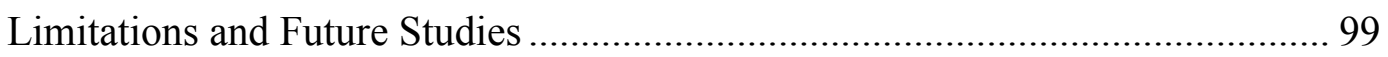

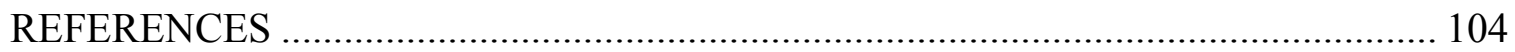

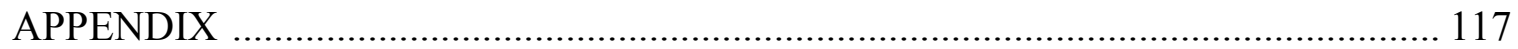

VITA 


\section{LIST OF TABLES}

TABLE

PAGE

CI Underlying Theories, Principles, and Technique................................................... 13

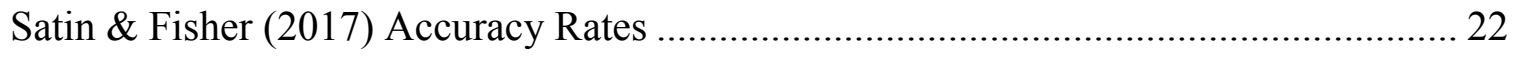

Representative SI and CI Interview Descriptive Statistics ....................................... 38

Exp. 1 Subjective Utility Descriptive Statistics (Common vs. Uniquely-CI).................. 50

Exp. 1 Subjective Utility Descriptive Statistics (Facial vs. Non-Facial) ........................ 53

Exp 1. Enhancing Investigative Utility - Identifying Perpetrator Logistic Regression ... 57

Exp. 1 Enhancing Investigative Utility - Resource Allocation Descriptive Statistics ..... 58

Exp 1. Enhancing Investigative Utility -Resource Allocation Multiple Regression........ 59

Exp. 2 Identifying the Perpetrator as a Suspect Descriptive Statistics .......................... 77

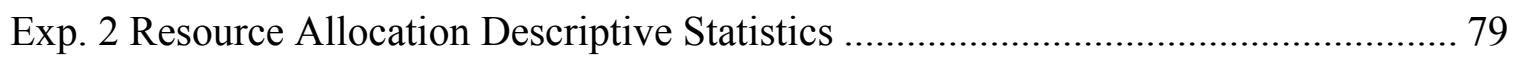

Exp. 2 Subjective Utility Descriptive Statistics (Common vs. Uniquely-CI).................. 82

Exp. 2 Subjective Utility Descriptive Statistics (Facial vs. Non-Facial) ........................ 85 
ABBREVIATIONS AND ACRONYMS

CI Cognitive Interview

DMP Division of Missing Persons

SI Standard Interview 


\title{
CHAPTER I
}

\author{
Literature Review
}

\section{The Inadequacy of Eyewitness Descriptions of Perpetrators}

\section{A. Incompleteness}

Incomplete and inaccurate perpetrator descriptions by witnesses are common albeit, problematic - in criminal investigations. As to completeness, a witness's description of a perpetrator is often generic and quite limited in substance; it generally consists of references to physical appearance (i.e., age, race, stature, weight, and height) and clothing (Douglass, Brewer, Semmler, Bustamante, \& Hiley, 2013; Gabbert \& Brown, 2015; Sporer, 1992; 1996). Laboratory studies have shown that even under optimal encoding conditions, witnesses provide incomplete perpetrator descriptions. For example, Sporer (2007) found that participants who were interviewed immediately after viewing a videotaped film of a theft reported only an average of 4.46 person details. Parallel findings have been shown in studies analyzing real police investigations. In his archival analysis of data from real criminal cases, Sporer (1992) found that — aside from the offender's hair — witnesses mentioned general attributes (i.e., age, build, height) more often than facial descriptors. The study also found the perpetrator's race/ethnicity to be mentioned more frequently than any facial feature (aside from glasses and beard), and found the most commonly reported descriptor to be the perpetrator's clothing (Sporer, 1992). In a subsequent archival analysis of 1,313 forensic witnesses in actual commercial robbery cases, van Koppen and Lochun (1997) similarly found witnesses to give very incomplete perpetrator-related information. The total number of perpetrator characteristics ranged from 1 to 23 (of a possible maximum of 43 descriptors) with a 
median of 8. Moreover, of the of 2,299 offender descriptions analyzed in the study, only 200 descriptions included more than 15 perpetrator characteristics. Features described by witnesses were more general (i.e., race, gender, build) than specific (i.e., facial features). Indeed, particular facial features - including, eyes, nose, facial complexion, mouth, eyes, teeth, chin, and ears - were mentioned in $5 \%$ or less of witness descriptions.

Incomplete perpetrator descriptions (that either omit or provide vague details regarding the face and/or other physical attributes) are problematic in criminal investigations. Generic information conveys a relatively indiscriminate portrait of the perpetrator (Fahsing, Ask, \& Granhag, 2004). For instance, a description of a "White male, about 5 feet 11 inches tall, weighing about 170 pounds" may apply to many potential suspects. This generic information does little in the way of obtaining leads on possible suspects (Fahsing et al., 2004). Unique details are needed to help police distinguish between potential suspects (e.g., the perpetrator walks with a limp, or has a large, crooked nose). Similarly, oft-recalled clothing descriptions may be of little value to police given that perpetrators can easily change and/or quickly discard their attire after committing a crime (Sporer, 1996); so, unless the clothing is described within minutes of the criminal occurrence, police generally assign little forensic relevance to clothing descriptions.

Police and investigators are cognizant of the incompleteness of perpetrator descriptions often provided by witnesses. For example, Kebbell \& Milne (1998) surveyed 159 British police officers regarding their perceptions of witnesses, of whom $76 \%$ of police reported that witnesses "rarely" or "never" provided as many "person" details as police want. Of the 78 British police officers more recently surveyed by 
Brown, Lloyd-Jones, and Robinson (2008), over 80\% reported that witnesses rarely provided as many person details as police would like. Thus, a more detailed description of the perpetrator and, particularly, unique details, are deemed by police to be critical investigative information (Kebbell \& Milne, 1998; Sporer, 1996). ${ }^{1}$

Sporer (1996) suggested that incomplete perpetrator descriptions should not be considered evidence that witnesses are unable to provide the underlying perpetratorrelated information. Rather, it may simply be a product of the way investigators elicit information from witnesses. In a typical police interview, an investigator will ask the witness a series of short-answer featural questions on the order of: How old was he? How tall was he? How much did he weigh? Was he wearing a green T-shirt?" (e.g., Brown, et al., 2008; Fisher, Geiselman, \& Raymond, 1987; George \& Clifford, 1992). In one particularly illustrative exchange reported by Fisher et al. (1987), the eyewitness began to narrate a detailed description of the perpetrator's appearance, and the police investigator quickly interrupted the narrative with, "Let me ask the questions, and you give me the answers." These closed-ended probes and accompanying interview

\footnotetext{
${ }^{1}$ It may be argued that eliciting a detailed perpetrator description should not, from a psychological standpoint, be a preferred police practice - that doing so will serve to hinder later investigative tasks, such as witness lineup identification accuracy. Laboratory research has shown that verbal descriptions, particularly those that are quantitatively robust, can interfere with subsequent perceptual identification tasks (e.g., Meissner \& Brigham, 2001; Schooler \& Engstler-School, 1990). However, this finding, known as the verbal overshadowing effect, is highly unstable. Indeed, Sporer (1992) found a positive correlation between the number of person descriptors and subsequent eyewitness identification accuracy. Participants who recalled a greater number of person details were more likely to make an accurate identification decision. Similarly, in an ecologically valid archival analysis, Valentine, Pickering, and Darling (2003) found that witnesses who were judged as having recalled a large number of perpetrator descriptors in an interview were more likely to positively identify the suspect than witnesses who were judged as either giving an average or a minimal number of details (see also Brown \& Lloyd-Jones, 2005; 2006; Meissner, 2002; Sporer, Kaminski, Davids, \& McQuiston, 2016; Wogalter, 1991; 1996). More recent research has found the effect to be unrelated to the accuracy, length, and content of the verbal description (Vanootighem, Brédart, \& Dehon, 2016), or has refuted the presence of the effect altogether (e.g., Mickes, 2016). Studies refuting verbal overshadowing are coupled by the moderating effect of retention interval that is, when there is a delay of ten or more minutes between the verbal description and identification, verbal overshadowing disappears (Meissner \& Brigham, 2001).
} 
interruptions minimize the amount of perpetrator (and other) information elicited from witnesses (Fisher, 1995; Fisher et al., 1987; George \& Clifford, 1992; Schreiber Compo, Hyman Gregory, \& Fisher, 2012; Wright \& Alison, 2004).

\section{B. Inaccuracy}

In addition to incomplete perpetrator descriptions, inaccurate perpetrator descriptions by witnesses are problematic in criminal investigations. Only a few studies have tested the accuracy of perpetrator descriptions elicited by witnesses. In fact, the literature so rarely addresses accuracy that some researchers have expressed a "dire need" for studies to focus not only on quantity but also on the accuracy of person descriptions (Sporer, 1996). A few archival analyses have addressed the issue. Van Koppen and Lochun (1997) analyzed description accuracy in real criminal cases by comparing the witness's perpetrator description to the police officer's description of the later-convicted suspect at the time of arrest. Needless to say, there are limitations to Van Koppen and Lochun's description accuracy measure, given that (a) ground truth (i.e., whether the convicted suspect is in fact the perpetrator) is unknown, and (b) the perpetrator's appearance may change subsequent to the time of the criminal offense (Gabbert \& Brown, 2015). Nevertheless, in the field (where there is no exact replica of the crime), comparison between the recalled description and other evidence of the perpetrator description is the best estimate of accuracy (e.g., Fisher, Geiselman, \& Amador, 1989). Comparing witness descriptions to police records, van Koppen and Lochun found that general characteristics that were more frequently reported by witnesses (i.e., gender, age, race, height, hair color, and face shape) were accurate in over $60 \%$ of perpetrator descriptions. By contrast, specific and unique descriptors that are reported less frequently 
by witnesses (i.e., nose, mouth, complexion, teeth, chin, and ears) were accurate in less than $40 \%$ of perpetrator descriptions.

Subsequent archival analyses similarly assessed the accuracy of perpetrator descriptions elicited by witnesses using more reliable measures. For example, Fahsing et al. (2004) gauged description accuracy against authentic video footage of the crime (rather than secondhand sources, i.e., police records). Overall, Fahsing et al. found witnesses to be quite accurate in their perpetrator descriptions. However, the accuracy of different attributes varied considerably — general and highly salient aspects of the perpetrator's physical appearance (e.g., gender, race/ethnicity, glasses, type of speech) were substantially more accurate than more nuanced, featural details (e.g., mouth shape, eyebrows, eye color). Similarly, Granhag and colleagues conducted an archival analysis of 29 perpetrator descriptions provided by witnesses to the murder of Swedish Foreign Minister Anna Lindh in 2003 (Granhag, Ask, Rebeluis, Öhman, \& Mac Giolla, 2013). The study notably measured a large number of witnesses to a single event occurring over a brief duration, whose descriptions were verifiable using photographs of the perpetrator captured by CCTV cameras minutes before the attack. Granhag et al. found witnesses' descriptions to provide a misleading portrait of the perpetrator. Of the verifiable perpetrator attributes, only $34.8 \%$ were correct, $23.7 \%$ were partly correct, and $41.5 \%$ were incorrect. Also, as in the Fahsing et al. study, accuracy was highly variable depending on whether the perpetrator descriptor was general (e.g., gender, race/ethnicity) or specific (e.g., facial).

The accuracy of a recalled perpetrator description - like completeness - may be a product of (or, at least exacerbated by) the way investigators elicit information from 
witnesses. A typical police interview often consists of a series of short-answer featural questions peppered with interruptions from the investigator (e.g., Fisher, 1995; Fisher et al., 1987; George \& Clifford, 1992; Schreiber Compo et al., 2012; Wright \& Alison, 2004). Systematic assessments of police interviews demonstrate that investigators follow an intuitive (rather than scientifically grounded) approach to interviewing, in which they isolate specific perpetrator details that they want to elicit and then direct the witness to answer questions about each of these details (see a recent review by Fisher, Schreiber Compo, Rivard, \& Hirn, 2014). The interview is primarily concerned with eliciting key characteristics that may confirm the investigator's preexisting beliefs about a potential suspect (e.g., Ask \& Granhag, 2007; Meissner \& Kassin, 2002; O’Brien, 2009).

An interviewing style that encourages witnesses to answer a string of predetermined questions is likely to come at the cost of accuracy (Evans \& Fisher, 2011; Koriat \& Goldsmith, 1994; 1996). This interviewing style is especially likely when dealing with (a) specific and unique descriptors that are not frequently volunteered by witnesses (Fahsing et al., 2004; van Koppen \& Lochun, 1997), and (b) facial descriptors, which are encoded holistically rather than as a collection of individual physical features (Diamond \& Carey, 1986; Tanaka \& Farah, 1993; Yin, 1969). Thus, police investigators appear to be furthering, rather than countering, the inadequacy of perpetrator descriptions provided by witnesses both in terms of completeness and accuracy. At the very least, there is considerable room to improve on police interviewing practices for eliciting perpetrator descriptions. 


\section{The Cognitive Interview}

The foregoing literature supports the need to explore a best-practice interviewing protocol that will presumably enhance witnesses' recall of perpetrator descriptors in investigative interviews. One such protocol, the Cognitive Interview (CI), is generally recognized as the "gold standard" in witness interviewing (e.g., Gabbert \& Brown, 2015). Developed by Geiselman, Fisher, and colleagues (1984), the CI is a memory retrieval procedure aimed at facilitating witness recall of events (revised by Fisher, Geiselman, Raymond, Jurkevich, \& Warhaftig, 1987, and then further modified by Fisher \& Geiselman, 1992). The CI enhances witness reporting in three ways: (a) utilizing cognitive and memory tools to aid the witness's memory retrieval process; (b) developing appropriate social dynamics between the interviewer and witness; and (c) enhancing communication between the interviewer and witness.

\section{A. CI Theoretical Principles}

The CI's cognitive underpinnings emanate from memory retrieval theory adapted to enhance witness recollection (Fisher 2010). One of the CI's core cognitive principles is context reinstatement, in which the context of the crime is recreated (i.e., the sights, sounds, smells, feelings, emotions, etc.) at the time of witness recall (Fisher \& Geiselman, 1992). Context reinstatement derives from the encoding specificity principle, which posits that recall is most effective when the conditions at encoding are the same as the conditions at retrieval (Tulving \& Thomson, 1973). Using context reinstatement as a memory facilitator, the CI interviewer instructs the witness to recreate the cognitive, emotional, and environmental context experienced at the time of the crime (Fisher \& Geiselman, 1992). The CI is also founded on the cognitive tenet that people have only 
limited mental resources to process information (Baddeley, 1986; Kahneman, 1973). If a witness attempts to search his or her memory for crime-relevant details while simultaneously attending to the interviewer's questions, recall performance may suffer (Fisher, 2010). Thus, the CI interviewer refrains from overloading the witness by asking relatively few questions, which are open-ended in nature, and by abstaining from asking questions while the witness is searching through his or her memory (Fisher \& Geiselman, 1992). Doing so allows the witness to provide longer narrative responses in his or her own words, at his or her own pace, and without interruption or distraction from the interviewer. The $\mathrm{CI}$ also encourages the witness to close his or her eyes at the time of memory retrieval, which has been shown empirically to enhance witness recall (Perfect, et al., 2008; Vredeveldt, Hitch, \& Baddeley, 2011). The CI also employs multiple and varied memory retrieval (Fisher \& Geiselman, 1992), which has been found repeatedly to yield new recollections that were not initially recalled by the rememberer (Oeberst, 2012). In an investigative context, asking a witness to recall crime details repeatedly, and to retrieve the to-be-remembered information using varied cues has been shown empirically to produce substantial new, accurate information (Gilbert \& Fisher, 2006). Thus, the CI interviewer asks the witness to recount the criminal event multiple times and in different ways (e.g., chronological order, reverse chronological order, changing personal perspective).

The CI is also premised on a metacognitive monitoring model of memory reporting, which posits that the accuracy of reported information improves when rememberers monitor and control their memory reports (Koriat \& Goldsmith, 1994; 1996). Using a mock crime interview paradigm, research has shown that, even after a 
substantial retention interval, witnesses can maintain the accuracy of their memory reports by controlling the quantity and precision of details reported (Evans \& Fisher, 2011). Based on metacognitive monitoring theory, the $\mathrm{CI}$ interviewer instructs the witness to refrain from guessing and, preferably, to indicate "I don't know" or "I don't remember" if applicable (Fisher \& Geiselman, 1992). The CI also derives from constructive memory theory whereby, at times, a rememberer incorporates outside information (e.g., from the interviewer, from other witnesses, from the media) into a real memory (Bartlett, 1932; Bransford \& Franks, 1971). Within the eyewitness literature, this phenomenon has been repeatedly and consistently shown to reduce the accuracy of witness information (e.g., Loftus, Miller \& Burns, 1978; Loftus \& Palmer, 1974; McCloskey \& Zaragoza, 1985). To minimize constructive recall, the CI interviewer is instructed to be particularly careful not to leak information to the witness either nonverbally (e.g., smiling or head-nodding) or verbally (e.g., asking leading or suggestive questions) about the criminal event (Fisher \& Geiselman, 1992).

The second core psychological process underlying the $\mathrm{CI}$ is social dynamics between the witness and interviewer. Witnesses and victims are often tasked with reporting unpleasant, highly traumatic, and/or emotionally distressing crime details; thus, it is crucial that the individual is as psychologically comfortable as possible during the interview (Fisher, 2010). Additionally, there is an inherent conflict between the interviewer's perceived social or expert status and the witness's superior knowledge of the criminal event (Fisher, 2010) - although the interviewer has more social status and is expected to control the interview, the witness has more knowledge and should actively participate in the interview. Thus, the CI is designed to increase the witness's comfort 
level, and to engineer the social dynamics so the witness plays a more active role in the interview. To do so, the CI interviewer develops personal, meaningful rapport with the witness at the outset of the interview (Fisher, 2010). Even though research shows rapport-building to increase the quality of recall by decreasing the reporting of inaccurate information (e.g., Roberts, Lamb, \& Sternberg, 2004; Vallano \& Schreiber Compo, 2011), standard police interviews often skip over this preliminary segment from the interview (e.g., Fisher et al., 1987). The CI also seeks to capitalize on the superior eventrelated knowledge of the witness by promoting active witness participation throughout the interview (Fisher \& Geiselman, 1992). Rather than having the interviewer pepper the witness with questions and interrupt the witness's initial responses with follow-up questions (as often occurs in police interviews, Fisher et al., 1987), the CI interviewer first asks open-ended questions (to promote extensive, rich narratives) and does not interrupt the witness during a narrative response (Fisher \& Geiselman, 1992); only after the witness completes his or her narrative response(s) does the interviewer ask targeted follow-up questions. In addition, the CI interviewer explicitly instructs the witness to take an active role in the interview. For example, the $\mathrm{CI}$ interviewer explains/instructs that (a) because the witness is the "expert," or person in the interview with all the knowledge and the pertinent information, s/he should be the one driving the course of the interview and the one who will be doing most of the talking; (b) the interviewer will not be asking many questions, and the witness should not wait for the interviewer to ask questions; and (c) the witness should not be deterred by the fact that the interviewer will be taking detailed notes. 
Communication is the third psychological process underlying the CI (Fisher \& Geiselman, 1992). Ineffective communication is likely to result in an ineffective interview, such that the witness withholds valuable information, provides irrelevant information or misinformation, etc. (Fisher, 2010). The CI is designed to allow the interviewer to effectively communicate his or her investigative needs to the witness, and to allow the witness to effectively communicate his or her event-related knowledge to the interviewer (Fisher \& Geiselman, 1992). First, the CI interviewer promotes extensive detailed responses by instructing the witness to report everything that s/he recalls, irrespective of whether the witness perceives that information to be trivial, out of chronological sequence, or contradictory (Fisher \& Geiselman, 1992). The "report everything" instruction helps relay to the witness the extraordinary level of description requested by the interviewer. It should not, however, be construed as an invitation to guess (see Memon, Wark, Bull, \& Koehnken, 1997); it merely directs the witness to provide event-related details in an unconstrained manner (Fisher \& Geiselman, 1992). In addition, the CI interviewer often provides an "ideal" or "model" statement to communicate effectively the level of detail requested from the witness (Hirn, Fisher, \& Carol, 2012). Given that forensic interviews are foreign to most witnesses, model statements provide a point of reference (allowing the witness to mirror the level of exemplified detail in the model statement). Research has shown interviewees to incorporate many details into their own responses as a result of receiving a model statement from an interviewer (Boggard, Meijer, \& Vrij, 2014; Ewens et al., 2016; Leal, Vrij, Warmelink, Vernham, \& Fisher, 2015). Effective communication is also promoted by the Cl's use of non-verbal output to allow the witness's responses to be compatible 
with his or her mental record of the event (Fisher \& Geiselman, 1992). For example, if information is inherently spatial (e.g., the location of objects in a room), then the witness should respond spatially (e.g., drawing a sketch of the room). Or, if information is inherently visual (e.g., a perpetrator description), then the witness should respond visually (e.g., looking at pictures that best represent the perpetrator's features, i.e., skin tone, facial shape, body shape, etc.). Code-compatible output minimizes the witness's translating a mental record into a verbal response and allows for an easier and more natural description of the event (Greenwald, 1970; Leibowitz, Gusy, Peterson, \& Blake, 1993). (See Table 1 for a breakdown of the CI's underlying theories, principles and techniques.) 
Table 1.

CI Underlying Theories, Principles, and Technique

\begin{tabular}{|c|c|c|}
\hline $\begin{array}{l}\text { Underlying } \\
\text { Theory }\end{array}$ & Principle & Technique \\
\hline \multirow{6}{*}{$\begin{array}{l}\text { Cognition and } \\
\text { memory retrieval }\end{array}$} & Context reinstatement & $\begin{array}{l}\text { Instruct the witness to recreate the cognitive, emotional, and environmental context } \\
\text { experienced at the time of the crime }\end{array}$ \\
\hline & $\begin{array}{l}\text { Limited mental resources to } \\
\text { process information }\end{array}$ & $\begin{array}{l}\text { Refrain from overloading the witness by asking relatively few questions, which are } \\
\text { open-ended in nature, and by abstaining from asking questions while the witness is } \\
\text { searching through his or her memory }\end{array}$ \\
\hline & Concentration/limit distractions & Encourage the witness to close his or her eyes at the time of memory retrieval \\
\hline & Multiple and varied retrieval & $\begin{array}{l}\text { Ask the witness to recount the criminal event multiple times and in different ways (e.g., } \\
\text { chronological order, reverse chronological order, changing personal perspective) }\end{array}$ \\
\hline & Metacognitive monitoring & $\begin{array}{l}\text { Instruct the witness to refrain from guessing and, preferably, to indicate "I don't know" } \\
\text { or "I don't remember" if applicable }\end{array}$ \\
\hline & Minimize constructive recall & $\begin{array}{l}\text { Interviewer is particularly careful not to leak information to the witness either non- } \\
\text { verbally (e.g., smiling or head-nodding) or verbally (e.g., asking leading or suggestive } \\
\text { questions) about the criminal event }\end{array}$ \\
\hline \multirow[b]{2}{*}{ Social dynamics } & Increase witness comfort & Develop personal, meaningful rapport with the witness at the outset of the interview \\
\hline & $\begin{array}{l}\text { Promote active witness } \\
\text { participation }\end{array}$ & $\begin{array}{l}\text { Ask open-ended questions (to promote extensive, rich narratives), do not interrupt the } \\
\text { witness during a narrative response, and instruct the witness to take an active role in the } \\
\text { interview }\end{array}$ \\
\hline \multirow{3}{*}{ Communication } & $\begin{array}{l}\text { Promote extensive detailed } \\
\text { responses }\end{array}$ & $\begin{array}{l}\text { Instruct the witness to report everything that s/he recalls, irrespective of whether the } \\
\text { witness perceives that information to be trivial, out of chronological sequence, or } \\
\text { contradictory, without guessing }\end{array}$ \\
\hline & $\begin{array}{l}\text { Communicate effectively the } \\
\text { level of detail requested }\end{array}$ & Provide an "ideal" or "model" statement as a point of reference \\
\hline & Code-compatible output & $\begin{array}{l}\text { If information is inherently spatial (e.g., the location of objects in a room), then the } \\
\text { witness should respond spatially (e.g., drawing a sketch of the room). Or, if } \\
\text { information is inherently visual (e.g., a perpetrator description), then the witness should } \\
\text { respond visually (e.g., looking at pictures that best represent the perpetrator's features, } \\
\text { i.e., skin tone, facial shape, body shape, etc.). }\end{array}$ \\
\hline
\end{tabular}




\section{B. CI Empirical Testing and Real-World Application}

The $\mathrm{CI}$ is the most widely accepted, scientifically based system for interviewing cooperative adult witnesses. It has been tested in more than 100 laboratory and field studies in the United States, England, Australia, and Germany (for recent reviews, see Fisher, et al., 2014; Holliday, Brainerd, Reyna, \& Humphries, 2009; for a recent metaanalysis, see Memon, Meissner, \& Fraser, 2010). The CI has been shown empirically to enhance witness recall, eliciting between 25 and 50 percent more correct statements than a standard police interview (Memon et al., 2010). The CI advantage is even more pronounced in an ecologically valid setting. In a field study by Fisher, Geiselman, and Amador (1989) involving victims and witnesses to real crimes, police detectives trained to use the $\mathrm{CI}$ elicited $47 \%$ more information after than before training, and $63 \%$ more information than comparable detectives who were not trained in the CI (see also Clifford \& George, 1996; Colomb, Ginet, Wright, Demarchi, \& Sadler, 2013; George \& Clifford, 1992).

The CI's improvement in the quantity of witness recall is extremely reliable. In the recent meta-analysis by Memon and colleagues (2010), 58 of the 59 reviewed experiments found the $\mathrm{CI}$ to elicit more correct information than a standard interview (with a large weighted mean effect size of $d=1.20$ ). The CI advantage has also been shown to be particularly robust, holding constant across a variety of interviewing and witness conditions (Köhnken, Milne, Memon, \& Bull, 1999; Memon et al., 2010). The improvement in CI-elicited witness recall is especially impressive given that it is generally accomplished at comparable or slightly higher rates of accuracy than a standard police interview (Köhnken et al., 1999; Memon et al., 2010). 


\section{Using the CI to Elicit Perpetrator Descriptions}

Although the CI has substantial empirical support and far-reaching application, extant research has largely failed to test the CI's impact on a ubiquitous (albeit, critical) aspect of witness interviews - describing the perpetrator (e.g., Sporer, 1996). The paradigm typically used to examine the effectiveness of the CI involves interviewing witnesses to a staged or recorded crime or other non-threatening event. Witnesses are assigned randomly to one of two interview conditions (the CI or a "structured/standard interview," which mirrors generally accepted interviewing principles) and are asked to recall the crime/event (see Fisher et al., 2014 for review). The goal of a typical CI study is to elicit improved episodic recall - names, dates, times, places, actions (both physical and verbal), chronology and sequences, and contextual information associated with the criminal event. Person-related information is necessarily included in the recall task. However, this information (even when categorically coded) is rarely analyzed separately from other crime-related details.

The few studies that coded the data separately for person-related information and other kinds of information (e.g., actions, setting) contained very broad "person" categories that included many statements unrelated to a person's physical appearance (e.g., Dando, Wilcock, Behnkle, \& Milne, 2011; Geiselman et al., 1984; Holiday et al., 2012; Memon, Holley, Milne, Koehnken, \& Bull; 1994; Milne \& Bull, 2003). For example, in testing the CI's impact on enhancing memory for family meeting occurrences, Leins, Fisher and colleagues (2014) parsed the data into four categories: people, conversations, actions, and settings. The researchers found the CI to elicit twice as many "people" details as a standard interview. However, "people" was 
operationalized to include any statement that involved a person (e.g., what actions that person took, what that person said, contextual information about that person, etc.). The analysis was not limited to a physical description of a person.

Almost no studies have focused specifically on whether the CI improves a perpetrator description elicited in an investigative interview. A few studies have scratched the surface, yet missed the mark, in answering this important research question. For instance, Gwyer and Clifford (1997) studied the effect of the CI on witness recognition in an identification lineup task. As part of the study, the researchers coded CI-elicited recall for person descriptors. ("The physical appearance of the perpetrator and clothing worn by the perpetrator.") However, no independent assessment was made of the quantity or accuracy of that particular category of descriptor. Instead, the researchers combined all categories of information elicited, finding the CI to produce significantly more total correct recall than the standard interview. Person descriptors were specifically assessed only in terms of the correlation between accuracy and witness confidence for that categorical variable. Finger and Pezdek (1999) also sought to test the Cl's ability to enhance a verbal description, however (a) the interviews consisted of a pre-printed script rather than being an interactive interview, and (b) many fundamental elements of the CI were omitted from the study design (e.g., building rapport, establishing social dynamics, utilizing limited mental resources, instructing the eyewitness not to guess, eye closure, multiple and varied retrieval, code-compatible output). Milne and Bull (2003) also coded CI-elicited recall categorically for person descriptors, e.g., "what the magician was wearing and looked like.” Although Milne and Bull analyzed quantity and accuracy of person information separately from the other categories of descriptors (i.e., actions, 
objects, surroundings), person information was broadly defined to include statements unrelated to the target person's physical appearance, e.g., "the magician magicked a dove" was coded as both a person detail category and as an action category detail (see also Dando et al., 2011; Geiselman et al., 1984; Holiday et al., 2012; Memon et al., 1994).

Given the conspicuous gap in the literature regarding use of the CI to elicit a perpetrator description, Satin and Fisher (2017) examined whether the CI improved witness recall of a perpetrator description. The researchers hypothesized that the CI would be superior to a standard police interview both in terms of the completeness and accuracy of the perpetrator description. College students witnessed a staged crime and were interviewed about the perpetrator using either a CI or standard police interview. The standard interview (SI) (which mirrored interviewing practices commonly followed by police officers, as confirmed by real police officers in pilot testing; see also Schreiber Compo et al., 2012) began by building rapport, and explaining the purpose of the interview. Then, the interviewer asked an initial open-ended question: "What did the thief look like?" followed by asking targeted follow-up questions on 13 categories of person descriptors (e.g., skin tone, hair color, hair style, build, markings/scars/tattoos). The interviewer then asked the witness if there was any further information s/he could recall, and concluded the interview after receiving verbal confirmation that the witness could not recall any further information.

The CI was modified to elicit only person descriptors. As in the SI, the modified CI used in this study began by building rapport and explaining the purpose of the interview. In addition, the interviewer instructed the witness to take an active role in the 
interview, instructed the witness not to guess and to report everything/provide detailed responses, and provided a 30-40 second example of an "ideal" response (in which the interviewer provided a detailed description of an animal's face). Next, as in the SI, the questioning began with an initial open-ended prompt: "Tell me everything you can about what the perpetrator looked like." At the completion of the witness's initial narrative, the interviewer then asked the witness to close his or her eyes while the interviewer reinstated the context. After, the interviewer engaged in multiple retrieval, again asking the witness, "Tell me everything you can about the thief" (while maintaining eye closure). At the completion of the witness's second narrative, the interviewer asked targeted follow-up questions on 19 categories of person descriptors (e.g., hair, with subcategories for color, length, style, hairline, and texture; non-physical descriptors, i.e., mannerisms and demeanor). Follow-up questions were not pre-determined; rather, the questions depended on the information that was elicited in the witness's initial two free narrative responses. Where appropriate, targeted questions included code-compatible output using visual charts of different facial shapes (e.g., diamond, square, oval), male and female body shapes (e.g., rectangle, hourglass, pear), skin tones (the chart included 66 different skin colors/shades ranging from ivory to black), and eyebrow shapes (e.g., curved, angled, rounded). As in the SI, the interviewer then asked the witness if there was any further information s/he could recall, and concluded the interview after receiving verbal confirmation that the witness could not recall any further information.

Each audio-recorded interview was transcribed in its entirety, after which research assistants (a) parsed each interview into unique units of perpetrator-related information (e.g., "blonde hair pulled back in a braid" would be parsed into three units: blonde hair, 
pulled back, in a braid); (b) compiled a typewritten list of all perpetrator-related descriptors elicited during each interview; (c) categorically coded each descriptor by type (facial vs. non-facial) and by interview phase ${ }^{2}$; and (d) counted the number of descriptors in each interview. In addition, accuracy of the perpetrator descriptors was coded by four research assistants, who (for each of the 67 interviews) independently compared each recalled perpetrator descriptor (or, unit) to a photograph of the perpetrator, and rated the accuracy of that descriptor on a six-point Likert scale $(1=$ not at all accurate, $6=$ extremely accurate).

Satin and Fisher (2017) found the CI to elicit more than three times the number of perpetrator details elicited by the standard interview (67.44 vs. 20.00 descriptors, on average). Completeness was more than simply a product of the length of the $\mathrm{CI} /$ number of questions asked. First, the CI elicited more perpetrator descriptors than the SI in Phase I, where all participants received the same one request: Give a detailed description of the thief (CI: $M=26.4, S D=15.80 ;$ SI: $M=8.43, S D=5.46$ ). Second, although the CI incorporated a second open-ended request (Phase II) that the SI did not, the second phase of the CI accounted for less than $10 \%$ of all the information elicited by the CI, so it could not have accounted for most of the CI effect (Phase II CI: $M=7.69, S D=7.88$ ). Third, in Phase III, the ratio of number of descriptors elicited to questions asked was higher in the CI (50:41) than in the SI (12:12), that is, more information was generated per CI question than per SI question. The CI undoubtedly asked more questions of the witness than the SI in Phase III. However, Satin and Fisher proffered that the greater number of CI

\footnotetext{
${ }^{2}$ The CI incorporated three phases: initial request for an open-ended narrative, second request for an openended narrative, follow-up direct questions; the SI incorporated two phases: initial request for an openended narrative, follow-up direct questions).
} 
follow-up questions was more likely a product of the CI's success rather than a cause of its success. That is, CI interviewers had more opportunities to ask follow-up questions than SI interviewers simply because the CI had elicited more units of information early in the interview (Phase I), and these early-recalled units were the basis for later asking specific follow-up questions.

Satin and Fisher assessed accuracy by first calculating the median accuracy score (across the four coders) for each descriptor. Then, the median scores were recoded into different accuracy "cutoffs" (or stringency levels) along the 6-point scale ( $1=$ not at all accurate, $6=$ extremely accurate). The cutoffs for a descriptor to be considered accurate were: (a) greater or equal to 2; (b) greater or equal to 3; (c) greater or equal to 4; (d) greater or equal to 5; and (e) equal to 6 . For each cutoff, the accuracy rate was then calculated as an output-bound measure (Koriat \& Goldsmith, 1994): (\# Correct) / [(\# Correct $)+(\#$ Incorrect)]. When the cutoff was very stringent (i.e., when only a median score of 6 was counted as correct, and anything below 6 was considered inaccurate), the SI accuracy rate (.31) was significantly higher than the CI accuracy rate (.24). However, as the cutoff became more lenient, the SI and CI produced comparable accuracy rates (see Table 2 for SI and CI accuracy rates at each cutoff). Thus, Satin and Fisher found that when using a very stringent accuracy criterion, the CI was less accurate than the SI, whereas when using a more lenient decision criterion, there were no significant differences between the accuracy rates of the CI and SI. Satin and Fisher's finding aligns with prior CI studies, which have generally found the CI to be comparable to the SI in terms of accuracy using a 2-point dichotomous scale (accurate vs. inaccurate). A 
dichotomous accuracy scale is akin to the more lenient cutoffs on Satin and Fisher's 6point scale, which produced comparable accuracy rates between the SI and CI.

Satin and Fisher were the first to focus on the Cl's effect on the quantity and accuracy specifically of a perpetrator description. They found that (a) the CI elicited substantially more perpetrator-related information than the SI; and, (b) the perpetratorrelated information elicited from the CI was just as accurate as the information elicited from the SI, unless an extremely stringent decision criterion for accuracy was used. 
Table 2.

Satin \& Fisher (2017) Accuracy Rates

\begin{tabular}{|c|c|c|c|c|c|c|}
\hline \multirow[b]{2}{*}{ Cutoff } & \multicolumn{3}{|c|}{ SI } & \multicolumn{3}{|c|}{$\mathrm{CI}$} \\
\hline & $\mathrm{n}=$ Accurate $*$ & $\mathrm{n}=$ Inaccurate $* *$ & Accuracy Rate & $\mathrm{n}=$ Accurate $*$ & $\mathrm{n}=$ Inaccurate $\mathrm{I}^{* *}$ & Accuracy Rate \\
\hline$=6$ & 249 & 533 & .32 & 503 & 1579 & .24 \\
\hline$\geq 5$ & 517 & 265 & .66 & 1339 & 743 & .64 \\
\hline$\geq 4$ & 674 & 108 & .86 & 1784 & 298 & .85 \\
\hline$\geq 3$ & 729 & 53 & .93 & 1950 & 132 & .94 \\
\hline$\geq 2$ & 752 & 30 & .96 & 2008 & 74 & .96 \\
\hline
\end{tabular}

*Reflects the total number of descriptors in the 67 interviews that were accurate based on the cutoff.

**Reflects the total number of descriptors in the 67 interviews that were inaccurate based on the cutoff. 


\section{Cognitive Interview Investigative Utility}

\section{A. Hole in the CI Literature}

Of the more than one hundred CI published studies conducted, no published study has found the CI to improve police job performance. The literature examines only whether the CI gathers more information than a standard police interview. While there is no question that the CI elicits relatively more witness information (Köhnken et al., 1999; Memon et al., 2010), quantity cannot be used as a proxy for investigative utility. Consider, for example, Satin and Fisher's (2017) study, which demonstrated the CI to produce a more complete perpetrator description (i.e., more perpetrator attributes) than a standard police interview. Eliciting a large number of perpetrator-related details does not necessarily mean that the description will be of investigative use to police. The larger quantity of (and presumably more specific and unique) CI-elicited perpetrator descriptors may be difficult for decision makers to keep track of while engaging in police-related tasks. For example, it may be easier for police to identify potential suspects from mugshot photographs using a description like, "young Hispanic male with short brown hair" than using a description like, "18-20 year old, Nicaraguan male with ashy mediumbrown hair about 2-inches in length." The additional information in the second description may be too cognitively demanding for police to effectively incorporate into their investigative decision-making.

To date, researchers have assumed the CI is useful to police because it elicits more, high-quality information from witnesses (Fisher et al., 1989; Geiselman \& Fisher, 2014). It is presumed that CI-elicited information will necessarily translate into improved police (prosecutor, juror, judge, etc.) performance. However, the CI's value is 
not actually decided by the initial investigative phase (when the witness provides a description of the perpetrator). Rather, it is determined by whether that information improves police performance in the subsequent phases of an investigation - specifically, whether it helps the police home in on/identify the perpetrator as the suspect, which will increase the efficiency and reliability of subsequent investigative tasks (e.g., a lineup). To establish the value/usefulness of the CI in police investigations, evidence is needed that it helps the police complete critical tasks, such as identifying and investigating the right suspect - i.e., the perpetrator rather than an innocent suspect (Fisher et al., 2014). Extant CI research has yet to test the utility of the CI in a police investigation, which was the primarily goal of the current study.

\section{B. Empirical Basis for CI Utility}

The current study tested the CI's investigative utility using a two-fold inquiry: First, will police properly use the CI in their investigative decisions and, second, will police perceive the CI-elicited perpetrator descriptors as subjectively useful to their investigative decisions (and, thus, be willing to use the CI to interview witnesses)?

Whether police are capable of using CI-elicited perpetrator information in such a way as to further their investigative goals has yet to be determined. However, extant field research has demonstrated the real impact of incorporating best-practice (non-CI) interviewing procedures into a police investigation. Orbach et al. (2000) designed an interview protocol that has considerable overlap with the CI - the National Institute of Child Health and Development (NICHD) Investigative Interview - to maximize the amount of information obtained from child victims in sexual abuse cases. The NICHD Investigative Interview contains some of the same cognitive, social dynamics, and 
communication tools as the CI (e.g., open-ended prompts, instructions on the level of detail requested and not to guess, building rapport, etc.), which are modified slightly for child witnesses. The NICHD Investigative Interview has been shown to (a) generate more investigative leads (Darvish, Hershkowitz, Lamb, \& Orbach, 2005, 2008); (b) result in more criminal charges; and (c) produce more guilty verdicts compared to those investigations in which a standard interview method is used (Pipe, Orbach, Lamb, Abbott, \& Stewart, 2008).

Satin and Fisher (2017) conducted initial pilot testing of the CI's investigative utility in conjunction with their CI perpetrator description study. As discussed above, sixty-seven interviews were conducted in the study (approximately half using the CI and half using an SI). The perpetrator descriptions elicited from these interviews were then given to a second group of student participants who were told that the Division of Missing Persons (DMP) was searching for a person who was kidnapped ${ }^{3}$, and the only information the DMP had was a description of the missing person. The participants then completed a complex set of survey tasks, which were divided into to three distinct sections, each testing one aspect of investigative utility: (a) similarity judgments; (b) resource allocation; and (c) search set construction. First, to measure similarity judgments, each participant was sequentially shown ten suspected "missing person" photographs, and was asked to rate the similarity of each photograph to the typewritten description of the "missing person" on a ten-point scale ranging from 1: poor match to 10: excellent match. The participant was also asked to provide an accompanying

\footnotetext{
${ }^{3}$ The criminal event was converted into a missing person investigatory task to preclude participants from engaging in criminal facial stereotyping, to encourage them to rely solely on the written description in their decision making (e.g., Macrae \& Shepard, 1989).
} 
confidence judgment for each similarity rating on a ten-point scale ranging from 1: not at all confident to 10: extremely confident. Next, to measure resource allocation, the participant was shown an array of the ten suspected "missing persons" and was asked to indicate how many hours the DMP should spend investigating each photographed person to determine if $\mathrm{s} / \mathrm{he}$ is truly the "missing person." The participant was instructed to assume s/he had only 100 total hours to investigate, and was asked to indicate the number of hours (from 0 to 100) for each photograph. Third, to measure search set construction, the participant was shown an array of the ten suspected "missing persons" and was asked to place checkmarks beneath six of the photographs so that the DMP could construct a search set of individuals who were most likely to be the missing person.

Pilot testing found that the CI-elicited descriptions (characterized as "missing person descriptions" for participants taking the survey task) did not help participants make better investigative decisions than SI-generated descriptions. Specifically, relative to an SI-elicited description, participants provided with CI-elicited descriptions were no more likely to (a) rate the target person's face as a better match to the provided descriptors than the non-target faces; (b) spend more time investigating the target person than the non-targets; or (c) include the target person in a lineup at a higher probability than a non-target.

Why were the decision-makers not able to better use the objectively more complete descriptions provided by the CI than by the SI? Methodological limitations of the pilot study may have made it difficult for decision makers to make good use of the provided descriptors. First, the likeness measure may have impeded decision making (both in terms of participants performing the task as well as the inherent nature of the 
task). The initial survey task completed by participants was to make similarity and confidence judgments for each photographed individual and the written description of the “missing person.” In total, participants made 20 individual Likert-based judgments (repeatedly referencing sometimes lengthy lists of written descriptors for each determination). Given that individuals have only limited mental resources to process information (Kahneman, 1973), the similarity and confidence judgments may have been too cognitively taxing for participants at the outset of the survey task, and participants may not have had sufficient mental resources for the remaining survey questions (resource allocation and lineup composition/base rate). Moreover, facial similarity judgments have been shown to suffer from psychometric problems derived from substantial interparticipant variability - an array of faces that appears highly similar to one participant may not appear at all similar to another participant (Lindsay, 1994). Thus, the initial task completed by participants (before their mental resources were depleted) may have been unreliable.

Second, the resource allocation task was open to varying methodological interpretation. Participants were asked to allocate the amount of resources (or, the number of hours) they would spend investigating each of the ten photographed individuals based on the description they had been given. However, resource allocation was not adequately operationalized in the survey task. As a result, it is unclear whether allocating less time indicated that the participant was less confident that the photographed individual was indeed the person whose description they had been given. Alternatively, allocating fewer resources may have indicated that the photographed individual was 
indeed the person described (and, therefore, the participant needed less time to follow up with and/or further investigate that individual).

Third, the ten photographs used in the survey may have been too similar in appearance. High similarity between fillers and suspects has been shown in lineup identification tasks to increase the role of extra-recognition influences on the identification process, such as guessing (Luus and Wells, 1991; Navon, 1992). Although the pilot study did not entail a lineup identification task, it is possible that the non-target photographs were not sufficiently dissimilar from the target photographs to allow the written descriptors to discriminate effectively. Greater dissimilarity of appearance between the target and non-target photographs may have increased ecological validity and decreased guessing by participants.

Finally, the hypothetical task lacked ecological validity. Rather than being told that a crime occurred, and that the description provided to the participant was of the perpetrator, participants were told that the police were searching for a kidnapped individual, and that the description was of the missing person. Converting the criminal task into a missing person task precluded participants from engaging in criminal facial stereotyping (Dumas \& Testé, 2006; Macrae \& Shepard, 1989; Shoemaker, South, \& Lowe, 1973) and compelled participants to rely solely on the written description in their decision making. Nonetheless, participants may not have understood their role in the investigation, and may have questioned why the DMP would not already have a picture of the missing person from the victim's family. Providing the participants with a more salient role - as a mock police officer searching for an armed robber or murderer - would 
perhaps have incentivized students to take their survey task more seriously and resulted in participants' better understanding of their responsibility in answering the questions.

The current study tested the CI's investigative utility, eliminating the methodological limitations of Satin and Fisher's pilot study. Specifically, the current study sought to reduce cognitive load, clarify instructions, better operationalize measures, increase participant motivation and ecological validity, decrease similarity of suspect photographs, and allow decision makers to make better use of the CI-elicited descriptors.

It is also important to determine whether police perceive CI-elicited information as subjectively useful to their investigative decisions. In other words, do police metacognitively deem CI-elicited information useful to their police-related tasks? Research shows that police generally consider perpetrator descriptions a vital source of evidence that can provide a crucial lead in a criminal investigation (Brown et al., 2008; Kebbell \& Milne, 1998). Police often rely on perpetrator descriptions from witnesses to narrow the search for possible suspects (often disseminating the perpetrator's description internally as well as to the general public in hopes of obtaining leads on possible suspects). Indeed, the Police and Criminal Evidence Act of the United Kingdom (PACE, 1984) requires police to record the perpetrator description initially given by a witness. Moreover, PACE requires any resulting lineup to be constructed such that each lineup member matches the witness's initial description of the perpetrator in terms of age and general appearance. A "match to description" strategy has similarly been advocated as a recommended lineup construction approach in the United States (e.g., Neuschatz \& Cutler, 2008; Wells, Rydell, \& Seelau, 1993). 
It stands to reason that the more complete and accurate the perpetrator description by a witness, the more police will assess it as useful to their investigations. The practical value of the CI is empirically backed by a meta-analysis by Meissner, Sporer, and Susa (2008) on the relationship between facial description and subsequent person identification accuracy. Although Meissner and colleagues found a significant negative relationship (more complete person descriptions were more likely to result in inaccurate identification decisions), this finding was moderated by accuracy. In other words, the more complete descriptions tended to contain more inaccurate facial descriptors, hence, leading to inaccurate identifications. It was thus concluded from the meta-analysis that (a) more accurate descriptions are significantly associated with greater accuracy in identifications; (b) descriptions that contain more incorrect person details are associated with greater inaccuracy in identifications; and (c) descriptions that are congruent with perpetrators increase the likelihood that perpetrators are in lineups. If the CI elicits a more complete and accurate description of the perpetrator, that description will likely be more congruent with the suspect in a subsequent lineup, thus resulting in more target-present lineups and fewer target-absent lineups (which will be of great practical value to police investigators). If police are able to see the value of CI-elicited perpetrator descriptors in completing their investigative tasks (specifically in terms of the bottom line - e.g., raising the base rate of including perpetrators in lineups, catching criminals, closing cases), it is reasonable to assume that police will assess the $\mathrm{CI}$ as useful to their investigations and, thus, will be willing to use the CI to interview witnesses. The current study tested this proposition by asking police to subjectively rate the utility of various perpetrator descriptors after completing key police-related tasks. 


\section{CI Usability Concerns}

Satin and Fisher's (2017) pilot findings identified potential issues with the Cl's ease of use in an investigation. It cannot be assumed that merely providing police with a detailed, high-quality perpetrator description will result in better searches and identifications of guilty suspects. Thus, in the current study, it was not only important to address the basic question of whether the $\mathrm{CI}$ improves investigative utility, but also to consider in what form(s) the CI might be more effective, or "user-friendly," to police. That is, the CI-elicited descriptors might be presented to decision makers in a more effective form (e.g., changing the order in which the descriptors are presented) so that decision makers make better use of the descriptors. There are a variety of potential theoretical and practical concerns that may impede CI usability.

First, when using a perpetrator description to identify a photo of a suspect, the police investigator is tasked with transferring a list of verbally recalled person descriptors into a visual image (i.e., photograph) of that person, which involves using different underlying cognitive modalities (e.g., Schooler, 2002; Wells, 1985). The mismatch between a perpetrator description (verbal) and a suspect photo identification (visual) - or, more generally, the incompatibility between the stimulus and the response (Pashler, 1984) - may hinder the police investigator's task (e.g., Fitts \& Deininger, 1954; Fitts \& Seeger, 1953; Schooler \& Engstler-Schooler, 1990). The degree of stimulus-response compatibility characterizing a task can be affected by the congruence between the stimulus and response characteristics (Dassonville, Lewis, Foster, \& Ashe, 1999; Fitts \& Deininger, 1954). Kornblum, Hasbroucq, and Osman (1990) describe compatibility as the "dimensional overlap" between a stimulus and response, meaning that some stimulus- 
response combinations are more compatible in that they involve the same underlying modalities (e.g., visual stimulus/visual response). Incompatible presentation modalities can hinder task performance (e.g., Stephan \& Koch, 2016). Thus, it is possible that stimulus-response compatibility extends to perpetrator descriptions. It may be the case that, because a witness's verbal description of a perpetrator and that perpetrator's photograph are modally incongruent (verbal/visual), performance of the investigator's perceptual selection task is hindered. The current study sought to account for this usability concern by providing a set of instructions to police to "attempt to mentally create a pictorial image of the perpetrator while reading his or her description" to increase the compatibility between the stimulus (descriptor list) and response (perpetrator photograph). Specifically, the current study sought to test whether the CI's investigative utility could be improved by enhancing the modal congruence between the witness's verbal description of a perpetrator and that perpetrator's photograph.

Investigators' tasks may also be made more difficult by the fact that describing a face verbally is necessarily a featural process - the witness is asked to describe the various features or descriptors of the perpetrator. However, perceptual facial identification is a holistic process - the investigator is attempting to select a topographic whole or configural image (e.g., Diamond \& Carey, 1986; Tanaka \& Farah, 1993; Yin, 1969). Cognitive psychology literature suggests that while object recognition is a partdriven process (e.g., a house is recognizable by its doors or windows), face recognition is dependent on a holistic analysis (e.g., Tanaka \& Farah, 1993). Researchers have shown that face recognition is a "special" form of pattern recognition involving minimal part decomposition (Farah, Wilson, Drain, \& Tanaka, 1998; McKone, Martini, \& Nakayama, 
2003). For example, Farah (2000) demonstrated that object parts were equally recognized whether the object was presented as an upright whole, inverted whole, or in isolation by parts. Just the opposite occurred with facial features (e.g., a nose or ears), which were best recognized within upright, whole faces. These findings suggest that the featural method by which the perpetrator is described (even if accurate) may not comport with the holistic facial information that would most benefit police in recognizing a picture of the perpetrator (Tanaka \& Farah, 1993; Valentine, 1988; Yin, 1969). In other words, a featural perpetrator description may hinder the subsequent holistic processing of a perpetrator's photograph by investigators. To account for this concern, the current study sought to enhance the CI's investigative utility by "feeding" the list of descriptors to decision makers in a theoretically appropriate manner - holistically followed by featurally (Diamond \& Carey, 1986; Tanaka \& Farah, 1993; Yin, 1969), and in a more efficient manner (i.e., categorically, such that all similar person descriptors are chunked together in the description).

In sum, the third aim of the current study was to test the Cl's impact on investigative utility using procedural methods that reduce cognitive load, allow decision makers to make better use of the CI-elicited descriptors, and make the CI as "userfriendly" as possible.

\section{Current Study}

Although I assumed that the additional perpetrator-related information elicited from a CI would aid the police in their investigation of a crime, the current study tested this assumption empirically. The two experiments mirrored the multi-phased nature of a criminal investigation, in which police first interview a witness about the perpetrator, 
then use the witness's perpetrator description to find and consider potential suspects, and then select one particular suspect to pursue and to allocate investigative resources toward (e.g., conducting a lineup, interrogation, etc.). Experiment 1 was conducted with undergraduate students playing the role of police investigative decision makers. In Experiment 2, police and students served as the decision makers. In addition, the procedure used in Experiment 2 was refined based on the results of the first experiment. 


\section{CHAPTER II}

\section{Experiment 1}

Experiment 1 explored three primary questions about whether the $\mathrm{CI}$ is a superior investigative interviewing tool for perpetrator descriptions than a standard police interview: (1) Are decision makers able to use CI-elicited information to identify/select the perpetrator as a suspect and to efficiently allocate investigative resources to pursuing the perpetrator)? (2) Do decision makers subjectively value the additional information elicited from the CI? (3) Are there methods by which to enhance the utility of CI perpetrator descriptions in investigative decision making?

(1) Objective Utility: I hypothesized that a CI-elicited perpetrator description would better allow decision makers to conduct critical investigative tasks than a standard police interview (see Darvish et al., 2005, 2008; Pipe et al., 2008). Specifically, I hypothesized that decision makers would be more likely to (a) correctly identify the perpetrator as a suspect (by matching the perpetrator's photograph to the eyewitness's description of the perpetrator); and (b) assign a greater number of hours to investigating the perpetrator.

(2) Subjective Utility: Information elicited from the CI is likely to discriminate between the perpetrator and innocent suspects, who may not be distinguishable on the basis of generic characteristics, such as age, race, hair color (Fahsing et al., 2004). Thus, I hypothesized that decision makers would deem CI perpetrator descriptions (consisting of descriptors found in both the SI and in the CI - or, common descriptors - as well as 
descriptors uniquely elicited by the CI) more subjectively useful than SI perpetrator descriptions (consisting of common descriptors only ${ }^{4}$ ).

(3) Enhancing Investigative Utility: I hypothesized that the utility of a CI-elicited perpetrator description would be enhanced (or, would be more useful) if presented to investigators in a theoretically-appropriate and procedurally-efficient manner. Specifically, I hypothesized that CI-elicited perpetrator descriptions would be more useful to decision makers if they were instructed to mentally create a pictorial image of the perpetrator while processing the description than if no mental image instructions were provided. Constructing a mental image is expected to allow for compatibility between the stimulus/descriptor list and the response/perpetrator photograph (Dassonville et al., 1999; Fitts \& Deininger, 1954; Fitts \& Seeger, 1953; Kornblum et al., 1990; Stephan \& Koch, 2016). I also predicted that CI-elicited perpetrator descriptions would be more useful if the list of descriptors was "fed" to decision makers in a theoretically appropriate manner (holistically followed by featurally (Diamond \& Carey, 1986; Tanaka \& Farah, 1993; Yin, 1969)), and in an efficient manner (i.e., categorically, such that all similar person descriptors are chunked together in the description, as explained below).

\section{Method}

\section{Participants}

Three hundred and thirty-six students at Florida International University (FIU) were recruited to participate in Experiment 1 from the psychology department participant pool via Sona-Systems. There were no prior relevant studies on which to base a power analysis to determine the sample size for observable effects. Thus, no power analysis

\footnotetext{
${ }^{4}$ All descriptors elicited in the SI were also elicited in the CI and, thus, there were no uniquely SI-elicited descriptors.
} 
was conducted and, instead, the participant sample size mirrored that which has been used in prior CI studies (multiplied across conditions). Students signed up for a one-hour appointment in a computer lab on campus. Each participant was awarded one research credit for participation, to be applied toward a psychology course research requirement. Each time slot was assigned randomly to an experimental condition before the participant arrived at the computer laboratory.

The final sample size for Experiment 1 consisted of 320 student participants - the data from 16 participants were excluded from the sample, because the participants were familiar with one or more of the individuals whose pictures were used as part of the stimulus materials. Of the 320 students comprising the final sample, the average age was 21.76 years old, and the majority of participants were female $(78.3 \% ; 21.7 \%$ male $)$ and Hispanic (69.0\%; 11.9\% African-American; 11.6\% White; 3.8\% Asian; 3.7\% Other). Materials

The data and materials from Satin and Fisher's (2017) study were used for purposes of Experiment 1.5 As noted above, Satin and Fisher exposed 67 student witnesses to a staged, simulated robbery. The witnesses were then interviewed using either the $\mathrm{CI}$ or an SI to elicit a description of the robber. These interviews were then reduced to individual lists of perpetrator descriptors. Specifically, each of the 67 audiorecorded interviews was transcribed by a professional court reporting company, parsed into unique units of perpetrator-related information per witness, counted, and categorically coded by descriptor type. Descriptors were identified both by category and

\footnotetext{
${ }^{5}$ For a detailed account of the staged event, interviews materials, and procedures used by Satin and Fisher (2017), see Appendix A.
} 
by subcategory of attribute (e.g., "light brown hair" was coded categorically as "hair" and subcategorically as “color”).

The four most representative interviews in each interview condition were selected as stimulus materials for the current study (see Appendices B-E for examples). Representativeness of each interview was determined by whether the interview approximated the average quantity and median accuracy scores for its respective interview type: CI or SI. ${ }^{6}$ (See Table 3 for the mean quantity and median accuracy scores for the eight representative interviews relative to all 67 interviews. $)^{7}$

Table 3.

Representative SI and CI Interview Descriptive Statistics

\begin{tabular}{lllll}
\hline & \multicolumn{2}{c}{ SI } & \multicolumn{2}{c}{ CI } \\
\cline { 2 - 5 } Interviews & Quantity* & Accuracy** & Quantity* & Accuracy** \\
\hline Representative 1 & 19.00 & 5.50 & 59.00 & 5.00 \\
Representative 2 & 20.00 & 5.00 & 67.00 & 5.00 \\
Representative 3 & 20.00 & 5.00 & 67.00 & 5.00 \\
Representative 4 & 21.00 & 5.00 & 76.00 & 5.00 \\
\hline All 67 & 20.00 & 5.00 & 67.44 & 5.00
\end{tabular}

\footnotetext{
*Quantity refers to the number of descriptors. Quantity was calculated using the mean number of descriptors per interview.

**Accuracy was measured on a six-point scale $(1=$ not at all accurate, $6=$ extremely accurate $)$ and was calculated using the median accuracy ratings (across the four coders) of each descriptor in each interview.
}

\footnotetext{
${ }^{6}$ In addition, the mean of the four representative interviews in each condition matched the overall mean of that interview condition ( $\mathrm{SI}: \mathrm{N}=35, \mathrm{CI}: \mathrm{N}=32$ ), thus establishing that "typical," non-outlier interviews were selected in each interview condition.

${ }^{7}$ Of the four representative interviews in the SI condition, two interviews were of the male confederate perpetrator and two interviews were of the female confederate perpetrator. Of the four representative interviews in the CI condition, three interviews were of the male confederate perpetrator and one interview was of the female confederate perpetrator. I believe the difference in representative male/female perpetrator interviews did not influence the results in the current study, given that there were no main effects for confederate perpetrator (male vs. female) (see Results sections infra).
} 
For each of these eight interviews, a typewritten list of all perpetrator-related attributes (both physical and non-physical descriptors) was compiled. Repeated descriptors were omitted from each list. Additionally, all other information elicited during the interview (i.e., relevant actions, other persons, objects, events, etc.) and the interviewer's questions were omitted from the list.

The list of perpetrator descriptors was presented to participants either as a typewritten list or as a tape recording spoken by the experimenter. The typewritten list was written on a one-sided white page in Times New Roman font, size 12, using lowercase letters organized under a single column. The auditory list was spoken by a female voice at a rate of three seconds per descriptor. Participants who were presented with a spoken list used Creative Noise-Cancelling Headphones, model-HN $605 .^{8}$

The descriptors in the lists presented to participants were organized in one of two ways. Half of the descriptor lists were reordered/grouped in a theoretically and practically appropriate manner. Specifically, the perpetrator was described by holistic descriptors initially (e.g., age, race, height, weight, build, skin tone), followed then by specific featural descriptors (e.g., eye color, nose shape). In addition, the perpetrator was described categorically based on the earliest time that a category was mentioned by the witness (e.g., if the participant mentioned "blue eyes" but later in the interview added that the eyes were "speckled" and "crescent-shaped," the category eyes was presented initially as "blue, speckled, crescent-shaped eyes"). (See Appendix B for an example from the SI condition; see Appendix $\mathrm{C}$ for an example from the CI condition.) The other half of the

\footnotetext{
${ }^{8}$ Pilot testing was conducted to determine the rate at which the descriptors were spoken. The total spoken presentation time was approximately equal to the time it took the average person to read each typewritten descriptor list.
} 
descriptor lists were not grouped (i.e., the perpetrator was described in the exact manner and order recalled by the witness in the investigative interview). (See Appendix D for an example from the SI condition; see Appendix E for an example from the CI Condition.)

Presentation modality of the perpetrator descriptor list (spoken vs. written) was manipulated only to avoid a potential confound with the pictorial image instruction. If participants performed better after closing their eyes and listening to the description of the perpetrator, the confound of presentation modality with the pictorial image instruction would make it impossible to determine if the improved performance resulted from the pictorial image instruction or from the fact that the descriptor list was presented as a spoken list rather than as a written list. Thus, presentation modality was varied in the experiment.

Design

Experiment 1 employed a 2 (interview type: SI vs. CI) x 2 (pictorial image instructions: given vs. not given) x 2 (presentation modality: spoken vs. written) x 2 (order of descriptor list: grouped vs. not) between subjects factorial design. The main dependent variables of interest were accuracy in selecting the perpetrator as a suspect, percentage of resources allocated toward investigating the perpetrator, and subjective utility ratings.

\section{Procedure}

On the day of the appointment, a research assistant consented the participant, seated the participant in front of a computer, and instructed the participant to turn on his or her computer and complete an online Qualtrics survey. Those participants in the auditory presentation condition were also instructed to place a pair of headphones over 
their ears prior to beginning the survey. The Qualtrics survey began with the following instructions:

Imagine that you are a detective in the FIU Police Department. The FIU police department is looking for an individual that has been suspected of stealing a car from a student parking lot on campus last week. A witness who saw the perpetrator steal the car was interviewed by the FIU police, and gave the following description of the car thief.

Participants in the written pictorial image instruction condition next received the following practice task instructions:

When you read the witness's description of the car thief on the next page, you will be asked to try to imagine what the car thief looks like.

To become comfortable with the task of visualizing/imagining what a person looks like based on a written description of that person, you will first need to practice.

Below is a description of a clown. Please read the description carefully from start to finish. (The survey will not allow you to move on to the next page until a sufficient time for reading the description has passed).

As you read the description of the clown, please try to imagine what this clown looks like. Try to visualize this clown and create a picture of what the clown looks like in your head.

Participants in the spoken pictorial image instruction condition next received the following variation of the practice task instructions:

When you listen to the witness's description of the car thief on the next page, you will be asked to try to imagine what the car thief looks like.

To become comfortable with the task of visualizing/imagining what a person looks based on a recorded description of that person, you will first need to practice. Below is an audio recording of a clown.

Please click on the below audio recording and listen to the description of the clown, which will be read twice. Do NOT stop the recording or attempt to move on to the next page until the recording is complete. (The survey will not allow you to move on to the next page until the audio recording is complete). 
As you listen to the description, please close your eyes and try to imagine what this clown looks like. Try to visualize this clown and create a picture of what the clown looks like in your head. It is very important that you close your eyes during the entire recording to help you visualize what the clown looks like.

Depending on the presentation modality, the participant then (a) read the typewritten list of clown descriptors from start to finish twice; or (b) listened to an audio recording of a clown's description (which was read by the experimenter twice). The participant was prohibited from moving on to the next page of the survey (a) until the participant affirmed that $\mathrm{s} /$ he had thoroughly read the clown descriptor list twice (but not less than the length of time of the audio recording); or (b) after the participant listened to the entire audio recording of the clown description. After reading/listening to the clown's description, participants in the pictorial image instruction condition were asked whether they were able to visualize/imagine what the clown looks like. All participants answered affirmatively. Participants were then given a manipulation check ("What color are the clown's cheeks?") to make sure they were paying attention and able to remember the clown's description;. Participants were precluded from continuing on to the next survey task until they accurately answered the manipulation check. Participants were allowed to attempt the response as many times as necessary to correctly answer the manipulation check question.

After completing the practice task, depending on the presentation modality, the participant (a) read a typewritten list of descriptors of the car thief from start to finish twice (written); or (b) listened to an audio recording of the car thief's description (which was read by the experimenter twice) (spoken). The participant was prohibited from 
moving on to the next page of the survey (a) until the participant affirmed that $\mathrm{s} / \mathrm{he}$ had thoroughly read the perpetrator descriptor list twice (but not less than the length of time of the audio recording); or (b) after the participant listened to the entire audio recording of the perpetrator description. Participants in the pictorial image instruction condition were also instructed try to imagine what the person looked like while reading or listening to the perpetrator description and, specifically, to try to to visualize this person and create a mental picture of what the person looked like.

The participant was then prompted to continue on to the next page of the survey, which contained the following instructions:

On the following computer screens, you will view a number of photographs. Your job will be to look at each photograph and, based on the eyewitness's description of the car thief, answer a number of questions, which will help the FIU police find the car thief and solve the crime.

Please note that you will be able to access the written [spoken] description of the perpetrator at any time while answering the following questions. It will be located at the end of the instructions on each survey page.

Please also note, and this is very important, that there may be inaccuracies in some of the parts of the description of the car thief that you have been provided (e.g., it may say the person was wearing a baseball cap when in fact the person was wearing a cowboy hat). As a result, it is very important that you not only consider each individual descriptor but that you also consider the entire description in answering the following questions.

The participant was then prompted to continue on to the next page of the survey, on which the participant viewed an array of ten color photographs - consisting of one of the two confederate perpetrators ("Perpetrator") and nine innocent suspects ("Suspect"). Photographs of the Perpetrator and Suspects were taken by the experimenter to mirror 
booking photographs on the Florida Department of Corrections Offender Network. All photographs were taken from the same perspective using the same camera. Photographs were cropped so that only the head, neck, and shoulders of each individual were visible. Although the nine Suspect photographs (or, 18 in total for the two Perpetrators) matched the Perpetrator in terms of basic physical attributes (i.e., age range, race/ethnicity, gender), the appearance of each Suspect was dissimilar from the appearance of the Perpetrator. Perpetrators and Suspects were photographed wearing different clothing than that which was worn during commission of the crime, and the clothing differed across the various photographs.

Immediately above the photo-array, the participant was prompted to read the following instructions:

The FIU Police Department has a limited budget and must limit its investigation of the car thief to only a few potential suspects. Based on the description of the car thief you have been given, which three suspects from the photographs below would you suggest that the police continue to investigate?

In other words, which three suspect photographs best match the description of the car thief you have been provided? Which three suspects do you think are most likely to be the car thief based only on the description you have been given? (Please select only three suspects).

After reading the instructions, the participant then placed checkmarks beneath the three photographs s/he deemed most likely to be the perpetrator based on the written/spoken description provided.

The participant was then prompted to continue on to the next page of the survey, on which the participant viewed the same array of photographs. However, the seven photographs not selected by the participant on the previous page were disabled, and only 
the three photographs selected by the participant were highlighted. The participant received the following instructions:

The FIU Police Department cannot spend an infinite amount of time investigating each of the three suspects that you think might be the car thief. Instead, the police must decide which potential suspect(s) to focus their time and resources on based on what the police already know about the car thief. In our case, all we know is what the car thief looks like based on the witness's description.

Assume the police only have 100 hours in total to investigate the three suspects you just selected. How many hours should the police spend investigating each suspect? You should assign the most hours to the suspect you believe is most likely to be the car thief based on the description you have been given and you should assign the least hours to the suspect you believe is least likely to be the car thief based on the description you have been given.

Please enter the number of hours in the spaces provided to the left of each photograph.

After reading the instructions, the participant entered the number of hours (from 0 to 100) in the spaces provided to the left of each of the three photographs. The participant was prohibited from moving on to the next part of the survey until exactly 100 hours were allocated between the three suspects.

The participant was then prompted to continue on to the next page of the survey, which included a list of perpetrator attributes that were contained in the written/spoken list provided to the participant. For example, the list may have contained the following attributes: age; race/ethnicity; gender; hair color; eye color; skin tone; body type; markings/scars/tattoos. The list did not contain the specific descriptors (e.g., mediumbrown hair; heart-shaped tattoo); rather, the list contained the categorical name for each descriptor (e.g., hair color; tattoo description). The participant was asked to rank each descriptor category in terms of how useful it was in helping the participant identify the 
perpetrator from the photographs. Specifically, the participant ranked each descriptor on a four-point Likert scale $(1=$ Extremely Useful, $4=$ Not At All Useful $)$.

The participant was then prompted to continue on to the final page of the survey, which asked the participant demographic questions, including the participant's age, race/ethnicity, gender, current GPA, and asked the participant a series of questions on his or her prior research participation at the University (to ensure that the participant had not already participated in a prior related study). This last section of the survey also contained several debriefing questions. The participant was asked whether s/he knew any of the individuals in the suspect photographs. Additionally, the participant was asked about the ease or difficulty of each survey task, the usefulness of the description in answering the survey questions, and whether there is additional information not contained in the written description that would have helped the participant better identify the perpetrator. ${ }^{9}$ Following completion of the online survey, the participant was given course credit and dismissed.

\section{Results}

\section{Objective Utility}

Perpetrator Selection as a Suspect. Preliminary analyses were conducted to assess whether interview condition (SI, CI) interacted with confederate perpetrator (male, female) on the perpetrator selection measure. A logistic regression was conducted with perpetrator selection as the criterion variable and with interview condition, confederate perpetrator, and the interaction between the two as the predictor variables. The

\footnotetext{
9 Very few participants provided additional information, and that information which was provided was too sparse from which to draw meaningful insights.
} 
regression equation fit significantly better than the null model, $x^{2}(3)=13.93, p<.001$, Nagelkerke $\mathrm{R}^{2}=.059$. However, the interaction between interview condition and confederate perpetrator was not significantly associated with perpetrator selection as a suspect, $\mathrm{B}=1.07$, Wald $=3.39, p=.07, \mathrm{OR}=2.91$. Thus, the data were collapsed across perpetrator confederates.

Perpetrator selection as a suspect (by matching the perpetrator's photograph to the witness's description of the perpetrator) was examined for all 320 participants across interview conditions. Of the 160 participants who made their selection decision using an SI-elicited description of the perpetrator, 90 participants $(56.3 \%)$ selected the perpetrator as a suspect, whereas 70 participants $(43.8 \%)$ did not. Of the 160 participants who made their selection decision using a CI-elicited description, 116 participants $(72.5 \%)$ selected the perpetrator as a suspect, whereas 44 participants (27.5\%) did not. A Chi-square test for independence (with Yates Continuity Correction) indicated a significant association between interview condition and perpetrator suspect selection, $x^{2}(1)=8.52, p=.004, \varphi$ $=.170$. The proportion of participants who selected the perpetrator as a suspect using a CI description was significantly higher than the proportion of participants who selected the perpetrator as a suspect based on a SI description.

Resource Allocation. Resource allocation was assessed for all 320 participants across interview condition. Those participants who made their investigative decision using an SI description allocated between 0 and 75 (out of 100) hours, allocating a mean of 19.66 hours $(S D=21.01)$, to further investigating the perpetrator. Those participants who made their investigative decision using a CI description allocated between 0 and 100 
(out of 100) hours, allocating a mean of 31.06 hours $(S D=24.57)$, to further investigating the perpetrator.

A two-way between-subjects analysis of variance was conducted to explore the impact of interview type and confederate perpetrator on resource allocation. There was a main effect of interview type, $F(1,316)=29.13, p<.001, \eta_{p}^{2}=.084$, such that more hours were allocated to pursuing the perpetrator using a CI description than using an SI description. There was no main effect of confederate perpetrator, $F(1,316)=3.43, p=$ $.07, \eta_{p}^{2}=.011$. There was also an unexpected significant interaction between interview condition and confederate perpetrator, $F(1,316)=8.87, p<.001, \eta_{p}^{2}=.027$. More hours were allocated toward pursuing the perpetrator for the CI than for the SI, but the difference was greater for the female perpetrator (CI: $M=40.93, S D=23.95$; SI: $M=$ $18.13, S D=19.07)$ than for the male perpetrator $(\mathrm{CI}: M=27.78, S D=23.98 ; \mathrm{SI}: M=$ $21.19, S D=22.80)$

\section{Subjective Utility}

Common Descriptors vs. Uniquely-CI Descriptors. Descriptive statistics were used to assess the subjective value decision makers assigned to descriptors produced by both the SI and CI (Common Descriptors) and to uniquely CI-elicited descriptors (Uniquely-CI Descriptors) in the eight representative interviews. ${ }^{10}$ Across all participants, both the Common Descriptors and the Uniquely-CI Descriptors were

\footnotetext{
${ }^{10}$ Again, all descriptors elicited in the SI were also elicited in the CI and, thus, there were no uniquely SIelicited descriptors.
} 
deemed only slightly-to-moderately useful (Common Descriptors: $M=2.40, S D=.38$; Uniquely-CI Descriptors: $M=2.82, S D=.42) .{ }^{11}$

Analyses were conducted to assess subjective utility ratings between interview conditions. First, an independent-samples $t$-test was conducted to compare the subjective utility ratings of SI descriptions (consisting of only Common Descriptors) and CI descriptions (consisting of both Common and Uniquely-CI Descriptors). ${ }^{12} \mathrm{SI}$ descriptions $(M=2.42, S D=.35)$ were rated as significantly more useful than $\mathrm{CI}$ descriptions $(M=2.57, S D=.36), t(318)=-3.72, p<.001, \eta^{2}=-.045$. Next, an independent-samples $t$-test was conducted to compare the subjective utility ratings of only Common Descriptors between the CI and SI. Levene's test demonstrated unequal variances across interview conditions, $F=7.55, p=.006$, so degrees of freedom were adjusted from 318 to 308.67 . Assuming unequal variances, there was no significant difference in the average subjective utility ratings of Common Descriptors elicited from the SI or CI, $t(308.67)=1.37, p=.17, \eta^{2}=.006$. No similar inferential statistic was run for Uniquely-CI Descriptors across interview conditions, since these descriptors were not, by definition, included in SI perpetrator descriptions. (See Table 4 for Common and Uniquely-CI Descriptor descriptive statistics in each interview condition.)

\footnotetext{
${ }^{11}$ Lower numbers indicate a higher subjective utility rating based on the four-point Likert scale used $(1=$ Extremely Useful, 4 = Not At All Useful).

12 Participants rated each descriptor individually, after which I calculated the mean of all descriptors within the CI and within the SI.
} 
Table 4.

Exp. 1 Subjective Utility Descriptive Statistics (Common vs. Uniquely-CI)

\begin{tabular}{|c|c|c|c|c|c|c|c|c|c|}
\hline \multirow[b]{2}{*}{ Type of Descriptor } & \multicolumn{3}{|c|}{ SI } & \multicolumn{3}{|c|}{$\mathrm{CI}$} & \multicolumn{3}{|c|}{ Total } \\
\hline & Mean & SD & $\mathrm{n}$ & Mean & SD & $\mathrm{n}$ & Mean & SD & $\mathrm{n}$ \\
\hline Common & 2.42 & .35 & 160 & 2.37 & .41 & 160 & 2.40 & .38 & 320 \\
\hline Uniquely-CI & - & - & - & 2.82 & .42 & 160 & 2.82 & .42 & 160 \\
\hline Combined & 2.42 & .35 & 160 & 2.57 & .36 & 320 & 2.61 & .40 & 480 \\
\hline
\end{tabular}


Further analyses were conducted to assess subjective utility ratings within each interview condition. For SI cases, the mean subjective utility ratings mirrored the allinclusive descriptive statistics - Common Descriptors were deemed only slightly-tomoderately useful $(M=2.42, S D=.35)$. Uniquely-CI Descriptors were not, by definition, included in SI perpetrator descriptions, so no descriptive statistics were calculated for these Uniquely-CI Descriptors in SI interviews. The CI cases also mirrored the all-inclusive descriptive statistics-Common Descriptors and Uniquely-CI Descriptors were deemed slightly-to-moderately useful (Common Descriptors: $M=2.37$, $S D=.41$; Uniquely-CI Descriptors: $M=2.82, S D=.42$ ), with Uniquely-CI Descriptors being rated as significantly less useful than Common Descriptors, $t(318)=-9.76, p<$ $.001, \eta^{2}=-.426$

Facial vs. Non-facial Descriptors. Common Descriptor categories consisted mostly of non-facial descriptors. Of the 23 categories of Common Descriptors, 19 $(82.6 \%)$ consisted of non-facial descriptor categories (e.g., age), whereas $4(17.4 \%)$ consisted of facial descriptor categories (e.g., chin). In contrast, Uniquely-CI Descriptor categories consisted of more facial than non-facial descriptors. Of the 29 categories of Uniquely-CI Descriptors, 13 (44.8\%) consisted of non-facial descriptor categories, whereas $16(55.2 \%)$ consisted of facial descriptor categories.

A two-way between-subjects analysis of variance was conducted to explore the impact of descriptor type (facial vs. non-facial) and interview condition (SI vs. CI) on subjective utility assessments (see Table 5). Levene's test demonstrated unequal variances across interview conditions, $F=35.48, p<.001$, so a more stringent significance level of .01 was used for evaluating the results. There was a main effect of 
descriptor type, $F(1,636)=60.89, p<.001, \eta_{p}^{2}=.087$, such that non-facial descriptors were rated as significantly less useful than facial descriptors (Non-Facial: $M=2.56, S D=$ .39 ; Facial: $M=2.24, S D=.67)$. There was also a main effect of interview type, $F(1$, $636)=40.88, p<.001, \eta_{p}^{2}=.060$, such that CI subjective utility ratings were significantly lower than SI subjective utility ratings (CI: $M=2.53, S D=.48 ; \mathrm{SI}: M=2.26, S D=.63$ ). There was not a significant interaction between descriptor type and interview type, $F(1$, 636) $=1.69, p=.19, \eta_{p}^{2}=.003$ 
Table 5.

Exp. 1 Subjective Utility Descriptive Statistics (Facial vs. Non-Facial)

\begin{tabular}{|c|c|c|c|c|c|c|c|c|c|}
\hline \multirow[b]{2}{*}{ Type of Descriptor } & \multicolumn{3}{|c|}{ SI } & \multicolumn{3}{|c|}{$\mathrm{CI}$} & \multicolumn{3}{|c|}{ Total } \\
\hline & Mean & SD & $\mathrm{n}$ & Mean & SD & $\mathrm{n}$ & Mean & SD & $\mathrm{n}$ \\
\hline Non-Facial & 2.46 & .38 & 160 & 2.67 & .37 & 160 & 2.56 & .39 & 320 \\
\hline Facial & 2.07 & .76 & 160 & 2.40 & .53 & 160 & 2.24 & .67 & 320 \\
\hline Combined & 2.26 & .63 & 320 & 2.53 & .48 & 320 & 2.40 & .57 & 640 \\
\hline
\end{tabular}

NOTE: Lower numbers indicate that the descriptors were rated as more useful/valuable. 


\section{Enhancing Investigative Utility}

The final analyses explored whether there are methods to enhance the investigative utility of CI descriptions. First, a hierarchical binary logistic regression was conducted with perpetrator selection as the criterion variable and with interview type (CI vs. SI), pictorial image instructions (given vs. not given), presentation modality (spoken vs. written), order of descriptor list (grouped vs. not), and interactions between the foregoing variables as the predictor variables (see Table 6). ${ }^{13}$ On step 1, interview type, pictorial image instructions, presentation modality, and order of descriptor list were entered into the regression model. The regression equation fit significantly better than the null model, $x^{2}(4)=12.31, p=.02$, Nagelkerke $\mathrm{R}^{2}=.052$. As expected based on earlier analyses, interview type was significantly associated with selecting the perpetrator as a suspect, $\mathrm{B}=.73$, Wald $=9.17, p=.002, \mathrm{OR}=2.07$. However, neither pictorial image instruction, $\mathrm{B}=-.28, \mathrm{Wald}=1.41, p=.24, \mathrm{OR}=.75$, nor order of descriptor list, $\mathrm{B}$ $=-.11$, Wald $=.23, p=.63, \mathrm{OR}=.89$, were significantly associated with selecting the perpetrator as a suspect. There was no significant difference between the likelihood that the perpetrator was selected as a suspect whether participants received or did not receive a pictorial image instruction prior to the perpetrator description. Similarly, there was no significant difference between the likelihood that the perpetrator was selected as a suspect whether participants received the list of descriptors (a) holistically followed by featurally and in a categorically grouped manner; or (b) in the order in which the witness recalled the descriptors. Presentation modality was also not significant, $\mathrm{B}=.28$, Wald $=1.41, p$

\footnotetext{
${ }^{13}$ Because confederate perpetrator did not interact (in a comprehensible way) with interview type or produce a main effect of either of the objective utility variables, this nuisance variable was omitted from the enhancing investigative use analyses.
} 
$=.24, \mathrm{OR}=1.33$, indicating that this variable did not confound the effect of pictorial image instruction on perpetrator selection. ${ }^{14}$ On step 2 , the interaction terms were entered into the regression equation. The regression equation did not fit significantly better than the null model, $x^{2}(7)=13.67, p=.06$. None of the interactions between the foregoing utility enhancing methods were significantly associated with selecting the perpetrator as a suspect, all $\mathrm{Bs}< \pm .52$, Walds ranging from .02 to 2.55 , all $p \mathrm{~s}>. .28$, ORs ranging from .60 to 1.67 .

Second, a hierarchical multiple regression was conducted with resource allocation as the criterion variable and with interview type (CI vs. SI), pictorial image instructions (given vs. not given), presentation modality (spoken vs. written), order of descriptor list (grouped vs. not), and interactions between the foregoing variables as the predictor variables (see Tables 7-8). When entered on step 1, interview type, pictorial image instructions, presentation modality, and order of descriptor list accounted for a significant, small-to-moderate amount of overall variance in resource allocation, $F(4$, $315)=5.40, p<.001, \mathrm{R}^{2}=.06$. As expected, the partial regression coefficient relating interview type to resource allocation was significant, $\mathrm{b}=11.41, p<.001$. However, no significant effect was shown for either the partial regression coefficient relating pictorial image instruction to resource allocation, $\mathrm{b}=-1.43, p=.58$, or relating order of descriptor list to resource allocation, $\mathrm{b}=.74, p=.77$. The partial regression coefficient relating presentation mode to resource allocation was also not significant, $\mathrm{b}=2.99, p=.25$, indicating that this variable did not confound the effect of pictorial image instruction on

\footnotetext{
${ }^{14}$ The above finding shows that the confounding in the design of the study did not have a negative effect (i.e., was not influential) on interpreting the data.
} 
resource allocation. When the interaction terms were entered on step 2, a moderate and significant amount of overall variance in resource allocation was explained, $F(7,312)=$ $3.22, p<.001, \mathrm{R}^{2}=.07$. However, the interaction terms did not account for a significant increase in the explained variance, $\Delta F(3,312)=.37, p=.78, \Delta \mathrm{R}^{2}=.00$, and none of the interaction terms were significantly associated with resource allocation, bs ranging from \pm 2.92 to \pm 3.41 , all $p$ s $>.51$. 
Table 6

Exp 1. Enhancing Investigative Utility - Identifying the Perpetrator Logistic Regression

\begin{tabular}{|c|c|c|c|c|c|c|c|}
\hline & Predictor & $\mathrm{B}$ & SE & OR & Wald & $\begin{array}{l}95 \% \mathrm{CI} \text { (for } \\
\text { OR) }\end{array}$ & $p$ \\
\hline \multicolumn{8}{|l|}{ Step 1} \\
\hline & Interview Type & .73 & .24 & 2.07 & 9.17 & $1.29-3.30$ & .002 \\
\hline & Pictorial Image Instruction & -.28 & .24 & .75 & 1.41 & $.47-1.20$ & .24 \\
\hline & Order of Descriptor List & -.11 & .24 & .89 & .23 & $.56-1.42$ & .63 \\
\hline & Presentation Modality & .28 & .24 & 1.33 & 1.41 & $.83-2.12$ & .24 \\
\hline \multicolumn{8}{|l|}{ Step 2} \\
\hline & $\begin{array}{l}\text { Interview Type x Pictorial } \\
\text { Image Instruction }\end{array}$ & .52 & .48 & 1.67 & 1.15 & $.65-4.27$ & .28 \\
\hline & $\begin{array}{l}\text { Interview Type x Order of } \\
\text { Descriptor List }\end{array}$ & .21 & .48 & 1.23 & .19 & $.48-3.15$ & .67 \\
\hline & $\begin{array}{l}\text { Interview Type x } \\
\text { Presentation Modality }\end{array}$ & -.06 & .48 & .94 & .02 & $.37-2.41$ & .90 \\
\hline
\end{tabular}


Table 7

Exp. 1 Enhancing Investigative Utility - Resource Allocation Descriptive Statistics

\begin{tabular}{|c|c|c|c|c|c|c|c|}
\hline \multirow[b]{2}{*}{ Utility Enhancement Tool } & & \multicolumn{3}{|c|}{ SI } & \multicolumn{3}{|c|}{$\mathrm{CI}$} \\
\hline & & Mean & SD & $\mathrm{n}$ & Mean & $\mathrm{SD}$ & $\mathrm{n}$ \\
\hline \multirow[t]{2}{*}{ Pictorial Image Instruction } & Given & 18.20 & 21.27 & 80 & 31.09 & 25.13 & 80 \\
\hline & Not & 21.11 & 20.77 & 80 & 31.04 & 24.16 & 80 \\
\hline \multirow[t]{2}{*}{ Order of Descriptor List } & Grouped & 19.30 & 21.88 & 80 & 29.96 & 24.66 & 80 \\
\hline & Not & 20.02 & 20.23 & 80 & 32.17 & 24.59 & 80 \\
\hline \multirow[t]{2}{*}{ Presentation Modality } & Spoken & 17.31 & 19.78 & 80 & 30.43 & 24.67 & 80 \\
\hline & Written & 22.00 & 22.04 & 80 & 31.70 & 24.61 & 80 \\
\hline
\end{tabular}


Table 8

Exp 1. Enhancing Investigative Utility -Resource Allocation Multiple Regression

\begin{tabular}{|c|c|c|c|c|c|c|}
\hline & Predictor & $\mathrm{b}$ & $\mathrm{SE}$ & $\mathrm{t}$ & $\begin{array}{l}95 \% \mathrm{CI} \text { (for } \\
B)\end{array}$ & $p$ \\
\hline \multicolumn{7}{|l|}{ Step 1} \\
\hline & Interview Type & 11.41 & 2.56 & 4.46 & $6.37-16.44$ & .00 \\
\hline & Pictorial Image Instruction & -1.43 & 2.56 & -.56 & $-6.47-3.61$ & .58 \\
\hline & Order of Descriptor List & .74 & 2.56 & .29 & $-4.29-5.78$ & .77 \\
\hline & Presentation Modality & 2.99 & 2.56 & 1.17 & $-2.05-8.02$ & .25 \\
\hline \multicolumn{7}{|l|}{ Step 2} \\
\hline & $\begin{array}{l}\text { Interview Type x Pictorial } \\
\text { Image Instruction }\end{array}$ & 2.95 & 5.14 & .58 & $-7.15-13.06$ & .57 \\
\hline & $\begin{array}{l}\text { Interview Type x Order of } \\
\text { Descriptor List }\end{array}$ & 2.92 & 5.14 & .57 & $-7.19-13.03$ & .57 \\
\hline & $\begin{array}{l}\text { Interview Type x } \\
\text { Presentation Modality }\end{array}$ & -3.41 & 5.14 & -.66 & $-13.52-6.70$ & .51 \\
\hline
\end{tabular}




\section{Discussion}

Experiment 1 explored three key components of the CI's investigative utility in a criminal case: objective utility, subjective utility, and enhancing investigative utility. The central findings were: (1) CI perpetrator descriptions significantly improved investigative decision makers' performance in (a) accurately identifying the perpetrator as a suspect, and (b) allocating investigative resources toward investigating the perpetrator; (2) participants subjectively valued the mean of CI-elicited descriptors less than SI-elicited descriptors; and (3) investigative utility was not enhanced by presenting CI-elicited perpetrator descriptions to investigators in a theoretically appropriate and procedurally efficient manner.

(1) Objective Utility: The current experiment is the first to establish the practical value of the CI in criminal investigations. To date, the CI's value has been measured only in terms of its impact on the quantity and accuracy of recall in a witness interview. However, extant research has failed to test whether decision makers properly use that information in the course of an investigative task. The CI's investigative utility is particularly striking within the context of a perpetrator description, which is generally quite limited in scope and content (Fahsing et al., 2004; Granhag et al., 2013; Sporer, 1992; 1996; 2007; van Koppen \& Lochun, 1997). As demonstrated in the current experiment, the CI allowed investigative decision makers to more accurately identify the perpetrator as a suspect, and to more effectively allocate their resources to pursuing the perpetrator, hence spending less investigative time on useless and dangerous tasks (e.g., investigating and potentially convicting innocent suspects). Specifically, as hypothesized, investigative decision makers were significantly more likely to identify the 
perpetrator as a suspect (as opposed to an innocent suspect) using a CI description than using an SI description. Additionally, as hypothesized, investigative decision makers allocated significantly more resources (i.e., hours) to further investigating the perpetrator (as opposed to innocent suspects) using a CI description than using an SI perpetrator description.

Perpetrator selection and resource allocation proved strong measures of investigative utility: The CI resulted in a near 30\% increase in correct suspect selection decisions (SI: 90-out-of 160, CI: 116-out-of-160). This finding is particularly impactful given that selecting a "suspect" is one of the first tasks performed by law enforcement as part of a criminal investigation. Investigating the actual perpetrator as opposed to an innocent suspect is likely to have a ripple effect on all subsequent phases of the investigation (e.g., changing the base rate of a lineup). Participants who based their investigative decision on a CI description rather than on an SI description also allocated significantly more hours to further investigating the perpetrator. The CI-SI difference in resources allocated, on some level, magnifies the CI-SI difference in perpetrator selection. The more time police spend investigating perpetrators (as opposed to innocent suspects), the more incriminating information police will collect and, hence, the more likely police will be to choose these guilty (rather than innocent) individuals to criminally charge and prosecute.

Resource allocation produced an inexplicable interaction between interview condition and confederate perpetrator. There are many reasons why the CI may have been more valuable for one perpetrator than for another, given the infinite number of differences between the perpetrators (i.e., male vs. female, Caucasian vs. Black, tall vs. 
short, etc.). One possibility is that the CI might be more effective for perpetrators who had more distinctive characteristics, or were otherwise generally more likely to be included in the search set (perhaps because they looked more like the stereotype of a robber). Here, that was not the case, as both perpetrators were equally likely to be included in the search set. Whereas the CI was more effective (compared to the SI) for one of the perpetrators than for the other, the current dataset did not offer any insights into why the CI was more effective for one perpetrator over the other. There may be something unique to the current study (e.g., the particular perpetrators, the staged event, the viewing conditions) that made the CI more effective than the SI for one perpetrator over another. On the other hand, the interaction may simply be a result of Type I error (as supported by its small effect size). ${ }^{15}$

(2) Subjective Utility: Investigative decision makers provided generally low utility ratings for the perpetrator descriptions. The descriptors that were elicited in both the SI and CI (e.g., age, gender, race) and the more specific descriptors elicited only in the CI (e.g., hair thickness, nose shape) were rated as moderately-to-slightly useful.

Perhaps the most interesting aspect of subjective utility was its failure to map on to objective utility. Participants were significantly better at performing key investigative tasks when using more complete descriptions containing both common and unique/specific details about the perpetrator; however participants rated CI descriptions (containing Common and Uniquely-CI Descriptors) as less useful than SI descriptions (containing only Common Descriptors). Moreover, within CI interviews, Uniquely-CI Descriptors were rated as less useful than Common Descriptors. Within CI interviews, it

\footnotetext{
${ }^{15}$ The interaction effect was also unreliable, as it was not reproduced in Experiment 2 (see Experiment 2 Results infra).
} 
is intelligible that participants weighed naturally elicited descriptors (e.g., age, race, sex, hair color) as more useful than more particularized and unique descriptors that are not normally offered (without interviewer prompting) in a witness's description of a perpetrator (e.g., proximity of eyes to nose, resemblance to an animal). The recognition heuristic proposes that if a judgment maker is presented with two objects and only one of those objects is recognized, then the recognized object will be given a higher judgment value with respect to the criterion (Goldstein \& Gigerenzer, 2002). ${ }^{16}$ In the current experiment, participants may have recognized customary, oft-recalled perpetrator descriptors (e.g., age, weight) but not uncustomary, rarely-recalled descriptors (e.g., he had an eagle's peak, she looked like a rooster) and, thus, assigned higher subjective utility ratings to those customary, oft-recalled descriptors. In other words, descriptors that were recognized as typically comprising a person description were rated as more useful than descriptors that were considered more unconventional and not recognizable.

Less intelligible, however, is the finding that CI-elicited descriptions (containing Common and Uniquely-CI Descriptors) were rated as less useful than SI-elicited descriptions (containing only Common Descriptors). The foregoing finding mismatches the current study's objective utility findings and, at first glance, appears to challenge the literature dictating that unique and specific perpetrator details (that help to further parse guilty from innocent suspects) would, in combination with common descriptors, be considered critical evidence to decision makers (e.g., Brown et al., 2008; Kebbell \& Milne, 1998). However, the ostensible conundrum between subjective and objective

\footnotetext{
${ }^{16}$ The recognition heuristic's effect varies depending on the criterion used (e.g., an easily recognized city like New York City may be given a higher judgment value than a less recognized city like Chattanooga, however if the criterion task is changed to "which city is less recognizable," then Chattanooga will be given a higher judgment value than New York City).
} 
utility findings is more likely to be a result of the differing values measured. Subjective utility assessed the mean value of all the descriptors (i.e., how subjectively valuable decision makers perceived the average/typical descriptor). Objective utility measured the total value of all the descriptors (taken as a collective whole). Each individual descriptor contributed only a fixed amount in terms of utility, and while the mean of the CI-elicited descriptors may have contributed slightly less than the mean of the SI-elicited descriptors. However, when the large number of the CI descriptors were combined, they were more useful than the combination of the relatively small number of SI descriptors. So, while the typical or average SI descriptor may have been perceived by decision makers as minimally more valuable than the average $\mathrm{CI}$ descriptor, the combination of CI descriptors was actually more valuable than the combination of SI descriptors.

Alternatively, it may be the case that the incongruity between objective utility findings and subjective utility ratings derived from decision makers' failure to follow instructions when completing the subjective utility task. Participants were instructed to rank each descriptor in terms of its use in completing the investigative tasks (i.e., selecting the perpetrator as a suspect and allocating resources to pursuing the perpetrator). Suspect photographs matched the perpetrator photographs in terms of basic physical attributes (e.g., age range, gender). However, of the participants asked to rate the utility of "gender," $" 17$ more than $80 \%$ deemed this descriptor "extremely useful" in completing the investigative tasks. The descriptor category of "gender" could not possibly have been useful to decision makers, given that the nine suspects (nonperpetrators) always matched the perpetrator on gender: For the male perpetrator, the

${ }^{17}$ Only 128 participants rated the utility of gender, as this descriptor was not included in 162 of the interview descriptor lists used. 
other nine photos were of males, and for the female perpetrator, the other nine photos were of females. Similarly, of the participants asked to rate the utility of "age," nearly $50 \%$ rated the descriptor as either "extremely useful" or "very useful" in completing the investigative tasks. Age could not possibly have been useful in parsing potential perpetrator photographs, because all suspects were of approximately the same age. The foregoing findings suggest that decision makers may have rated descriptors based on their general beliefs about what is normally useful and reliable in terms of identifying a person. If so, this procedural limitation would account for the incompatibility between the current experiment's objective utility findings and subjective utility ratings.

Facial and non-facial perpetrator descriptor findings were as expected. In accordance with extant literature, witnesses interviewed using an SI recalled few facial features (e.g., Sporer, 1992; van Koppen \& Lochun, 1992). Only 17.4\% of the descriptors recalled by SI eyewitnesses were facial features. By contrast, $55.2 \%$ of the CI-elicited descriptors were facial features. Decision makers valued facial features more than non-facial features in both interview conditions, which is to be expected given that the task was to select the perpetrator from suspect headshots (i.e., photographs that show only a person's face). However, in addition, both facial and non-facial features were rated as significantly more useful in SI descriptions than in CI descriptions. This finding may simply be a result of participants' misunderstanding of the subjective utility task (as discussed in the preceding paragraph). An alternate explanation is that the finding may derive from the sheer volume of descriptors in a CI description. Because CI decision makers had so many descriptors at their disposal, each descriptor may have been perceived as less useful than in an SI description where decision makers had only a few 
descriptors on which to rely in their decision making. That is, the considerable number of CI descriptors may have caused decision makers to undervalue diagnostic perpetrator information.

The dilution effect (Nisbett, Zukier, \& Lernley, 1981) is a judgment bias in which the presence of nondiagnostic information weakens, or dilutes, the impact of diagnostic information. It has been argued that the phenomenon derives from people's failure to distinguish between diagnostic and nondiagnostic information, such that judgment makers assume that all information they have been given is valuable (Troutman \& Shanteau, 1977). Relatedly, the fan effect (Anderson, 1974) posits that when more facts are associated with a concept, it interferes with verification of any one fact. The foregoing literature suggests that the breadth of Common Descriptors may have diluted the value of each CI descriptor.

(3) Enhancing Investigative Utility: The third aim of the current experiment was to present perpetrator descriptions to investigative decision makers in a "user-friendly" format. Some methods of providing descriptors to police may be more efficient than others. In an applied psychology field where laboratory experiments are often converted into legislative and judicial calls for action, providing law enforcement and lawmakers with a more productive way to utilize novel criminological findings is a crucial goal of researchers. The CI utility enhancement measures tested in Experiment 1 were not effective. Use of CI descriptions was not enhanced by providing instructions to "attempt to mentally create a pictorial image of the perpetrator while reading his or her description." Similarly, objective utility was not enhanced by "feeding" CI descriptors to decision makers holistically followed by featurally and categorically, such that all similar 
person descriptors were grouped together in the description. CI decision makers performed just as well in their investigative tasks when such enhancement procedures were not in place.

These null findings are informative for police from a practical standpoint. Even if the utility enhancement methods did work, police resources would be needed to implement the methods in a real-world setting. Indeed, rather than simply reading a written description of a perpetrator, police would have to tape record the witness's description and then play that tape for other police tasked with identifying the prime suspect. Future studies would benefit from exploring other potential methods that help to enhance the CI's (and other witness interviews') utility in a criminal investigation. However, as to the methods tested in Experiment 1, the CI perpetrator description was equally effective in its original form. 


\section{CHAPTER III}

\section{Experiment 2}

Experiment 1 took the first step in testing the CI's investigative utility in an area of forensic importance - witness perpetrator descriptions. However, it is (to my knowledge) the only experiment of its kind, having yet to be replicated in the lab or expanded beyond a convenience sample of student participants. Replication is a central component to cumulative science and knowledge (e.g., Brandt, et al., 2014). So too is generalizability - particularly in an applied discipline like witness interviewing, where psychological insights are used to solve practical investigative problems (Lane \& Meissner, 2008; Munsterberg, 1899). Needless to say, the CI is useful only if real police officers and detectives are able to incorporate it effectively into their investigative decisions on real criminal cases. Thus, Experiment 2 sought to reproduce and generalize the CI's effect on investigative utility by using not only student participants, but also police officers.

Participants in Experiment 1 were undergraduate psychology students with no expertise, training, or experience with a police investigation. Even though the CI perpetrator descriptions were useful to students' decision making, Experiment 1 students valued CI descriptors as being only slightly-to-moderately useful. Unlike student participants, police investigators will likely find the extra CI-elicited perpetrator-related information particularly meaningful and salient for several reasons. Efficient and accurate investigations are crucial to the successful outcome of a case given the timesensitivity and limited resources available to police investigators. If investigators spend the majority of their time investigating and following up with innocent suspects, precious 
resources will have been spent at the cost of apprehending perpetrators. A targeted, precise description of the perpetrator allows law enforcement to spend more time investigating the perpetrator and less time investigating innocent suspects. Additionally, obtaining critical perpetrator-related intelligence at the outset of an investigation shields investigators from making mistakes that may result in witness misidentifications, false confessions, and wrongful convictions.

If an investigator obtains a highly diagnostic description of the perpetrator (e.g., a description of the perpetrator that includes a distinctive scar or tattoo), the informationgathering purpose of a lineup is minimized and a formal identification or confession may no longer be necessary. Thus, the more likely that the perpetrator is in the lineup, the less critical the witness's identification becomes. Even if formal identification is still deemed necessary, it is more likely that the perpetrator will be in the lineup (as opposed to an innocent suspect) - the more likely that the perpetrator is in the lineup, the less consequential the false/correct identification tradeoff inherent in the use of reformed lineup system variables (Charman \& Wells, 2007). In other words, if there is a high prior probability that the perpetrator is in the lineup, it is more likely that a correct identification will occur and that the perpetrator will be convicted of the crime (Clark, 2012). If there is a low prior probability that an innocent suspect is in the lineup, it is less likely that a false identification and, hence, a wrongful conviction will occur (Clark, 2012).

Given the foregoing considerations, police investigators may especially value the extra evidence elicited from the CI and the impact that information will have on their investigation. Coupling these practical and motivational incentives with investigators' 
expertise, training, and experience suggests that police will both effectively use and subjectively value the additional information elicited from the CI to further an investigation and, hence, identify and pursue a guilty - rather than an innocent - suspect.

Experiment 2 examined the effectiveness of the CI by having students and police participants serve as decision makers. The main hypotheses as in Experiment 1 were tested in addition to two new hypotheses comparing police and student participants.

(1) Objective Utility: As in Experiment 1, I hypothesized that CI descriptions would better allow decision makers to conduct critical investigative tasks than SI descriptions. Specifically, I hypothesized that decision makers using a CI description would be more likely than decision makers using an SI description to (a) correctly select the perpetrator as a suspect; and (b) assign a greater number of hours to investigating the perpetrator as opposed to an innocent suspect. I also hypothesized that, relative to student participants, police would generally perform better than student participants in both interview conditions. In addition, I predicted that the CI advantage in (a) correctly select the perpetrator as a suspect, and (b) assigning a greater number of hours to investigating the perpetrator as opposed to an innocent suspect would be greater for police participants than for student participants.

(2) Subjective Utility: As in Experiment 1, I hypothesized that decision makers would deem CI perpetrator descriptions (consisting of Common Descriptors found in the SI and in the CI as well as of Uniquely-CI Descriptors) more subjectively useful than SI perpetrator descriptions (consisting of Common Descriptors only). In addition, I hypothesized that police participants would subjectively value the CI descriptions more 
than student participants (by rating these descriptions as more useful than student participants).

Method

\section{Participants}

Seventy-one police personnel were recruited to participate in Experiment 2 from police departments throughout South Florida. Police participated in this experiment in conjunction with an Investigative Interview Training Course offered and taught by Ronald Fisher at FIU. Police were assigned randomly to an experimental condition before arriving at the computer laboratory. Of the 71 participants comprising the final police sample, the average age was 37.44 years old, and the majority of participants were male $(60.6 \% ; 39.4 \%$ female) and Hispanic (57.7\%; 22.5\% African-American; $16.9 \%$ White; $2.8 \%$ Other). The majority of police participants worked for the Miami-Dade County Police Department (56.3\%; 14.1\% Broward Sheriff’s Office; 9.9\% Hialeah Police Department; 9.9\% Miami Beach Police Department; 7.0\% Doral Police Department; 1.4\% North Miami Police Department; 1.4\% North Miami Beach Police Department). The majority of police participants held the job title of Detective $(62.0 \% ; 23.9 \%$ Officer; 5.6\% Sergeant; 5.6\% Deputy; 2.8\% Lieutenant).

In addition, seventy students at FIU were recruited to participate from the psychology department participant pool via Sona-Systems. Students signed up for a onehour appointment in a computer lab on campus. Each participant was awarded one research credit for participation, to be applied toward a psychology course research requirement. Each time slot was assigned randomly to an experimental condition before the participant arrived at the computer laboratory. Three student participants were 
excluded, because the participants were familiar with one or more of the individuals whose pictures were used as part of the stimulus materials. Of the 67 participants comprising the final student sample, the average age was 23.33 years old, and the majority of participants were female $(79.1 \% ; 20.9 \%$ male $)$ and Hispanic $(53.7 \% ; 29.9 \%$ African-American; 4.5\% White; 1.5\% Asian; 10.4\% Other).

The final total sample consisted of 138 participants. The average age was 30.59 years old, and the majority of participants were female $(58.7 \% ; 41.3 \%$ male $)$ and Hispanic (55.8\%; 26.1\% African-American; 10.9\% White; 0.7\% Asian; 6.5\% Other).

\section{Design}

Experiment 2 employed a 2 (interview type: SI vs. CI) x 2 (participants: police vs. students) x 2 (order of descriptor list: grouped vs. not) ${ }^{18}$ between subjects factorial design. The main dependent variables of interest were accuracy in selecting the perpetrator as a suspect, percentage of resources allocated toward investigating the perpetrator, motivation, and subjective utility ratings.

The procedure of Experiment 2 was refined based on the results of Experiment 1. The results of Experiment 1 showed that neither the pictorial image instruction nor the presentation modality (spoken vs. written) enhanced the CI's investigative utility. Thus, these variables were eliminated from Experiment 2 to increase experimental power. Although the order of descriptor list similarly did not alter investigative utility, this

\footnotetext{
${ }^{18}$ As a reminder, descriptors lists were presented to participants in one of two ways. Half of the lists were grouped such that the perpetrator was described in a theoretically-appropriate manner - by holistic descriptors initially (e.g., age, race, height, weight, build, skin tone), followed then by specific featural descriptors (e.g., eye color, nose shape) - and in a practically appropriate manner - categorically based on the earliest time that category was mentioned by the eyewitness (e.g., if the participant mentioned "blue eyes" but later in the interview added that the eyes were "speckled" and "crescent-shaped," the category eyes was presented initially as "blue, speckled, crescent-shaped eyes"). The other half of the lists were not grouped, meaning that the descriptors were listed in the order that they were recalled by the witness. (See Appendices B-E for examples.)
} 
variable was once again manipulated in Experiment 2 because I was not certain which order best reflected actual police investigative procedure. Having spoken with police officers in South Florida in preparation for the current study, I learned that police who conduct interviews do, in fact, receive witness information (e.g., a perpetrator description) in whatever order it is generated by the witness. In addition, when the perpetrator description is written on a police form, it is generally organized by feature (e.g., hair: black, straight, long curly). Thus, to increase ecological validity, Experiment 2 included both descriptor list orders (i.e., theoretically and practically grouped as well as not grouped).

Materials

The materials used in Experiment 2 were the same as those used in Experiment 1, aside from the following change: All perpetrator descriptors were presented to participants as a typewritten list on a one-sided white page in Times New Roman font, size 12, using lowercase letters organized under a single column.

\section{Procedure}

The procedure used in Experiment 1 was replicated aside from semantic and practical changes that were necessary given the new population of participants. The language was rewritten throughout the police version of the Qualtrics survey for practical purposes (e.g., "Imagine that you are a detective in the Miami-Dade Police Department" was changed to "Imagine that your police department has assigned you the following investigation/case."). Additionally, to motivate police and students to treat the experiment as an important investigation, (1) the incident in question was changed to the more serious crime of armed robbery (as opposed to a car theft), and (2) participants were 
instructed about the purpose and potential policy implications of the study. Prior to receiving Experiment 1's initial instructions, police participants were presented with the following:

PLEASE NOTE that the purpose of this study is to find the best ways to increase police efficiency and accuracy in criminal investigations. Doing so will help protect you, your colleagues, and your department from afterthe-fact criticism by lawyers, judges, advocacy groups, the media, and the general public regarding your investigative decisions. Thus, it is EXTREMELY IMPORTANT that you treat this computer study as if it were a real police investigation.

Students were given the same initial instruction aside from minor wording changes (e.g., "protect you, your colleagues, and your department" was changed to "protect the police.”)

Additionally, after completing the subjective utility task and before answering demographic questions, participants were given a debriefing question that served as a manipulation check for participant motivation. Specifically, participants were asked to rank their motivation to do well on the experiment on a seven-point Likert scale $(l=$ Extremely Motivated, $4=$ Neither Motivated nor Unmotivated, $7=$ Extremely

\section{Unmotivated).}

Results

Objective Utility

Preliminary Analysis - Motivation. A preliminary analysis was conducted to assess the motivation of Experiment 2 participants to do well in the survey tasks. A twoway between-subjects analysis of variance was conducted to explore the impact of interview condition and participant type on motivation ("How motivated were you to do well in this experiment?" with $1=$ Extremely Motivated, $4=$ Neither Motivated nor 
Unmotivated, 7 = Extremely (nnotivated). The interaction effect between interview condition and participant type was not statistically significant, $F(1,134)=1.14, p=.29$, $\eta_{p}^{2}=.008$. There was also no main effect of interview condition, $F(1,134)=2.92, p=$ $.09, \eta_{p}^{2}=.021$, or of participant type, $F(1,134)=.01, p=.93, \eta_{p}^{2}=.000$. Notably, both participant groups were extremely-to-very motivated to do well in the experiment (police: $M=1.61, S D=.82 ;$ students: $M=1.62, S D=.93$ ).

Perpetrator Selection as a Suspect. Preliminary analyses were conducted to assess whether interview condition (SI vs. CI) interacted with confederate perpetrator (male vs. female) or with order of descriptor list (grouped vs. not) on the perpetrator selection measure. A logistic regression was conducted with perpetrator selection as the criterion variable and with interview condition, confederate perpetrator, and order of descriptor list, and the interactions between these variables as the predictor variables. The regression equation did not fit significantly better than the null model, $x^{2}(5)=8.77, p$ $=.12$, Nagelkerke $\mathrm{R}^{2}=.09$. The interactions between interview condition and confederate perpetrator $(\mathrm{B}=1.47$, Wald $=2.35, p=.13, \mathrm{OR}=4.34)$ and between interview condition and order of descriptor list $(\mathrm{B}=-.56$, Wald $=.54, p=.46, \mathrm{OR}=.57)$ were non-significant. Thus, the data were collapsed across confederate perpetrator and order of the descriptor lists.

Perpetrator identification as a suspect (by matching the perpetrator's photograph to the witness's description of the perpetrator) was examined for all 138 participants across interview conditions. Of the 68 participants who based their identification decision on an SI description of the perpetrator, 40 participants (58.8\%) selected the perpetrator as a suspect, whereas 28 participants $(41.2 \%)$ did not. Of the 70 participants 
who based their identification decision on a CI description of the perpetrator, 54 participants $(77.1 \%)$ selected the perpetrator as a suspect, whereas 16 participants (22.9\%) did not. (See Table 9 for perpetrator selection crosstabulations for each interview and participant condition). 
Table 9.

Exp. 2 Identifying the Perpetrator as a Suspect Descriptive Statistics

\begin{tabular}{|c|c|c|c|c|c|c|c|c|c|}
\hline \multirow[b]{3}{*}{ Participant } & \multicolumn{5}{|c|}{ SI } & \multicolumn{4}{|c|}{ CI } \\
\hline & \multirow[t]{2}{*}{ Select Perp } & \multicolumn{2}{|c|}{ No } & \multicolumn{2}{|c|}{ Yes } & \multicolumn{2}{|c|}{ No } & \multicolumn{2}{|c|}{ Yes } \\
\hline & & Count & $\%$ & Count & $\%$ & Count & $\%$ & Count & $\%$ \\
\hline Student & & 12 & 37.5 & 20 & 62.5 & 9 & 25.7 & 26 & 74.3 \\
\hline Police & & 16 & 44.4 & 20 & 55.6 & 7 & 20.0 & 28 & 80.0 \\
\hline Combined & & 28 & 41.2 & 40 & 58.8 & 16 & 22.9 & 54 & 77.1 \\
\hline
\end{tabular}


A hierarchical binary logistic regression was conducted with perpetrator selection as the criterion variable and with interview type (CI vs. SI), participant type (police vs. students), and their interaction as the predictor variables. On step 1, interview type and participant type were entered into the regression model. The regression equation did not fit significantly better than the null model, $x^{2}(2)=5.38, p=.07$, Nagelkerke $\mathrm{R}^{2}=.05$. Participant type was not significantly associated with selecting the perpetrator as a suspect, $\mathrm{B}=-.03$, Wald $=.00, p=.95, \mathrm{OR}=.98$. Police and students were not significantly different as to perpetrator selection. However, as in Experiment 1, interview type was significantly associated with selecting the perpetrator as a suspect, $\mathrm{B}=.86$, Wald $=5.20, p=.02, \mathrm{OR}=2.36$. Participants who received a CI-elicited perpetrator description were more likely than participants using an SI-elicited perpetrator description to accurately select the perpetrator as a suspect. On step 2 , the interaction term was entered into the regression equation. The regression equation did not fit significantly better than the null model, $x^{2}(3)=.06, p=.11$. The interaction between interview type and participant type was not statistically significant, $\mathrm{B}=.61$, Wald $=.66, p=.42, \mathrm{OR}=$ 1.85 .

Resource Allocation. Resource allocation was assessed for all 138 participants across interview condition and participant type. Those participants who based their investigative decision on an SI description of the perpetrator allocated between 0 and 75 (out of 100) hours, allocating a mean of 23.12 hours $(S D=22.18)$, to further investigating the perpetrator. Those participants who based their investigative decision on a CI description of the perpetrator allocated between 0 and 100 (out of 100) hours, allocating a 
mean of 32.61 hours $(S D=23.30)$, to further investigating the perpetrator. (See Table 10 for resource allocation descriptive statistics for each interview and participant condition).

Table 10

Exp. 2 Resource Allocation Descriptive Statistics

\begin{tabular}{|c|c|c|c|c|c|c|c|}
\hline \multirow[b]{2}{*}{ Participant } & \multirow[b]{2}{*}{$\mathrm{n}$} & \multicolumn{3}{|c|}{ SI Description } & \multicolumn{3}{|c|}{ CI Description } \\
\hline & & Mean & SD & $\mathrm{N}$ & Mean & SD & $\mathrm{N}$ \\
\hline Student & 67 & 24.59 & 21.28 & 32 & 33.91 & 25.26 & 35 \\
\hline Police & 71 & 21.81 & 23.17 & 36 & 31.31 & 21.46 & 35 \\
\hline Combined & 138 & 23.12 & 22.18 & 68 & 32.61 & 23.30 & 70 \\
\hline
\end{tabular}

A four-way between-subjects analysis of variance was conducted to explore the impact of interview condition (CI vs. SI), participant type (police vs. student), confederate perpetrator (male vs. female), and order of descriptor list (grouped vs. not) on resource allocation. Levene's test demonstrated unequal variances across interview conditions, $F=1.95, p=.02$, so a more stringent significance level of .01 was used for evaluating the results. There was no main effect of confederate perpetrator, $F(1,122)=$ $.00, p=.98, \eta_{p}^{2}=.000$, or of order of descriptor list, $F(1,122)=.12, p=.73, \eta_{p}^{2}=.001$. There was also no main effect of participant, $F(1,122)=.00, p=.33, \eta_{p}^{2}=.000$, that is, police and student participants did not allocate a significantly different number of hours to investigating the perpetrator. However, there was a main effect of interview condition, $F(1,122)=8.20, p=.01, \eta_{p}^{2}=.063$, such that more hours were allocated to pursuing the 
perpetrator using a CI description than using an SI description. None of the interactions between the foregoing variables were significant, $F$ s ranging from .12 to 4.39 , all $p \mathrm{~s}>$ .04 .

\section{Subjective Utility}

Common Descriptors vs. Uniquely-CI Descriptors. First, descriptive statistics were used to assess the subjective value decision makers assigned to Common Descriptors and Uniquely-CI Descriptors in the eight representative interviews across all participants. Both the Common Descriptors and the Uniquely-CI Descriptors were deemed slightly-to-moderately useful, with Uniquely-CI Descriptors being rated as less useful on average than Common Descriptors (Common Descriptors: $M=2.28, S D=.39$; Uniquely-CI Descriptors: $M=2.78, S D=.44)^{19}$.

A two-way between-subjects analysis of variance was conducted to explore the impact of interview condition (SI vs. CI) and participant type (police vs. student) on the average subjective utility ratings of all descriptors. There was a main effect of interview condition, $F(1,134)=21.40, p<.001, \eta_{p}^{2}=.138$. Participants rated SI descriptions $(M=$ $2.24, S D=.38)$ as significantly more useful than CI descriptions $(M=2.53, S D=.36)$. There was also a main effect of participant type, $F(1,134)=7.10, p=.01, \eta_{p}^{2}=.050$. Police rated descriptors significantly more useful $(M=2.30, S D=.42)$ than students $(M=$ $2.48, S D=.34)$. There was no interaction between interview condition and participant type, $F(1,314)=.40, p=.53, \eta_{p}^{2}=.003$

\footnotetext{
${ }^{19}$ Again, lower numbers indicate a higher subjective utility rating based on the four-point Likert scale used $(1=$ Extremely Useful, $4=$ Not At All Useful $)$.
} 
Next, a two-way between-subjects analysis of variance was conducted to explore the impact of interview condition (SI vs. CI) and participant type (police vs. student) on the average subjective utility ratings of Common Descriptors. There was no main effect of interview type, $F(1,134)=1.63, p=.20, \eta_{p}^{2}=.012:$ SI and CI Common Descriptor subjective utility ratings did not significantly differ. However, there was a main effect of participant type, $F(1,134)=10.57, p<.001, \eta_{p}^{2}=.073$. Police participants rated the Common Descriptors of significantly more investigative use in their decision making $(M$ $=2.17, S D=.61)$ than did student participants $(M=2.39, S D=.54)$. There was also no interaction between interview condition and participant type, $F(1,314)=.00, p=.95, \eta_{p}^{2}$ $=.000$. (See Table 11 for Common and Uniquely-CI Descriptor descriptive statistics in each interview condition.) 
Table 11.

Exp. 2 Subjective Utility Descriptive Statistics (Common vs. Uniquely-CI)

\begin{tabular}{|c|c|c|c|c|c|c|c|c|c|c|}
\hline \multirow[b]{2}{*}{ Type of Descriptor } & & \multicolumn{3}{|c|}{ SI } & \multicolumn{3}{|c|}{$\mathrm{CI}$} & \multicolumn{3}{|c|}{ Total } \\
\hline & & Mean & $\mathrm{SD}$ & $\mathrm{n}$ & Mean & $\mathrm{SD}$ & $\mathrm{n}$ & Mean & $\mathrm{SD}$ & $\mathrm{n}$ \\
\hline \multirow[t]{2}{*}{ Common } & Police & 2.14 & .41 & 36 & 2.22 & .41 & 35 & 2.18 & .41 & 71 \\
\hline & Student & 2.35 & .32 & 32 & 2.43 & .34 & 35 & 2.40 & .33 & 67 \\
\hline \multirow[t]{2}{*}{ Uniquely-CI } & Police & 0 & 0 & 0 & 2.77 & .47 & 35 & 2.77 & .47 & 35 \\
\hline & Student & 0 & 0 & 0 & 2.79 & .41 & 35 & 2.79 & .41 & 35 \\
\hline
\end{tabular}

NOTE: Lower numbers indicate that the descriptors were rated as more useful/valuable. 
Next, an independent-samples $t$-test was conducted to compare the subjective utility ratings of Uniquely-CI Descriptors between student and police participants. There was no significant difference in the average subjective utility ratings of Uniquely-CI Descriptors between student and police participants, $t(68)=.15, p=.88, \eta^{2}=.000$. Both participant groups deemed Uniquely-CI Descriptors only slightly-to-moderately useful in their investigative decision making (students: $M=2.79, S D=.41$; police: $M=2.77, S D=$ $.47)$.

In addition, a two-way analysis of variance was conducted to assess the impact of descriptor type (Common vs. Uniquely-CI) and participant type (police vs. student) on subjective utility ratings in CI cases. There was a main effect of descriptor type, $F(1$, $136)=43.08, p<.001, \eta_{p}^{2}=.241$. In CI cases, Common Descriptors $(M=2.33 ; S D=$ .39) were rated significantly more useful than Uniquely-CI Descriptor $(M=2.78 ; S D=$ $.44)$. However, there was no main effect of participant, $F(1,136)=2.70, p=.10, \eta_{p}^{2}=$ .019 , that is, police and student participants using a CI perpetrator description did not significantly differ in their subjective utility assessments. There was also no interaction between descriptor type and participant type, $F(1,316)=1.99, p=.16, \eta_{p}^{2}=.014$.

Facial vs. Non-facial Descriptors. A three-way between-subjects analysis of variance was conducted to explore the impact of descriptor type (facial vs. non-facial), interview condition (SI vs. CI), and participant type (police vs. student) on subjective utility assessments. Levene's test demonstrated unequal variances across interview conditions, $F=6.81, p<.001$, so a more stringent significance level of .01 was used for evaluating the results. There was a main effect of descriptor type, $F(1,268)=22.34, p<$ $.001, \eta_{p}^{2}=.077$, such that facial descriptors $(M=2.15, S D=.67)$ were rated as more 
useful than non-facial descriptors $(M=2.45, S D=.43)$. There was also a main effect of interview condition, $F(1,268)=39.23, p<.001, \eta_{p}^{2}=.128$, in that SI descriptors were rated as more useful than CI descriptors. In addition, there was a main effect of participant, $F(1,268)=9.62, p<.001, \eta_{p}^{2}=.035$; descriptors were rated as more useful by police $(M=2.20 ; S D=.62)$ than by students $(M=2.41 ; S D=.53)$. None of the higher order interactions between the foregoing variables were significant, $F s$ ranging from .00 to 2.64 , all $p \mathrm{~s}>.04$. (See Table 12 for facial and non-facial descriptive statistics in each interview condition). 
Table 12.

Exp. 2 Subjective Utility Descriptive Statistics (Facial vs. Non-Facial)

\begin{tabular}{|c|c|c|c|c|c|c|c|c|c|c|}
\hline \multirow[b]{2}{*}{ Type of Descriptor } & & \multicolumn{3}{|c|}{ SI } & \multicolumn{3}{|c|}{$\mathrm{CI}$} & \multicolumn{3}{|c|}{ Total } \\
\hline & & Mean & $\mathrm{SD}$ & $\mathrm{n}$ & Mean & $\mathrm{SD}$ & $\mathrm{n}$ & Mean & SD & $\mathrm{n}$ \\
\hline \multirow[t]{2}{*}{ Non-Facial } & Police & 2.19 & .42 & 36 & 2.52 & .40 & 35 & 2.35 & .44 & 71 \\
\hline & Student & 2.36 & .35 & 32 & 2.74 & .38 & 35 & 2.56 & .41 & 67 \\
\hline \multirow[t]{2}{*}{ Facial } & Police & 1.73 & .78 & 36 & 2.39 & .51 & 35 & 2.05 & .74 & 71 \\
\hline & Student & 2.15 & .73 & 32 & 2.35 & .41 & 35 & 2.26 & .59 & 67 \\
\hline
\end{tabular}

NOTE: Lower numbers indicate that the descriptors were rated as more useful/valuable. 


\section{Discussion}

Experiment 2 re-tested the CI's investigative utility in a criminal case with a more diverse and externally valid population of participants consisting of police and students. The central findings were as follows: (1) as in Experiment 1, CI descriptions significantly improved investigative decision makers' performance in (a) accurately identifying the perpetrator as a suspect, and (b) allocating investigative resources toward investigating the perpetrator; (2) police and student participants did not significantly differ in their performance of investigative tasks; (3) as in Experiment 1, participants subjectively valued CI-elicited descriptions less than SI-elicited descriptions; and (4) police valued Common Descriptors (found in both the SI and CI descriptions) more than students, but police did not differ from students when evaluating Uniquely-CI Descriptors (found exclusively in the CI descriptions).

(1) Objective Utility: Experiment 2 replicated the effect of the CI on investigative utility, thereby showing the reliability of the effect. As hypothesized, Experiment 2 investigative decision makers were significantly more likely to select the perpetrator as a suspect (as opposed to an innocent suspect) using a CI description than using an SI description. The CI resulted in a $31 \%$ increase in correct suspect selection decisions. Also, as in Experiment 1, investigative decision makers allocated significantly more resources (i.e., hours) to further investigating the perpetrator (as opposed to innocent suspects) using a CI description than using an SI perpetrator description. ${ }^{20}$ Experiment 2

\footnotetext{
${ }^{20}$ Resource allocation once again produced an inexplicable interaction between interview condition and confederate perpetrator. As explained in Experiment 1, there are many reasons why the CI may have been more valuable for one perpetrator than for another, given the infinite number of differences between the perpetrators. There may be something unique to this study (e.g., the particular perpetrators, the staged
} 
thus confirms the stability of perpetrator identification and resource allocation as CI investigative utility measures.

Police and students participants did not differ in their performance of the measured investigative utility tasks. That is, police and students performed substantially similar in identifying the perpetrator as a suspect and allocating resources toward pursuing the perpetrator. This finding speaks to the generalizability of this study. Moreover, the Cl's investigative utility was demonstrated across different participant populations (one of which included actual police officers recruited from seven departments throughout South Florida), evidencing the robustness of the CI's investigative utility. ${ }^{21}$

Similar performance between police and student participants also speaks to the leeway future researchers have to use convenience samples to test investigative utility. This study adds to extant eyewitness research showing police and students to function the same in terms of basic perceptual and cognitive tasks (Charman, Kavetski, \& Mueller, 2017; Park, Lee, \& Lee, 1996; Vrij, Akehurst, Brown \& Mann, 2006; Zimmerman, 2003). The ability to use convenience samples of students (which will allow for larger sample sizes and greater power) as proxies for police in future research is one less roadblock on the path to empirically testing and improving police efficiency and accuracy in criminal investigations.

event, the viewing conditions) that made the CI more effective than the SI for one perpetrator over another, or the interaction may simply be a result of Type I error.

${ }^{21}$ Needless to say, this is the only experiment to replicate CI utility using police officers - the true scope of the CI's generalizability and robustness in terms of investigative utility hinges on experimental replication in different laboratories using different participant populations as well as application in real-world cases. 
(2) Subjective Utility: Subjective utility findings were stable across experiments. Experiment 2 investigative decision makers provided slightly to moderately useful ratings for the perpetrator descriptions, and in CI cases, Uniquely-CI Descriptors were rated as significantly less useful than Common Descriptors. Similarly, as in Experiment 1, decision makers valued facial features more than non-facial features in both interview conditions; however, both facial and non-facial features were rated as significantly more useful in SI descriptions than in CI descriptions. Experiment 2 thus confirms the reliability of the subjective utility phenomenon (but, perhaps, not the validity of subjective utility task, as discussed below).

As in Experiment 1, subjective utility did not map onto objective utility. Although decision makers did not value CI descriptions more than SI descriptions, CI descriptions significantly improved investigative decision making. Moreover, police did not value the CI's investigative utility more than students. Although police generally rated descriptors higher than students, and although police deemed Common Descriptors (elicited in both interview conditions) of more investigative use than students, police did not value CI descriptions or Uniquely-CI Descriptors more than students.

The practical consequences of police misjudging the value of perpetrator descriptions would indeed be problematic. Police who undervalue perpetrator descriptions may, for example, be disinclined to conduct a comprehensive (and, timeconsuming) interview of an eyewitness to elicit particularized perpetrator details (e.g., Kebbell, Milne, \& Wagstaff, 1999). Doing so has the potential to impair crucial tasks early in an investigation, such as those measured in this study - that is, selecting the perpetrator (as opposed to an innocent person) as the criminal suspect, and allocating 
investigative time and resources to further investigating the perpetrator (as opposed to an innocent suspect). Given the progressive nature of a criminal investigation, inaccurate initial investigative tasks lead to inaccurate ensuing tasks (i.e., lineup identifications, interrogations, prosecutions, and convictions).

However, the foregoing practical risks are not of imminent concern given the differing nature of the subjective utility and objective utility assessments in the current study. As discussed in Experiment 1, subjective utility measured the mean value across all of the descriptors (i.e., the average/typical CI descriptor and SI descriptor), whereas objective utility measured the collective value of the $\mathrm{CI}$ and SI descriptors. It is akin to having two piles of coins: some nickels and some dimes. Even though the average dime is worth more than the average nickel, if you have enough nickels (i.e., more than twice as many dimes) then the larger pile of nickels is worth more than the smaller pile of dimes. Here, while individual CI descriptors may have been valued less than the SI descriptors, when all of the CI descriptors were combined, their large quantity was collectively more valuable than the smaller quantity of SI descriptors.

The mismatch between subjective and objective utility findings may also derive from the procedural limitations of this study's subjective utility task. As in Experiment 1, participants were instructed to rank each descriptor in terms of its use in completing the investigative tasks. However, of the police participants asked to rate the utility of "gender," 22 more than $85 \%$ deemed this descriptor "extremely useful" in completing the investigative tasks. Similarly, of the student participants asked to rate the utility of "gender," nearly $95 \%$ deemed this descriptor "extremely useful" in completing the

${ }^{22}$ Only 32 students and 36 police, respectively, rated the utility of gender, as this descriptor was not included in 70 of the interview descriptor lists used. 
investigative task. As noted in Experiment 1, the descriptor category of "gender" could not possibly have been useful to decision makers, given that all 10 potential suspect photographs were of women for the female perpetrator and were of men for the male perpetrator. The "age" descriptor produced similar findings - over $85 \%$ of police and over $65 \%$ of students deemed this descriptor "extremely useful" or "very useful." Again, all potential suspects were of approximately the same age, so the "age" descriptor could not possibly have been informative for Experiment 2's police-related tasks.

Police (and students) may have valued those descriptors with which they were most familiar (i.e., those descriptors that are often recalled by witnesses). Prior survey research has shown that police report gender, clothing, age, race, height, hair length, and hair color - all of which were Common Descriptors in this study - as the most frequently recalled descriptors by witnesses (Brown et al. 2008). By contrast, police report the most rarely recalled descriptors as including ears, chin, lips, cheeks, neck, eyebrows - all of which were Uniquely-CI Descriptors in this study (Brown et al.). It may be the case that Experiment 2 police participants recognized Common Descriptors as those that they typically obtain in an investigation and thus rely on to identify a suspect; hence, police rated those descriptors as more useful than descriptors that are rarely recalled by witness and, thus, not regularly at investigators' disposal (see Goldstein \& Gigerenzer, 2002). 


\section{CHAPTER IV}

\section{General Discussion}

\section{Practical Implications}

The current study is the first to establish the practical value of the CI to police. To date, the CI's value has been defined only in terms of its impact on the quantity and accuracy of recall in a witness interview. However, extant research has failed to test whether that information is useful to police in the course of a criminal investigation. As demonstrated by the current study, which tested not only student participants but also actual police officers, proper use of the CI allows investigative decision makers to more effectively identify the perpetrator as a suspect, and spend less investigative time on useless and dangerous tasks (e.g., investigating and potentially convicting an innocent suspect).

Investigating the actual perpetrator as opposed to an innocent suspect is likely to have a domino effect on all subsequent phases of the investigation, including increasing the base rate of including perpetrators in lineups (i.e., the probability that police include the perpetrator, as opposed to an innocent suspect, in a lineup). The accuracy of lineup identifications varies markedly as a function of base rates (Clark, 2012; Malpass, 2006; Wells \& Olson, 2002). Correct identifications of a perpetrator can occur only when the actual perpetrator is in the lineup. False identifications of an innocent suspect can occur only when an innocent suspect, as opposed to the perpetrator, is in the lineup. Thus, by increasing the base rate of a lineup, investigators can profoundly increase the rate of correct identifications while also reducing the rate of false identifications. If there is a high prior probability that a perpetrator is in the lineup, it is more likely that a correct 
identification will occur and that the perpetrator will be convicted of the crime (Clark, 2012). If there is a low prior probability that an innocent suspect is in the lineup, it is less likely that a false identification and, hence, a wrongful conviction will occur (Clark, 2012).

Using a witness interviewing procedure to influence a resulting lineup base rate is a promising, alternative approach to current witness identification reform. While there has been a reduction in the rate of false identifications associated with empiricallyrecommended witness identification system variable reform (e.g., sequential lineups; unbiased lineup instructions), recent research has shown a general trade-off pattern such that lower false identification rates in recommended lineup procedures also result in lower correct identification rates (Brewer \& Palmer, 2010; Carlson, Gronlund, \& Clark, 2008; Clark, 2012; Lindsay, Mansour, Beaudry, Leach, \& Bertrand, 2009; Steblay, Dysart, \& Wells, 2011). The trade-off between false and correct identification rates presumably occurs because many system variables alter response bias, the inclination of a witness to identify someone from a lineup. Thus, if a procedure induces more conservative responding, it will have the desirable effect of reducing false identifications along with the undesirable effect of reducing correct identifications (Gronlund, Wixted, \& Mickes, 2013).

Improving the base rate of a lineup is not susceptible to the trade-off derived from altering response bias (Wells \& Olson, 2002). Increasing the base rate will increase correct identifications and decrease false identifications for any fixed rate of discrimination (i.e. for any lineup procedure). In their analysis of base-rate effect equivalency curves, Wells, Yang, and Smalarz (2015) showed that even a relatively 
modest change to the base rate of a lineup can have more impact on the reliability of witness identification evidence than traditional system variables. The current study points to a more-than-modest change in the base rate (as evidenced by the Cl's approximate $30 \%$ increase in perpetrator selection and significant increase in hours allocated toward investigating the perpetrator as a suspect relative to the SI). Using the $\mathrm{CI}$ early in an investigation (to interview witnesses more effectively and thereby elicit better descriptions of the perpetrator) may change the base rate of a later-conducted lineup sizably thereby protecting the justice system from wrongful convictions derived from juror misjudgments based on faulty lineup identifications (e.g., Cutler, Penrod, \& Stuve, 1988).

Many other valuable byproducts (other than improving the lineup base rate) derive from using the $\mathrm{CI}$ early in an investigation. A perpetrator description that leads police to pursue a guilty (as opposed to innocent) suspect has the potential to protect against innate cognitive biases - e.g., confirmation bias and tunnel vision (Findley \& Scott, 2006) - that can lead to decision errors by police (see O'Brien \& Findley, 2015). Research has shown police to exhibit a strong lie bias, such that they make the assumption that suspects are being deceptive throughout an investigation - e.g., they believe a suspect is lying when s/he says "I am innocent" (Meissner \& Kassin, 2002). This bias is so strong that experienced law enforcement officers have been shown empirically to maintain their beliefs in the face of clear exonerating evidence (Meissner $\&$ Kassin, 2002). However, if police pursue a guilty suspect, then their investigative tendency to select and filter evidence that will build a case for conviction (and to ignore or dismiss evidence that contradicts that guilt) will not result in a wrongful conviction. 
There are also real-time policy implications to this study. In an applied field such as witness interviewing, the support of both due process proponents (agencies advocating the protection of defendants' rights and fundamental fairness under the law) and crime control proponents (agencies geared toward reducing crime in society using criminal penalties as a means of deterrence) is of the utmost importance (Packer, 1964). Collaboration between these two criminal justice camps and the scientific community is crucial to improve the accuracy and utility of witness interviewing and resulting investigative procedures. Given that lives and liberties hinge on police decision making, the CI's ability to enhance the accuracy and utility of a criminal investigation will have marked, real-time policy implications for the justice system. Police will benefit from streamlined investigations and improved investigatory resources (rather than wasting time, money, and labor on innocent suspects). Prosecutors and defense attorneys will benefit from a decrease in frivolous and wrongful prosecutions. Judges and jurors will benefit from reliable investigative procedures and lineup constructions that are more resistant to scientific scrutiny and, hence, appellate review. Finally, and most notably, defendants facing criminal charges, trial, and prison sentences will less likely be innocent persons who were inaccurately labeled a suspect. Thus, the legal system as a whole will be less susceptible to potential miscarriage of justice.

\section{Research Implications}

The current study is the first to measure utility of the CI, as opposed to measuring the amount and accuracy of witness information gathered (as a proxy for investigative utility). In the past, CI researchers have implied that witness statements are more useful if they contain more (and equally accurate) information than a standard police interview 
(Fisher et al., 1989; Geiselman \& Fisher, 2014). Although quantity and accuracy measure the potential utility of the CI, they do not measure the CI's actual utility. That is, quantity and accuracy contribute to the informativeness of witness information; however, informativeness does not necessarily equate to police catching the perpetrator and solving a crime.

Actual utility (e.g., selecting the perpetrator as a suspect), in addition to being a more direct assessment tool, may also be a more reliable CI measurement than accuracy. The perpetrator descriptors used in the current study were measured on a 6-point scale (Satin \& Fisher, 2017). As previously noted, when a very stringent accuracy criterion was used, the SI accuracy rate was significantly higher than the CI accuracy rate (SI = $.32, \mathrm{CI}=.24)$. However, when the same descriptors were measured using more lenient decision criteria on the 6-point scale, the SI and the CI produced comparable accuracy rates (see Table 2). These findings suggest that $\mathrm{CI}$ and SI conclusions based on accuracy may depend on how researchers operationalize accuracy. In other words, it may be less reliable to measure CI and SI accuracy than actual utility, given that the CI's and SI's error rate changes depending on the stringency of the decision criterion used.

Perhaps even more interesting is the discord found between the current study's accuracy and utility findings. Lenient accuracy criteria resulted in CI descriptions leading to better performance of police-related tasks (i.e., selecting the perpetrator as a suspect) than equally accurate but less complete SI descriptions. However, using the very stringent accuracy criterion, a different finding emerged. Although the CI elicited less accurate perpetrator descriptions than the SI, it was more useful than the SI in subsequent police-related tasks. This finding points to a complex relationship between quantity and 
accuracy in terms of investigative utility. A less accurate (but more complete) perpetrator description may be more forensically useful to police than a more accurate (but less complete) perpetrator description. This suggests that a large increase in quantity can, in some sense, overcome a small decrease in accuracy in terms of investigative use. It is not obvious how much of a reduction in accuracy can be overcome by an increase in quantity - however, in this experiment, where the CI elicited three times the number of perpetrator descriptors than the SI, it is clear that a minimal reduction in accuracy can be compensated for by a large increase in quantity. Thus, although both quantity and accuracy contribute to utility, each measure is in some sense substitutable for the other; a decrease in one measure can be compensated for by an increase in the other measure. The exact quantity-accuracy "compensation formula" for CI utility has yet to be empirically defined. It is quite likely that, even if it was, the compensation formula would vary from study to study/context to context.

The current study's findings are also notable in that they were observed in a controlled laboratory setting. In a real-world criminal investigation, motivation to perform police-related tasks is presumably much higher. It is also likely that in real investigations, the burden of processing information (i.e., the perpetrator descriptors) is shared among numerous police and detectives involved in the case. Hence, in a police investigation, decision makers might find it even easier to use the extensive list of perpetrator descriptors elicited from the CI. This is particularly likely given that, in real investigations, police have the ability to use perpetrator descriptors in conjunction with other, non-descriptors they possess (e.g., tips from informants, modus operandi, prior criminal history, proximity between a suspect's residence and the crime scene). In sum, 
factors germane to a real-world investigation (i.e., increased police motivation, support, and non-descriptor information) stand to increase the potency of the Cl's utility beyond that which was observed in the lab.

\section{Using the CI in Real-World Cases}

Police and student participants did not differ in their performance of investigative utility tasks: Both groups benefited equally from the CI in terms of identifying the perpetrator as a suspect and allocating resources toward pursuing the perpetrator. Notwithstanding the CI's value to police, critics may suggest that the CI (which was, on average, twenty minutes longer than the SI) is too time-consuming to be used in realworld investigations (e.g., Kebbell et al., 1999). Although the CI may, at times, take longer to perform than a standard witness interview, within the context of a lengthy criminal investigation - in which police must spend time (a) traveling to and from the location of each witness, (b) writing a report of each interview, (c) traveling to and from court to testify, and (d) waiting to and participating in direct and cross-examination on the witness stand at trial - an additional 20 minutes is a mere "drop in the bucket." If police are under time pressure in a particular investigation (e.g., they have numerous witnesses to interview within a short period of time), then a full CI might not be feasible. In such a case, it may be worthwhile to devise a modified, shorter version of the CI. Although future research is needed to design and test a truncated version of the CI, initial empirical findings have been promising (Dando, Wilcock, Milne \& Henry, 2009; Davis, McMahon, \& Greenwood, 2004).

The ability to modify and adapt various CI components to the unique needs of a particular interview is one of the strengths of the CI (Fisher, 2010). Indeed, the modified 
version of the CI used in this study differed from the full CI by focusing exclusively on person descriptors. The $\mathrm{CI}$ is not a holistic recipe that requires formulaic adherence; rather it is a toolbox of techniques, some of which apply in certain interviews and some of which do not (Fisher, 2010). An interviewer can choose to use (or not use) codecompatible output (via, for example, a body shape chart) to assist a witness to describe a perpetrator's body, depending on whether the interviewer deems it helpful to the witness. An interviewer may also decide during a CI to follow up on particular details of, for example, a perpetrator's tone of voice or body posture based on information elicited in the witness's prior responses. The diagnostic superiority of this "toolbox" approach to interviewing highlights the need for flexibility when interviewing cooperative witnesses and the self-limiting drawbacks of using a standardized checklist of categorical pieces of information in an interview.

An alternative approach to the practical constraints associated with conducting a full CI may be to determine which CI elements are most effective in gathering accurate and/or valuable information, and then to restrict the interview only to those elements. For example, some perpetrator descriptors may be more valuable to police than others (either to help the police identify a potential suspect to investigate, or to select a suspect to place in a lineup). Or, in some cases, perpetrator descriptors may not be as important as eventrelated details (e.g., cyber crimes in which the perpetrators are never seen by the witnesses). Tailoring the $\mathrm{CI}$ to the specific investigative task or goal is one way to reduce the time associated with conducting the interview. 


\section{Limitations and Future Studies}

One limitation of the study was the use of fixed photographs, which precluded decision makers (particularly those using a CI-elicited perpetrator description) from using many distinctive descriptors recalled by witnesses. For example, the male confederate perpetrator was described by several witnesses as having a gap between his two front teeth. However, in the pictures of the perpetrator and foil suspects, all individuals had their mouths closed. So, decision makers could not use this descriptor to discriminate between the perpetrator (who had a gap between his front teeth) and the foils (who may not have had gaps between their front teeth). The male perpetrator was also repeatedly described as exhibiting a gentle demeanor and being soft-spoken; however, no live video or audio footage of the perpetrator or suspects was played for investigative decision makers. The same particularized characteristics emerged for the female confederate, such as that she spoke with a nervous undertone and that she smiled a lot. Again, these features were not displayed in a stationary photograph of the perpetrator. ${ }^{23}$ This limitation highlights the potential depth of the CI's effect in terms of investigative utility. In this study, the CI's effect was strong even without the use of certain distinctive characteristics (e.g, mannerisms, demeanor, tone of voice, body language). Allowing decision makers to consider all of the perpetrator characteristics elicited from a CI

\footnotetext{
${ }^{23}$ Police normally would have access to such perpetrator characteristics, especially in cases where the police know the perpetrator from past experience (e.g., being in the neighborhood and seeing someone's daily activities).
} 
interview may even further enlarge the effect. Future studies on the investigative utility of the CI would benefit from similar use of live and videotaped suspect footage. ${ }^{24}$

The photographs used in the current study were headshots. It is logical that facial descriptors were rated as more useful than non-facial descriptors in both experiments given that decision makers (a) viewed the head, neck, and shoulders of each suspect only, and (b) rated the descriptors after deciding how useful they were to determine which face was being described. However, this begs the question of whether subjective utility ratings would have changed if participants evaluated full-body photographs. The CI contained a larger number of facial descriptors than the SI (CI: 30.8\%, SI: $15.5 \%)$. Thus, the CI may be more impactful when used in conjunction with a headshot as opposed to a full-body photograph. Although CI utility using full body images is a pertinent area of research interest, it may not be the most ecologically valid. Indeed, police generally use a criminal database of mugshots (head, neck, and shoulders) as opposed to full-body photographs to identify potential suspects. Of course, looking through ten photographs is very different from what police would typically do in a criminal investigation. However, the task captures the essential psychological processes involved.

Overall, the utility of the CI in this study was limited to some degree by the "impoverished" set of stimuli that decision makers had to choose from (e.g., still photographs, no audio footage, headshots, no behavioral or background information). Presumably, because the photographs used in the current study contained only a limited set of visual information (i.e., general and facial descriptors), only those descriptors were useful. However, in the real world, police possess considerable information on each

\footnotetext{
${ }^{24}$ The use of video and audio suspect footage has been used in witness identification studies (e.g., Cutler \& Fisher, 1990; Pryke, Lindsay, Dysart, \& Dupuis, 2004).
} 
potential suspect including behavioral information, audio information (e.g., accent, tone of voice, speech impediments), non-facial information, and action-related information (e.g., modus operandi, prior criminal history). Future study designs should allow decision makers to use all of the CI descriptors recalled by a witness to determine the true depth of the CI's investigative utility.

Another study limitation concerned the use of only two measures of investigative utility. A witness interview, and the perpetrator description elicited therefrom, influences a criminal investigation in many respects. Future research would benefit from exploring some of these alterative utility measures, including the length of time to select a suspect, the order of subsequent investigative tasks, the substance of future investigative tasks (i.e., questions asked of witnesses, interrogation methods used, witness lineup procedures), and the rate of prosecutions and convictions. Investigative utility is a multifaceted construct that can - and should - be mined for its wealth of underlying measures of research interest.

Moreover, although 67 different interviews of the simulated robbery were conducted, I used only eight representative interviews (four in each interview condition) as stimulus materials for the current study. It may be the case that, for example, the four CI witnesses were unusually verbose or that the four SI witnesses were particularly reticent - although this is unlikely given that the interviews represented the mean number of descriptors and median accuracy rate in each interview condition. Future studies would benefit from testing a greater variety of witnesses interviews. The eight representative interviews were also broken down across two confederate perpetrators. Thus, it may also be the case that the confederate perpetrators had distinctive 
characteristics that were elicited by the CI but not by the SI. If so, future studies would benefit from testing the CI's utility across many different confederate perpetrators (with and without distinctive features). ${ }^{25}$

Additionally, the subjective utility task was not made contemporaneously with either of the objective utility tasks. It was only after participants identified suspects and then performed an additional task (assigning investigative resources, i.e., hours, toward further investigating 3-of-the-10 suspects) that participants rated the utility of the various descriptors for the foregoing two tasks. Because descriptor utility was rated after a delay, participants had to remember how they used each descriptor in their prior-performed tasks. This delay may have caused decisions to be distorted. This potential limitation is coupled by participants' apparent misunderstanding of the subjective utility task (as evidenced by their ratings of uninformative descriptors such as "age" and "gender"). Future research would benefit from assessing subjective utility concurrent with the performance of each investigative task, and including a manipulation check to ensure that participants follow the subjective utility rating instructions.

Finally, due to timing constraints, neither student nor police participants were thoroughly debriefed after participating in the study. Thus, participants' reasoning for their subjective utility ratings (and opinions regarding the ease or difficulty of the task) is unclear. As to police participants, the study would have benefited from debriefing

\footnotetext{
${ }^{25}$ Moreover, as noted in the Experiment 1 Method section, there was a mismatch between the number of representative male/female perpetrator descriptions used in the SI and CI condition. This mismatch occurred due to logistical constraints, which limited the number of representative descriptions that could be incorporated practically into the current study. Given the limited number of representative perpetrator descriptions, it was impossible to match on all possible differences, so I matched on the properties that were most likely to be integral to the analyses. Specifically, it was more important to measure representativeness in terms of mean quantity and median accuracy scores (which have been shown to make a difference in terms of objective utility) than to equate SI and CI interviews in terms of male vs. female perpetrator (for which no main effects were found in the current study).
} 
procedures designed to determine the best ways to (a) motivate police officers to use their real-world skills in the experimental task; and (b) make the experimental procedure more relevant to police investigators (e.g., in terms of the descriptor lists used, the way the descriptor lists are presented, the photo arrays, etc.). For example, certain crimes may be more "motivating" to police than others, or the layout or foils selected in a photo array may require tweaking based on standard police procedure. Future studies would benefit from implementing these debriefing procedures in order to properly refine experimental methods and add to the ecological validity of witness interviewing and investigative utility research.

The current study was the first to establish the CI's utility in a police investigation - both in terms of identifying the perpetrator as a suspect and allocating police resources toward pursuing the perpetrator. But, as with any novel research, the current study's findings lead to more questions than answers. For instance, does conducting the CI early in a police investigation increase the quality of a police report, or the quality of witness testimony in court? If so, does this lead to any other downstream effects (e.g., indictment and/or conviction rates)? The next empirical step is to determine just how far the Cl's utility extends through the criminal justice system. 


\section{REFERENCES}

Anderson, J. R. (1974). Retrieval of propositional information from long-term memory. Cognitive psychology, 6(4), 451-474. doi: 10.1016/0010-0285(74)90021-8

Ask, K., \& Granhag, P. A. (2007). Motivational Bias in Criminal Investigators' Judgments of Witness Reliability1. Journal of Applied Social Psychology, 37(3), 561-591. doi: 10.1111/j.1559-1816.2007.00175.x

Bartlett, F. C. (1932). Remembering: An experimental and social study. Cambridge: Cambridge University.

Baddeley, A. (1986). Oxford psychology series, No. 11. Working memory.

Bogaard, G., Meijer, E. H., \& Vrij, A. (2014). Using an example statement increases information but does not increase accuracy of CBCA, RM, and SCAN. Journal of Investigative Psychology and Offender Profiling, 11(2), 151-163. doi: 10.1002/jip.1409

Brandt, M. J., IJzerman, H., Dijksterhuis, A., Farach, F. J., Geller, J., Giner-Sorolla, R., ... \& Van't Veer, A. (2014). The replication recipe: What makes for a convincing replication? Journal of Experimental Social Psychology, 50, 217-224. doi: 0.1016/j.jesp.2013.10.005

Bransford, J. D., \& Franks, J. J. (1971). The abstraction of linguistic ideas. Cognitive psychology, 2(4), 331-350. doi: 10.1016/0010-0285(71)90019-3

Brewer, N., \& Palmer, M. A. (2010). Eyewitness identification tests. Legal and Criminological Psychology, 15, 77-96. doi:10.1348/135532509X414765

Brown, C., \& Lloyd-Jones, T. J. (2005). Verbal facilitation of face recognition. Memory \& Cognition, 33, 1442-1456. doi:10.3758/bf03193377

Brown, C., \& Lloyd-Jones, T. J. (2006). Beneficial effects of verbalization and visual distinctiveness on remembering and knowing faces. Memory \& Cognition, 34, 277-286. doi:10.3758/BF03193406

Brown, C., Lloyd-Jones, T. J., \& Robinson, M. (2008). Eliciting person descriptions from eyewitnesses: A survey of police perceptions of eyewitness performance and reported use of interview techniques. European Journal of Cognitive Psychology, 20(3), 529-560. doi: 10.1080/09541440701728474

Carlson, C. A., Gronlund, S. D., \& Clark, S. E. (2008). Lineup composition, suspect position, and the sequential lineup advantage. Journal of Experimental Psychology: Applied, 14(2), 118. doi:10.1037/1076-898X 
Charman, S. D., Kavetski, M., \& Mueller, D. H. (2017). Cognitive Bias in the Legal System: Police Officers Evaluate Ambiguous Evidence in a Belief-Consistent Manner. Journal of Applied Research in Memory and Cognition. doi:

10.1016/j.jarmac.2017.02.001

Charman, S., \& Wells, G. L. (2007). Applied lineup theory. In Lindsay, R. C. L, Ross, D. F., Read, J, D., \& Toglia, M. P. (Eds.) Handbook Of Eyewitness Psychology (pp. 219-254). Retrieved from http://www.researchgate.net/profile/Steve_Charman/publication/232501631_Ap plied_lineup_theory/links/09e41511400784d6a0000000.pdf

Clark, S. E. (2012). Costs and benefits of eyewitness identification reform psychological science and public policy. Perspectives on Psychological Science, 7(3), 238-259. doi:10.1177/1745691612439584

Clifford, B. R., \& George, R. (1996). A field evaluation of training in three methods of witness/victim investigative interviewing. Psychology Crime and Law, 2, 231248. doi:10.1080/10683169608409780.

Colomb, C., Ginet, M., Wright, D., Demarchi, S., \& Sadler, C. (2013). Back to the real: Efficacy and perception of a modified cognitive interview in the field. Applied Cognitive Psychology, 27(5), 574-583. doi: 10.1002/acp.2942

Cutler, B. L., \& Fisher, R. P. (1990). Live lineups, videotaped lineups, and photoarrays. Forensic Reports.

Cutler, B. L., Penrod, S. D., \& Stuve, T. E. (1988). Juror decision making in eyewitness identification cases. Law and Human Behavior, 12(1), 41-55. doi: 10.1007/BF01064273

Dando, C. J., Wilcock, R., Behnkle, C., \& Milne, R. (2011). Modifying the cognitive interview: Countenancing forensic application by enhancing practicability. Psychology, Crime \& Law, 17(6), 491-511. doi: 10.1080/10683160903334212

Dando, C., Wilcock, R., Milne, R., \& Henry, L. (2009). A modified cognitive interview procedure for frontline police investigators. Applied Cognitive Psychology, 23(5), 698-716. doi: 10.1002/acp.1501

Darvish, T., Hershkowitz, I., Lamb, M. E., \& Orbach, Y. (2005). The production of investigative leads in child sexual abuse interviews using the NICHD protocol. Society for Applied Research on Memory and Cognition.

Darvish, T., Hershkowitz, I., Lamb, M. E., \& Orbach, Y. (2008). The effect of the NICHD interview protocol on the elicitation of investigative leads in child sexual 
abuse investigations. In conference of the American Psychology and Law Society (AP-LS), Jacksonville, FL.

Dassonville, P., Lewis, S. M., Foster, H. E., \& Ashe, J. (1999). Choice and stimulusresponse compatibility affect duration of response selection. Cognitive Brain Research, 7(3), 235-240. doi: 10.1016/S0926-6410(98)00027-5

Davis, M. R., McMahon, M., \& Greenwood, K. M. (2005). The efficacy of mnemonic components of the cognitive interview: towards a shortened variant for timecritical investigations. Applied Cognitive Psychology, 19(1), 75-93. doi: 10.1002/acp. 1048

Diamond, R., \& Carey, S. (1986). Why faces are and are not special: an effect of expertise. Journal of Experimental Psychology: General, 115(2), 107. doi: 10.1037/0096-3445.115.2.107

Douglass, A. B., Brewer, N., Semmler, C., Bustamante, L., \& Hiley, A. (2013). The dynamic interaction between eyewitnesses and interviewers: the impact of differences in perspective on memory reports and interviewer behavior. Law and Human Behavior, 37(4), 290. doi: 10.1037/1hb0000034

Dumas, Rafaële, and Benoît Testé. "The influence of criminal facial stereotypes on juridic judgments." Swiss Journal of Psychology 65, no. 4 (2006): 237-244. doi: 10.1024/1421-0185.65.4.237.

Evans, J. R., \& Fisher, R. P. (2011). Eyewitness memory: Balancing the accuracy, precision and quantity of information through metacognitive monitoring and control. Applied Cognitive Psychology, 25(3), 501-508. doi: 10.1002/acp.1722

Ewens, S., Vrij, A., Leal, S., Mann, S., Jo, E., Shaboltas, A., ... \& Houston, K. (2016). Using the Model Statement to Elicit Information and Cues to Deceit from Native Speakers, Non-native Speakers and Those Talking Through an Interpreter. Applied Cognitive Psychology, 30(6), 854-862. doi: 10.1002/acp.3270

Fahsing, I.A., Ask, K., \& Granhag, P.A. (2004). The man behind the mask: accuracy and predictors of eyewitness offender descriptions. Journal of Applied Psychology, 89, 722-729. doi: 10.1037/0021-9010.89.4.722

Farah, M. J. (2000). The cognitive neuroscience of vision. Blackwell Publishing.

Farah, M. J., Wilson, K. D., Drain, M., \& Tanaka, J. N. (1998). What is" special" about face perception? Psychological review, 105(3), 482. doi: 10.1.1.117.4804

Findley, K. A., \& Scott, M. S. (2006). Multiple Dimensions of Tunnel Vision in Criminal Cases, The. Wis. L. Rev., 291. Retrieved from https://www.researchgate.net/profile/Keith_Findley/publication/228135783_The 
_Multiple_Dimensions_of_Tunnel_Vision_in_Criminal_Cases/links/54a08ef50c f267bdb90167d8.pdf

Finger, K., \& Pezdek, K. (1999). The effect of cognitive interview on face identification accuracy: Release from verbal overshadowing. Journal of Applied Psychology, 84(3), 340. doi: 10.1037/0021-9010.84.3.340

Fisher, R. P. (1995). Interviewing victims and witnesses of crime. Psychology, Public Policy and Law, 1, 732-764. doi:10.1037/1076-8971.1.4.732

Fisher, R. P. (2010). Interviewing cooperative witnesses. Legal and Criminological Psychology, 15, 25-38. doi:10.1348/135532509X441891

Fisher, R. P., \& Geiselman, R. E. (1992). Memory-enhancing techniques for investigative interviewing: The cognitive interview. Charles $\mathrm{C}$ Thomas, Publisher.

Fisher, R. P., Geiselman, R. E., \& Amador, M. (1989). Field test of the cognitive interview: Enhancing the recollection of actual victims and witnesses of crime. Journal of Applied Psychology, 74,(5), 722-727. doi:10.1037/00219010.74.5.722

Fisher, R. P., Geiselman, R. E., \& Raymond, D. S. (1987). Critical analysis of police interview techniques. Journal of Police Science and Administration, 15, 291297.

Fisher, R. P., Geiselman, R. E., Raymond, D. S., \& Jurkevich, L. M. (1987). Enhancing enhanced eyewitness memory: Refining the cognitive interview. Journal of Police Science \& Administration.

Fisher, R. P., Quigley, K. L., Brock, P., Chin, E., \& Cutler, B. L. (1990). The effectiveness of the cognitive interview in description and identification tasks. Paper presented at the American Psychology- Law Society, Williamsburg, VA.

Fisher, R. P., Schreiber Compo, N., Rivard, J., \& Hirn, D. (2014). Interviewing witnesses. The Sage Handbook of Applied Memory. Sage Publications, Los Angeles, 559-578.

Fitts, P. M., \& Deininger, R. L. (1954). SR compatibility: correspondence among paired elements within stimulus and response codes. Journal of experimental psychology, 48(6), 483. doi: 10.1016/S0926-6410(98)00027-510.1037/h0054967

Fitts, P. M., \& Seeger, C. M. (1953). SR compatibility: spatial characteristics of stimulus and response codes. Journal of experimental psychology, 46(3), 199. doi: $10.1037 / \mathrm{h} 0062827$ 
Gabbert, F., \& Brown, C. (2015). Interviewing for face identification. Forensic Facial Identification: Theory and Practice of Identification from Eyewitnesses, Composites and CCTV (pp. 15-41). doi: 10.1002/9781118469538.ch2

Geiselman, R. E., \& Fisher, R. P. (2014). Interviewing witnesses and victims. In M. St.Yves (Ed.) Investigative Interviewing: The Essentials. (pp. 29-62). Carswell: Toronto.

Geiselman, R. E., Fisher, R. P., Firstenberg, I., Hutton, L. A., Sullivan, S. Avetissian, I., $\&$ Prosk, A. (1984). Enhancement of eyewitness memory: An empirical evaluation of the cognitive interview. Journal of Police Science and Administration, 12, 74-80.

George, R., \& Clifford, B. R. (1992). Making the most of witnesses. Policing, 8(3), 185198.

Gilbert, J. A., \& Fisher, R. P. (2006). The effects of varied retrieval cues on reminiscence in eyewitness memory. Applied Cognitive Psychology, 20(6), 723-739. doi: $10.1002 /$ acp. 1232

Goldstein, D. G., \& Gigerenzer, G. (2002). Models of ecological rationality: the recognition heuristic. Psychological review, 109(1), 75. doi: 10.1037/0033295X.109.1.75

Granhag, P. A., Ask, K., Rebelius, A., Öhman, L., \& Mac Giolla, E. (2013). 'I saw the man who killed Anna Lindh!'An archival study of witnesses' offender descriptions. Psychology, Crime \& Law, 19(10), 921-931. doi: 10.1080/1068316X.2012.719620

Greenwald, A. G. (1970). Sensory feedback mechanisms in performance control: with special reference to the ideo-motor mechanism. Psychological review, 77(2), 73. doi: $10.1037 / \mathrm{h} 0028689$

Gronlund, S. D., Wixted, J. T., \& Mickes, L. (2014). Evaluating eyewitness identification procedures using receiver operating characteristic analysis. Current Directions in Psychological Science, 23(1), 3-10. doi:10.1177/0963721413498891

Gwyer, P., \& Clifford, B. R. (1997). The effects of the cognitive interview on recall, identification, confidence and the confidence/accuracy relationship. Applied Cognitive Psychology, 11, 121-145. doi:10.1002/(SICI)1099-0720(199704)11:2

Hilgard, E. R., \& Loftus, E. F. (1979). Effective interrogation of the eyewitness. The International journal of clinical and experimental hypnosis, 27(4), 342-357. 
Hirn, D. E., Fisher, R. P., \& Carol, R. (2012, March). Use of a hybrid interview method to retrieve memories created during decision making. Paper presented at the meeting of the American Psychology-Law Society, San Juan, PR.

Holliday, R. E., Brainerd, C. J., Reyna, V. F., \& Humphries, J. E. (2009). The cognitive interview: Research and practice across the lifespan. R. Bull, T. Valentine, \& T. Williamson (Eds.), Handbook of the psychology of investigative interviewing: Current developments and future directions, 137-160.

Holliday, R. E., Humphries, J. E., Milne, R., Memon, A., Houlder, L., Lyons, A., \& Bull, R. (2012). Reducing misinformation effects in older adults with cognitive interview mnemonics. Psychology and Aging, 27(4), 1191. doi: 0.1037/a0022031

Home Office (2011). Police and Criminal Evidence Act (1984). Retrieved from https://www.gov.uk/search?q=Police+and+Criminal+Evidence+Act +

Kahneman, D. (1973). Attention and effort (p. 246). Englewood Cliffs, NJ: Prentice-Hall. Retrieved from http://citeseerx.ist.psu.edu/viewdoc/download?doi=10.1.1.398.5285\&rep=rep1\&t ype $=$ pdf

Kebbell, M. R., \& Milne, R. (1998). Police officers' perceptions of eyewitness performance in forensic investigations. The Journal of Social Psychology, 138(3), 323-330. doi: 10.1080/00224549809600384

Kebbell, M. R., Milne, R., \& Wagstaff, G. F. (1999). The cognitive interview: A survey of its forensic effectiveness. Psychology, crime and law, 5(1-2), 101-115. doi: $10.1080 / 10683169908414996$

Köhnken, G., Milne, R., Memon, A., \& Bull, R. (1999). A meta-analysis on the effects of the cognitive interview. Psychology, Crime and Law, 5, 3-27.

Koriat, A., \& Goldsmith, M. (1994). Memory in naturalistic and laboratory contexts: Distinguishing the accuracy-oriented and quantity-oriented approaches to memory assessment. Journal of Experimental Psychology: General, 123(3), 297. doi: 10.1037/0096-3445.123.3.297

Koriat, A., \& Goldsmith, M. (1996). Monitoring and control processes in the strategic regulation of memory accuracy. Psychological Review, 103(3), 490. doi: 10.1037/0033-295X.103.3.490

Kornblum, S., Hasbroucq, T., \& Osman, A. (1990). Dimensional overlap: cognitive basis for stimulus-response compatibility--a model and taxonomy. Psychological review, 97(2), 253. doi: 10.1037/0033-295X.97.2.253 
Lane, S. M., \& Meissner, C. A. (2008). A 'middle road' approach to bridging the basicapplied divide in eyewitness identification research. Applied Cognitive Psychology, 22(6), 779-787. doi: 10.1002/acp.1482

Leal, S., Vrij, A., Warmelink, L., Vernham, Z., \& Fisher, R. P. (2015). You cannot hide your telephone lies: Providing a model statement as an aid to detect deception in insurance telephone calls. Legal and Criminological Psychology, 20(1), 129-146. doi: $10.1111 / 1 \mathrm{crp} .12017$

Leibowitz, H. W., Guzy, L. T., Peterson, E., \& Blake, P. T. (1993). Quantitative perceptual estimates: Verbal versus nonverbal retrieval techniques. Perception, 22(9), 1051-1060. doi: 10.1068/p221051

Leins, D. A., Fisher, R. P., Pludwinski, L., Rivard, J., \& Robertson, B. (2014). Interview protocols to facilitate human intelligence sources' recollections of meetings. Applied Cognitive Psychology, 28(6), 926-935.

Lindsay, R. C. L. (1994). Biased lineups: Where do they come from? In D. Ross, J. D. Read, \& M. P. Toglia (Eds.), Adult eyewitness testimony: Current trends and developments (pp. 182-200). New York: Cambridge University Press.

Lindsay, R. C. L., Mansour, J. K., Beaudry, J. L., Leach, A. M., \& Bertrand, M. I. (2009). Sequential lineup presentation: Patterns and policy. Legal and Criminological Psychology, 14(1), 13-24. doi:10.1348/135532508X382708

Loftus, E. F., Miller, D. G., \& Burns, H. J. (1978). Semantic integration of verbal information into a visual memory. Journal of experimental psychology: Human learning and memory, 4(1), 19. doi: 10.1037/0278-7393.4.1.19

Loftus, E. F., \& Palmer, J. C. (1974). Reconstruction of automobile destruction: An example of the interaction between language and memory. Journal of verbal learning and verbal behavior, 13(5), 585-589. doi: 10.1016/S00225371(74)80011-3

Luus, C. A., \& Wells, G. L. (1991). Eyewitness identification and the selection of distracters for lineups. Law and Human Behavior, 15(1), 43. doi: 10.1007/BF01044829

Macrae, C. N., \& Shepherd, J. W. (1989). Do criminal stereotypes mediate juridic judgements? British Journal of Social Psychology, 28(2), 189-191. doi: 10.1111/j.2044-8309.1989.tb00860.x

Malpass, R. S. (2006). A policy evaluation of simultaneous and sequential lineups. Psychology, Public Policy, and Law, 12(4), 394. doi:10.1037/10768971.12.4.394 
McCloskey, M., \& Zaragoza, M. (1985). Misleading postevent information and memory for events: Arguments and evidence against memory impairment hypotheses. Journal of Experimental Psychology: General, 114(1), 1. doi: 10.1037/00963445.114.1.1

McKone, E., Martini, P., \& Nakayama, K. (2003). Isolating holistic processing in faces (and perhaps objects). Perception of faces, objects, and scenes: Analytic and holistic processes, 92-119.

Meissner, C.A. (2002). Applied aspects of the instructional bias effect in verbal overshadowing. Applied Cognitive Psychology, 16, 911-928. doi: 10.1002/acp.918

Meissner, C. A., \& Brigham, J. C. (2001). A meta-analysis of the verbal overshadowing effect in face identification. Applied Cognitive Psychology, 15(6), 603-616. doi: 10.1002/acp. 728

Meissner, C. A., \& Kassin, S. M. (2002). " He's guilty!": investigator bias in judgments of truth and deception. Law and Human Behavior, 26(5), 469. doi: 10.1023/A:1020278620751

Meissner, C. A., Sporer, S. L., \& Susa, K. J. (2008). A theoretical review and metaanalysis of the description-identification relationship in memory for faces. European Journal of Cognitive Psychology, 20(3), 414-455. doi: $10.1080 / 09541440701728581$

Memon, A., Holley, A., Milne, R., Koehnken, G., \& Bull, R. (1994). Towards understanding the effects of interviewer training in evaluating the cognitive interview. Applied Cognitive Psychology, 8(7), 641-659. doi: 10.1002/acp.2350080704

Memon, A., Meissner, C. A., \& Fraser, J. (2010). The Cognitive Interview: A metaanalytic review and study space analysis of the past 25 years. Psychology, Public Policy, and Law, 16(4), 340. doi:10.1037/a0020518

Memon, A., Wark, L., Holley, A., Bull, R., \& Koehnken, G. (1997). Eyewitness performance in cognitive and structured interviews. Memory, 5(5), 639-656. doi: $10.1080 / 741941481$

Mickes, L. (2016). The Effects of Verbal Descriptions on Eyewitness Memory: Implications for the Real-World. Journal of Applied Research in Memory and Cognition, 5(3), 270-276. doi: 10.1016/j.jarmac.2016.07.003 
Milne, R., \& Bull, R. (2003). Does the cognitive interview help children to resist the effects of suggestive questioning?. Legal and Criminological Psychology, 8(1), 21-38. doi: 10.1348/135532503762871219

Munsterberg, H. (1899). Psychology and history. Psychological Review, 6(1), 1.

Navon, D. (1992). Selection of lineup foils by similarity to the suspect is likely to misfire. Law and Human Behavior, 16(5), 575. doi: 10.1007/BF01044624

Neuschatz, J. S., \& Cutler, B. L. (2008). Eyewitness identification. In H. L. Roediger III (Ed.), Learning and memory: A comprehensive reference: Vol. 2. Cognitive Psychology of Memory (pp. 845-865). Oxford: Elsevier.

Nisbett, R. E., Zukier, H., \& Lemley, R. E. (1981). The dilution effect: Nondiagnostic information weakens the implications of diagnostic information. Cognitive Psychology, 13(2), 248-277. doi: 10.1016/0010-0285(81)90010-4

O'Brien, B. (2009). Prime suspect: An examination of factors that aggravate and counteract confirmation bias in criminal investigations. Psychology, Public Policy, and Law, 15(4), 315. doi: 10.1037/a0017881

O’Brien, B., \& Findley, K. (2015). Psychological perspectives: Cognition and decision making. In Redlich, A. D. (2014). Examining wrongful convictions: Stepping back, moving forward (pp. 35-53). Durham, NC: Carolina Academic Press.

Oeberst, A. (2012). If anything else comes to mind... better keep it to yourself? Delayed recall is discrediting - unjustifiably. Law and human behavior, 36(4), 266. doi: $10.1037 / \mathrm{h} 0093966$

Orbach, Y., Hershkowitz, I., Lamb, M. E., Sternberg, K. J., Esplin, P. W., \& Horowitz, D. (2000). Assessing the value of structured protocols for forensic interviews of alleged child abuse victims. Child abuse \& neglect, 24(6), 733-752. doi: 10.1016/S0145-2134(00)00137-X

Packer, H. L. (1964). Two models of the criminal process. University of Pennsylvania Law Review, 113(1), 1-68. doi: 10.2307/3310562

Park, K. B., Lee, H., \& Lee, S. (1996). Monotonous social environments and the identification of crime suspects: A comparison of police cadets and civilian college students. Psychological reports, 79(2), 647-654. doi:

10.2466/pr0.1996.79.2.647

Pashler, H. (1984). Processing stages in overlapping tasks: evidence for a central bottleneck. Journal of Experimental Psychology: Human Perception and Performance, 10(3), 358. doi: 10.1037/0096-1523.10.3.358 
Perfect, T. J., Wagstaff, G. F., Moore, D., Andrews, B., Cleveland, V., Newcombe, S., ... $\&$ Brown, L. (2008). How can we help witnesses to remember more? It's an (eyes) open and shut case. Law and Human Behavior, 32(4), 314-324. doi: 10.1007/s10979-007-9109-5

Pipe, M. E., Orbach, Y., Lamb, M., Abbott, C. B., \& Stewart, H. (2008). Do best practice interviews with child abuse victims influence case processing. Unpublished report, US Department of Justice. Retrieved via https://www.ncjrs.gov/App/Publications/abstract.aspx?ID=246490

Pryke, S., Lindsay, R. C. L., Dysart, J. E., \& Dupuis, P. (2004). Multiple independent identification decisions: A method of calibrating eyewitness identifications. Journal of Applied Psychology, 89(1), 73. doi: 10.1037/0021-9010.89.1.73

Roberts, K. P., Lamb, M. E., \& Sternberg, K. J. (2004). The effects of rapport-building style on children's reports of a staged event. Applied Cognitive Psychology, 18(2), 189-202. doi: 10.1002/acp.957

Satin, G. E., \& Fisher, R.P. (2017). Eliciting Perpetrator-Related Information Using the Cognitive Interview. Manuscript in preparation.

Schooler, J. W. (2002). Verbalization produces a transfer inappropriate processing shift. Applied Cognitive Psychology, 16(8), 989-997. doi: 10.1002/acp.930

Schooler, J. W., \& Engstler-Schooler, T. Y. (1990). Verbal overshadowing of visual memories: Some things are better left unsaid. Cognitive Psychology, 22, 36-71. doi:10.1016/0010-0285(90)90003-M

Schreiber Compo, N., Hyman Gregory, A., \& Fisher, R. (2012). Interviewing behaviors in police investigators: A field study of a current US sample. Psychology, Crime \& Law, 18(4), 359-375. doi: 10.1080/1068316X.2010.494604

Shoemaker, D. J., South, D. R., \& Lowe, J. (1973). Facial Stereotypes of Deviants and Judgments of Guilt or Innocence. Social Forces, 51(4), 427-433. doi: $10.2307 / 2576687$

Sporer, S. L. (1992). I saw the man-but what did he look like? Person descriptions in an archival analysis of criminal cases. Paper presented at the Biennial Meeting of the American Psychology-Law Society, San Diego, CA.

Sporer, S.L. (1992). Postdicting eyewitness identification accuracy: Confidence, decision times and person descriptions among choosers and nonchoosers. European Journal of Social Psychology, 22, 157-180. doi: 10.1002/ejsp.2420220205 
Sporer, S. L. (1996). Psychological aspects of person descriptions. In Sporer, S. L., Malpass, R. S., \& Koehnken, G. (Eds.), Psychological Issues in Eyewitness Identification (pp. 53-86). Mahwah, NJ: Lawrence Erlbaum Associates. Retrieved from https://www.researchgate.net/profile/Siegfried_Sporer/publication/232450981_P sychological_aspects_of_person_descriptions//inks/560c26db08ae73e7a6a2d $\bar{d} 52$ .pdf

Sporer, S. L. (2007). Person descriptions as retrieval cues: Do they really help?. Psychology, Crime \& Law, 13(6), 591-609. doi: 10.1080/10683160701253986

Sporer, S. L., Kaminski, K. S., Davids, M. C., \& McQuiston, D. (2016). The verbal facilitation effect: re-reading person descriptions as a system variable to improve identification performance. Memory, 24(10), 1329-1344. doi: 10.1080/09658211.2015.1106561

Steblay, N. K., Dysart, J. E., \& Wells, G. L. (2011). Seventy-two tests of the sequential lineup superiority effect: A meta-analysis and policy discussion. Psychology, Public Policy, and Law, 17(1), 99. doi:10.1037/a0021650

Stephan, D. N., \& Koch, I. (2016). Modality-specific effects on crosstalk in task switching: Evidence from modality compatibility using bimodal stimulation. Psychological research, 80(6), 935-943. doi: 10.1007/s00426-015-0700-y

Tanaka, J. W., \& Farah, M. J. (1993). Parts and wholes in face recognition. The Quarterly Journal of Experimental Psychology, 46(2), 225-245. doi: $10.1080 / 14640749308401045$

Troutman, C. M., \& Shanteau, J. (1977). Inferences based on nondiagnostic information. Organizational Behavior and Human Performance, 19(1), 43-55. doi: 10.1016/0030-5073(77)90053-8

Tulving, E., \& Thomson, D. M. (1973). Encoding specificity and retrieval processes in episodic memory. Psychological review, 80(5), 352. doi: 10.1037/h0020071

Valentine, T. (1988). Upside-down faces: A review of the effect of inversion upon face recognition. British Journal of Psychology, 79(4), 471-491. doi: 10.1111/j.20448295.1988.tb02747.x

Valentine, T., Pickering, A., \& Darling, S. (2003). Characteristics of eyewitness identification that predict the outcome of real lineups. Applied Cognitive Psychology, 17(8), 969-993. doi: 10.1002/acp.939

Vallano, J. P., \& Compo, N. S. (2011). A comfortable witness is a good witness: Rapport-building and susceptibility to misinformation in an investigative mock- 
crime interview. Applied Cognitive Psychology, 25(6), 960-970. doi: 0.1002/acp. 1789

Van Koppen, P. J., \& Lochun, S. K. (1997). Portraying perpetrators: The validity of offender descriptions by witnesses. Law and Human Behavior, 21(6), 661. doi: 10.1023/A:1024812831576

Vanootighem, V., Brédart, S., \& Dehon, H. (2016, July). The verbal overshadowing effect in children and adults is unrelated to the specific content of descriptions. Poster session presented at the 6th International Conference on Memory, ICOM6, Budapest, Hungary.

Vredeveldt, A., Hitch, G. J., \& Baddeley, A. D. (2011). Eyeclosure helps memory by reducing cognitive load and enhancing visualisation. Memory \& cognition, 39(7), 1253-1263. doi: 10.3758/s13421-011-0098-8

Vrij, A., Akehurst, L., Brown, L., \& Mann, S. (2006). Detecting lies in young children, adolescents and adults. Applied Cognitive Psychology, 20(9), 1225-1237. doi: 10.1002/acp. 1278

Wells, G. L. (1985). Verbal descriptions of faces from memory: Are they diagnostic of identification accuracy? Journal of Applied Psychology, 70(4), 619. doi: $10.1037 / 0021-9010.70 .4 .619$

Wells, G. L., \& Olson, E. A. (2002). Eyewitness identification: information gain from incriminating and exonerating behaviors. Journal of Experimental Psychology: Applied, 8(3), 155. doi:10.1037/1076-898X.8.3.155

Wells, G. L., Rydell, S. M., \& Seelau, E. P. (1993). The selection of distractors for eyewitness lineups. Journal of Applied Psychology, 78(5), 835. doi: $10.1037 / 0021-9010.78 .5 .835$

Wells, G. L., Yang, Y., \& Smalarz, L. (2015). Eyewitness identification: Bayesian information gain, base-rate effect equivalency curves, and reasonable suspicion. Law and human behavior, 39(2), 99. doi: 10.1037/lhb0000125

Wogalter, M. S. (1991, September). Effects of post-exposure description and imaging on subsequent face recognition performance. In Proceedings of the Human Factors and Ergonomics Society Annual Meeting (Vol. 35, No. 9, pp. 575-579). SAGE Publications. Retrieved from http://www.safetyhumanfactors.org/wpcontent/uploads/2011/12/36Wogalter1991.pdf

Wogalter, M. S. (1996, October). Describing faces from memory: Accuracy and effects on subsequent recognition performance. In Proceedings of the Human Factors 
and Ergonomics Society Annual Meeting (Vol. 40, No. 11, pp. 536-540). SAGE Publications.

Wright, A. M., \& Alison, L. (2004). Questioning sequences in Canadian police interviews: Constructing and confirming the course of events? Psychology, Crime and Law, 10(2), 137-154. doi:10.1080/1068316031000099120

Yin, R. K. (1969). Looking at upside-down faces. Journal of Experimental Psychology, 81(1), 141. doi: $10.1037 / \mathrm{h} 0027474$

Zimmerman, L.A. (2003). Effects of stress on police and citizen eyewitness recall. The Canadian Journal of Police and Security Services, 1, 377-380. 


\section{APPENDIX A}

Satin \& Fisher (2017) Method

\section{Overview and Participants}

A total of 67 students enrolled in introductory psychology courses at FIU participated in the study in exchange for extra credit. The student participants witnessed a staged, simulated robbery, were randomly assigned to an interview condition (CI or SI), and were interviewed about their recollection of the robber.

\section{Materials}

Research assistants were provided with (1) an SI Interview Checklist; and (2) a CI Summary Sheet as part of their interview training. These handouts were used as a reference during training, and subsequently used during interviews to ensure that each component of the SI or CI (depending on condition) was completely and uniformly covered by the interviewer.

The SI Interview Checklist was created to mirror interviewing practices commonly followed by police investigators (Schreiber Compo et al., 2012) and supported by basic research (Geiselman, Fisher, Firstenberg, Hutton, Sullivan, Avetissian, \& Prosk, 1984; Hilgard \& Loftus, 1979). The experimenters also confirmed the representativeness of the SI Interview Checklist with several active-duty police officers and detectives who consulted on this research project. The SI Interview Checklist consisted of (a) building rapport; (b) explaining the purpose of the interview; (c) an initial open-ended free narrative; and (d) targeted follow-up questions on 13 categories of person descriptors (e.g., skin tone, hair color, hair style, build, markings/scars/tattoos). (See Appendix F for the complete SI Interview Checklist.) 
The CI Summary Sheet outlined a version of the CI modified to elicit only person descriptors. Specifically, the modified CI used in this study consisted of the elements of the SI, as well as (a) establishing social dynamics; (b) instructing the witness not to guess and report everything/provide detailed responses; (c) a 30-40 second example of an “ideal" response (in which the interviewer described an animal's face); (d) multiple and varied retrieval; (e) context reinstatement and eye closure; and (f) targeted follow-up questions on 19 categories of person descriptors, (e.g., hair, with subcategories for color, length, style, hairline, and texture; non-physical descriptors, i.e., mannerisms and demeanor) including code compatible facial shape, body shape, skin tone, and eyebrow charts, used when appropriate. (See Appendix G for the complete CI Summary Sheet.)

\section{Procedure}

Interview Training. Three research assistants received CI and SI interview training. The CI interview training consisted of one four-hour session, which included providing research assistants with the CI Summary Sheet, a lecture describing various components of the procedure, demonstrations of good and poor interviewing techniques, practice interviews and individual feedback on the quality of the interviews. After the training, the research assistants conducted and audio-recorded three practice CI interviews with friends or family, which the experimenters subsequently reviewed and provided feedback thereon. All research assistants fully adhered to the CI Summary Sheet by their third practice interview. After the training, the research assistants were instructed to use the CI Summary Sheet as a reference throughout the interviews, and to make sure each component listed on the CI was covered during each interview. 
The SI interview training consisted of one two-hour session, which included providing research assistants with the SI Interview Checklist, a lecture describing various components of the procedure, practice interviews and individual feedback on the quality of the interviews. After the training, the research assistants conducted and audiorecorded three practice SI interviews with friends or family, which the experimenters subsequently reviewed and provided feedback thereon. All research assistants fully adhered to the SI Interview Checklist by their third practice interview. After the training, the research assistants were instructed to use the SI Interview Checklist as a reference throughout the interview, and to make sure each component of the SI was covered during each interview.

Staged Event and Eyewitness Interviews. Participants were recruited via FIU's online research participant SONA system. Each participant scheduled a two-hour appointment at the cognitive psychology laboratory. On the day of the appointment, a confederate perpetrator posing as an experimenter greeted the participant. Two confederate-perpetrators individually appeared throughout the experiment with equal frequency to test for generalization across targets. The confederate perpetrator then led the participant into a laboratory conference room, consented the participant, and asked the participant to complete a demographic questionnaire.

Next, the confederate perpetrator explained to the participant that $\mathrm{s} / \mathrm{he}$ would be taking part in a marketing study designed to test student preferences regarding FIU's current and proposed school logos. The confederate perpetrator then read the participant a brief history of FIU, the vision and mission of FIU, and some rankings and facts about FIU. Next, the confederate perpetrator engaged in a brief question-and-answer session 
with the participant, in which the participant was asked (1) to describe in three words what FIU means or represents to the participant, and (2) to describe the participant's most memorable experience at FIU.

Following the question-and-answer session, the confederate perpetrator explained to the participant, "You will be filling out one more questionnaire, and then you will receive credit for your participation today. While you are doing so, I have to return this lockbox to the lab manager as it is the property of FIU." While instructing the witness, the confederate perpetrator pointed to a lockbox on a desk at the front of the room containing an oversized, highlighted sign on it that read Laboratory Money $(\$ 5,000)$. The confederate perpetrator then handed the participant a marketing questionnaire regarding FIU's logo designs. Subsequently, the confederate perpetrator stated, "I will be right back," and exited the room with the lockbox. When the confederate perpetrator had been absent for three minutes, a research assistant entered the room, inquired about the missing lockbox, expressed concern that it had been stolen, and asked the participant to be interviewed about the incident since s/he was the only witness to the crime.

The staged event was highly scripted (with the interaction between the confederate perpetrator and each participant lasting approximately 5 minutes). Prior to the staged event, the two confederate perpetrators jointly participated in two one-hour training sessions, in which the script was explained by the experimenters and rehearsed by each confederate perpetrator multiple times. During the second training session, the confederate perpetrators were also instructed to dress and appear exactly the same (including hair styles, facial hair, accessories, nail polish color, etc.) for each staged 
event. Additionally, pictures of the confederate perpetrators' staged event attire and appearance were taken for use in accuracy coding.

After the participant agreed to be interviewed, the participant was randomly assigned to either a CI or SI interview condition, escorted into an interview room, and interviewed by the research assistant about the perpetrator. All interviews took place in private plain rooms with two chairs, a desk or table with two blank note pads and spare pens/pencils. The research assistant and participant were seated directly across from one another. Interviews were recorded on Olympus VN-702PC digital audio recorders placed on the desk between the research assistant and participant. All interviews were limited in scope to a description of the perpetrator. Following the interview, the participant was debriefed, given course credit, and dismissed. 


\section{APPENDIX B}

\section{Example SI: Grouped}

- The car thief was black and probably from the United States. He didn't have an accent. His skin tone was pretty dark.

- He was maybe 20 to 24 years old.

- He wasn't that tall. He was maybe 5'10" or 5'9" in height.

- He was pretty thin. He weighed 160 pounds.

- He did not have any markings, scars, tattoos or piercings.

- He had short, black hair that was styled pretty casually. I don't think he had too much hair.

- He had brown or black-brown eyes, I think.

- He had a beard.

- He wore glasses.

- He was kind of nice and friendly.

- He was wearing a red t-shirt. 


\section{APPENDIX C}

\section{Example CI: Grouped}

- The car thief was a black male. His skin tone was not white, but he wasn't black either. He was light-skinned, in the middle. His skin tone was kind of dark, but he wasn't black - he was kind of tan. His skin tone was lighter than average.

- He was young - in his 20 s.

- He was normal height. He wasn't really short or really tall. His height was around $5^{\prime} 5^{\prime \prime}$ ' or $5^{\prime} 7^{\prime \prime}$ ' to like 6' 1 ', or 6'2',

- He was not skinny, and was not buff or like really like strong either. He was just like normal. He was normal weight for his height. He wasn't obese. His body shape was slightly broader in the shoulders than in the hips.

- He did not have any markings, scars, tattoos, or piercings.

- He reminded me of the Childish Gambino, who is a rapper, because his face looked like him, and his hairstyle and stuff. He looks exactly like the Childish Gambino actually.

- His face was kind of roundish. It wasn't like an oval head person - it was more like a round shape. His face shape was oblong, because his face was more circular.

- He had very short hair that wasn't black - it was kind of brownish. His hair wasn't like straight; it was nappy and kind of curly. His hairline had a peak - it wasn't straight.

- He did not have any facial hair.

- He didn't have acne. He was just a normal face - there was nothing that you could tell in terms of the texture of his skin.

- He had a pretty big forehead.

- His most prominent facial features were his nose, his eyes and his mouth, because I was thinking about his teeth.

- What made him unique was his teeth. He had spaces between his teeth. His front teeth had the spaces, not his regular other teeth

- He had big, brown eyes, that were more circular than oval. His eyes were set a little bit farther apart on his face than usual. His eyes were located in the middle of his face.

- He was nice. He was conversational and social. He didn't look like a person who would steal. He did not exhibit any distinctive behaviors or mannerisms. There was nothing about his personality that came through in a physical way.

- He was wearing a burgundy shirt with jeans. 


\section{APPENDIX D}

\section{Example SI: Not Grouped}

- The car thief wasn't that tall

- He was black

- He wore glasses

- He was kind of nice

- He was friendly

- He's probably from the United States

- He didn't have an accent

- His skin tone was pretty dark

- He was maybe $5^{\prime} 10^{\prime \prime}$ or $5^{\prime} 9^{\prime \prime}$ in height

- He weighed 160 pounds

- He was maybe 20 to 24 years old

- His hair color was black

- His hair style was pretty casual

- I don't think he had too much hair

- His hair length was short

- He had brown eyes i think, or black-brown eyes

- He had a beard

- He was wearing a red t-shirt

- He did not have any markings, scars, tattoos or piercings

- He was pretty thin 


\section{APPENDIX E}

\section{Example CI: Not Grouped}

- The car thief was male

- He was wearing a burgundy shirt with jeans

- He was normal height - not tall

- His skin tone was not white, but he wasn't black either

- He was light skinned - in the middle

- He had short hair; very short hair

- His hair wasn't black; it was kind of brownish

- He had spaces between his teeth

- He was not skinny

- He was not buff

- He was not like really like strong either

- He was just like normal

- He was nice

- I think he had brown eyes

- His hair wasn't straight; it was nappy

- His hair was kind of curly

- His hairline had a peak - it wasn't straight

- He wasn't really short or really tall

- His height was around 5'5' or 5'7' to like 6'1' or 6'2'"

- His skin tone was kind of dark

- But he wasn't black - he was kind of tan

- He was young

- He was in his 20s

- His front teeth had the spaces, not his regular other teeth

- His face was kind of roundish

- His face wasn't like an oval head person - it was more like a round face

- He had a pretty big forehead 
- I'm not sure if there were spaces on all of his other teeth

- His most prominent facial features were his nose, his eyes, and his mouth, because I was thinking about his teeth

- What made him unique was his teeth

- He was conversational

- He was social

- He didn't look like a person who would steal

- He did not exhibit any distinctive behaviors or mannerisms

- There was nothing about his personality that came through in a physical way

- He reminded me of the Childish Gambino, who is a rapper, because his face looked like him and his hair style and stuff

- He looks exactly like the Childish Gambino actually

- His race/ethnicity was black

- His skin tone was lighter than average

- He didn't have acne

- He was just a normal face

- There was nothing that you could tell in terms of the texture of his skin

- He was normal weight for his height

- He wasn't obese

- He had big eyes

- His eyes were more circular than oval

- His eyes were set a little bit farther apart on his face than usual

- His eyes were located in the middle of his face

- His face shape was oblong, because his face was more circular

- His body shape was slightly broader in the shoulders than in the hips

- He did not have any facial hair

- He did not have any markings, scars, tattoos, or piercings 


\section{APPENDIX F}

\section{SI Interview Checklist}

\section{Conducting the Standard Interview \\ Checklist}

1. Develop rapport (briefly).

2. Explain that you are going to ask the witness a number of Qs about the thief.

3. Begin with "what did the thief look like?"

4. Ask directed, specific questions to elicit information about the perpetrator's description, including:

- Sex

- Race/Ethnicity

- Skin Tone/Coloring

$\circ$ Height

$\circ$ Weight

- Age

- Hair Color

- Hair Style

- Eye Color

$\circ$ Facial Features

- Build

- Clothing

- Markings/Scars/Tattoos

5. Ask witness if there is anything else the witness can tell you about the thief.

Interviewer Notes \& Instructions:

- Move on to the next Q after the witness stops talking (pause for 1-2 seconds)

- If the witness isn't sure how to answer, tell them to "do whatever you can to answer to the best of your ability."

- If the witness starts guessing, tell them not to guess - but do not offer the "do not guess" instruction unless it is evident that you need to based on the witness's response.

- After the open-ended question, it may be appropriate to reask the same direct Q to ensure that the witness fully answers - unless it is very clear that the witness has already provided you with the response you need (i.e., if the witness already told you 


\section{APPENDIX G}

CI Summary Sheet

\section{Conducting the Cognitive Interview Summary of Steps}

PART I:

1. Develop rapport (briefly).

2. Explain the purpose of the interview - help police officers find and ID perpetrator based on witness's description.

3. Explain Social Dynamics: tell the witness not to wait for the interviewer to ask questions; explain the witness will be doing all the talking; explain power structure ("boss/secretary").

4. Explain that you are going to ask the witness to describe the thief, and that you need the witness to provide an extensive, detailed response.

b. Provide 30-40 second example of the beginning of an "ideal" description but using an animal's face.

c. After providing example, explain that nothing is out of bounds; the witness does not need to be politically correct; "offensive" or nonPC description may be the critical piece of info that leads to finding the thief.

5. Convey that the initial narrative will take approximately 5-10 minutes (more than a few words) because of the level of detail in the description.

6. DO NOT GUESS: Tell the witness to report everything, but not to guess ("Just say, 'I don't know"').

7. Ask an open-ended question about the perpetrator ("Tell me everything you can about the thief.")

8. After the witness has completed the first narrative (and you have paused for at least 5 seconds), follow-up by asking: "Is there anything else you can tell me about the thief?"

9. After the witness had completed the follow-up narrative (and you have paused), ask any additional open-ended questions you have from your notes - ask witness to elaborate on some of the things the witness said in his/her narrative.

Do not interrupt the witness while he/she is narrating.

Make notes to remind yourself to ask follow-up questions after the witness stops speaking.

After the witness stops narrating, pause for a few seconds (5) and encourage the witness to provide additional information. 
PART II:

1. Explain that what you are going to do next, in a few minutes, is to ask the witness to provide an even more detailed description of the thief. But, before they do, tell them that you are going to try something a little different:

a. Say you want the witness to relive the event/interaction with the thief

b. To help the witness do so and concentrate better, explain that it is very helpful to close your eyes - and ask the witness to do so (close your eyes while giving this instruction).

c. Slowly, in a soft voice, recreate the context (thoughts, feelings, surroundings, interaction with the thief).

d. [Wait at least 10 seconds until the witness has developed a clear mental image].

e. Ask an open-ended question about the perpetrator ("Tell me everything you can about the thief.")

f. After the witness has completed the first narrative (and you have paused for at least 5 seconds), follow-up by asking: "Is there anything else you can tell me about the thief?"

g. After the witness has completed the follow-up narrative (and you have paused), ask any additional open-ended questions you have from your notes - ask witness to elaborate on some of the things the witness said in his/her narratives.

Speak in a soft, non-invasive tone the entire time you want the witness to keep his/her eyes closed.

Do not interrupt the witness while he/she is narrating.

Make notes to remind yourself to ask follow-up questions after the witness stops speaking. After the witness stops narrating, pause for a few seconds (5) and encourage the witness to provide additional information.

PART III:

1. Ask more directed, specific questions at the end of the interview to elicit information not yet gathered about the perpetrator's description (including, but not limited to, the following characteristics):

2. Regularly remind the witness DO NOT GUESS throughout Part III of the interview.

\section{a. Distinguishing characteristics/descriptors -}

i. "What is the most prominent feature on the thief's face?"

ii. "What would differentiate the thief from another person of the same description; in other words, what makes the thief unique/distinctive?" 


\section{b. Non-Physical descriptors -}

i. Describe the witness's personality."

ii. "Did the witness exhibit any distinctive behaviors or mannerisms?" If so, what?

iii. "What would you expect this person do to for a living?" Why?

iv. "Was there anything about the thief's personality that came across in his/her appearance?" (e.g., an angry face; pleasant-looking, etc.)

c. Resemblance/Likeness - ask the W" who does the thief remind you of?"), and if so, in what way(s)? Remind the witness that he/she does not need to be politically correct. Also ask:

i. "Does the thief remind you of any famous person/celebrity/public figure?" If so, who and in what way(s)?

ii. "Does the thief remind you of any family member/friend/neighbor?" If so, who and in what way(s)?

iii. "Does the thief physically remind you of any type of animal or object?" If so, what animal/object and in what way(s)?

\section{d. Sex/Gender}

\section{e. Race/Ethnicity}

i. Specify ethnicity (e.g., instead of Hispanic/Latino, would be preferable to get a description such as Puerto Rican)

ii. Follow up to find out in what way(s) the perpetrator appeared to be of that ethnicity

f. Skin Tone/Coloring - (a) ask generally and then; (b) use the color chart below and attached as Ex. 1

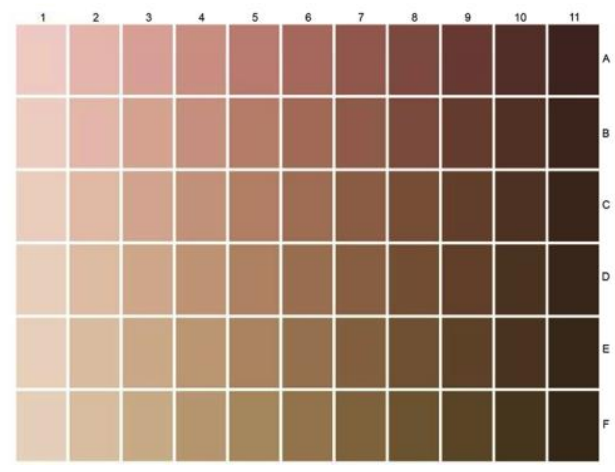


g. Skin Texture/Complexion - can be a general description (e.g., "leathery skin," "smooth complexion," etc.).

h. Height (or Height Range) - can be a general description (e.g., "very short," or "much taller than me") as opposed to making them guess the exact height.

i. Weight (or Weight Range) - can be general description (i.e., "heavy," "petite," "skinny," "big-boned," etc.) as opposed to making them guess the exact weight.

j. Age (or Age Range) - can be a general description (i.e., "young," "in college") as opposed to making them specify an exact age.

k. Hair

i. Color

ii. Length

iii. Style

iv. Hairline

v. Texture

l. Eyes

i. Color

ii. Shape

iii. Proximity of eyes

iv. Location of eyes on face

m. Eyebrows

i. Color

ii. Thickness

iii. Shape - (a) ask generally and then; (b) use the eyebrow chart below and attached as Ex. 2

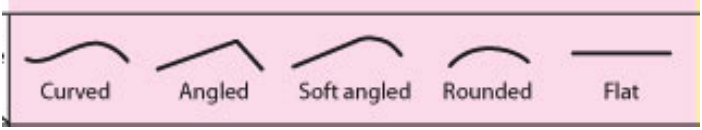

n. Overall Face Shape - (a) Ask about the overall face shape generally, and then; (b) use the geometric face shape chart below and attached as Ex. 3

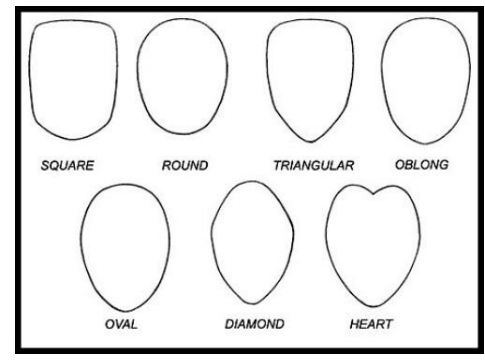


o. Facial Features (e.g., mouth, chin, ears, etc.) - ask the witness generally and then ask about individual featural components of the face.

p. Build - (a) ask generally, and then (b) also for an illustrative representation, use the geometric body shape chart below and attached as Ex. 4

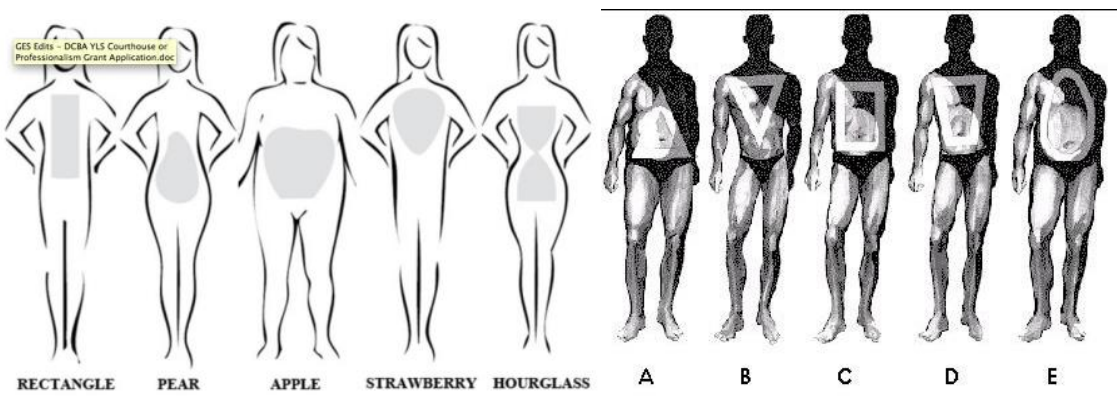

q. Facial Hair
i. Color
ii. Texture
iii. Shape
iv. Does it match color of hair on head?

r. Clothing

s. Accessories - Ask about any accessories (i.e., hats, glasses, jewelry, etc.)

t. Markings/Tattoos/Scars/Piercings

u. Finish by asking "If you were the interviewer, what would you ask yourself to get more information that $I$ haven't covered yet?" 
VITA

GERI E. SATIN

November 18, 1982

2005

2008

2014

2016

2014-2017

2017

2017
Born, Miami, Florida

B.A., English and Criminology

University of Florida

Gainesville, Florida

J.D., Law

University of Miami

Miami, Florida

UGS Presidential Fellowship Florida International University

Miami, Florida

M.S., Psychology

Florida International University

Miami, Florida

Graduate Assistant

Florida International University

Miami, Florida

Instructor

Florida International University

Miami, Florida

CASE Awards: Psychology's Best Thesis Florida International University Miami, Florida

\section{PUBLICATIONS AND PRESENTATIONS}

Molinaro, P., Fisher, R. P., Mosser, A. E., Satin, G. E., Robertson, B. (Under Review). Train-the-Trainer: Methodology to Learn the Cognitive Interview. Applied Cognitive Psychology.

Fisher, R. P., Mosser, A. E., \& Satin, G.E. (2015). Inconsistent Witness Testimony. In A. Reilly \& Pass, A. (Eds) Forensic Science. VOL 2. Grey House Publishing: Amenia, NY. Pages 590-92. 
Fisher, R. P., Mosser, A.E., Molinaro, P., \& Satin, G. E. (2015). Cognitive Interview Techniques. In A. Reilly \& Pass, A. (Eds) Forensic Science. VOL 1. Grey House Publishing: Amenia, NY. Pages 224-227.

Mosser, A. E., Fisher, R.P., Molinaro, P., Satin, G. E., Manon, M. (2016). Train-theTrainer: Training law enforcement investigators in the Cognitive Interview. Paper presented at the annual American Psychology-Law Society conference, Atlanta, GA. Mosser, A. E., Fisher, R.P., Molinaro, P., Satin, G. E., Manon, M. (2015). Training the trainer on the Cognitive Interview. Invited talk presented at the High Value Detainee Interrogation Group Research Symposium, Washington D.C.

Molinaro, P., Fisher, R. P., Mosser, A. E., Satin, G. E., Robertson, B. (2015). Training law enforcement trainers on the Cognitive Interview. Paper presented at the annual American Psychology-Law Society conference, San Diego, CA.

Molinaro, P., Fisher, R. P., Mosser, A. E., Satin, G. E. (2014). Training the trainer on the Cognitive Interview: Translating science into practice. Invited talk presented at the High Value Detainee Interrogation Group Presentation to Practitioners, Washington, D.C.

Molinaro, P., Fisher, R. P., Mosser, A. E., Satin, G. E., Robertson, B. (2014). Training law enforcement trainers on the Cognitive Interview. Invited talk presented at the High Value Detainee Interrogation Group Research Symposium, Washington, D.C. 